Universidade de Brasília

Instituto de Psicologia

Departamento de Processos Psicológicos

Básicos

Pós-Graduação em Ciências do Comportamento

Metacontingências na Cidade de Campinas, SP: Adesão à Campanha

da ONU de cidades resilientes

Marina Rocha Soares

Orientadora: Laércia Abreu Vasconcelos 
Universidade de Brasília

Instituto de Psicologia

Departamento de Processos Psicológicos

Básicos

Pós-Graduação em Ciências do Comportamento

\title{
Metacontingências na Cidade de Campinas, SP: Adesão à Campanha da ONU de cidades resilientes
}

\author{
Marina Rocha Soares \\ Orientadora: Laércia Abreu Vasconcelos

Dissertação
Programa de
Ciências do Compradadaçãa em
Departamento de
Psicológicos Básicos, Instituto de
Psicologia, Universidade de
Brasília, como parte dos requisitos
para obtenção do grau de Mestre em
Ciências do Comportamento (Área
de Concentração: Análise do
Comportamento).

Brasília, março de 2017 
Esta dissertação foi desenvolvida no Instituto de Psicologia da Universidade de Brasília com o auxílio de uma bolsa de mestrado concedida pelo CNPQ.

Comissão Examinadora

Dra. Laércia Abreu Vasconcelos (Presidente)

Universidade de Brasília

Dr. Airton Bodstein de Barros (Membro Externo)

Universidade Federal Fluminense

Dr. Elizeu Batista Borloti (Membro Externo)

Universidade Federal do Espírito Santo

Dra. Ana Rita Coutinho Xavier Naves (Membro Suplente)

Instituto de Educação Superior de Brasília 


\section{Índice}

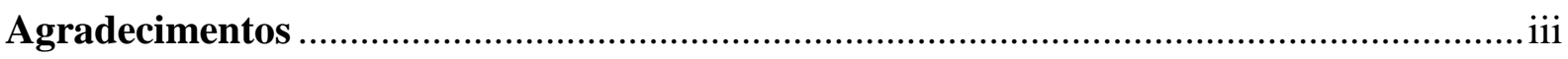

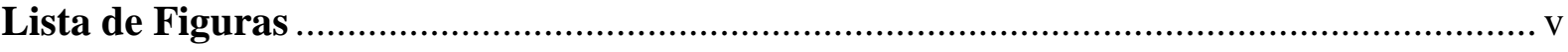

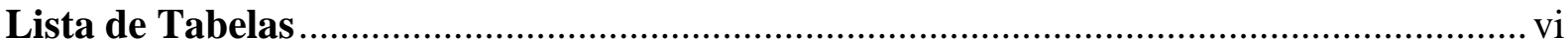

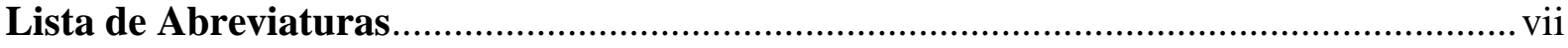

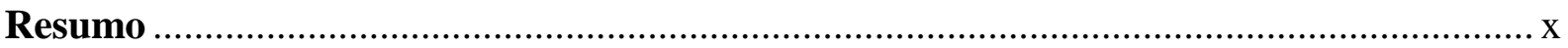

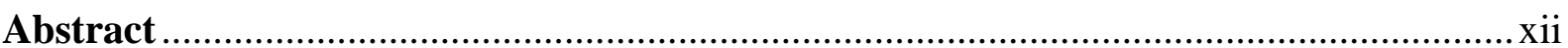

Evolução das Estratégias Internacionais no Enfrentamento de Desastres .......................... 12

Campanha "Construindo Cidades Resilientes - minha cidade está se preparando" ............ 18

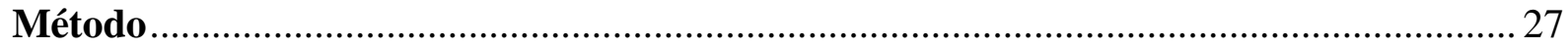

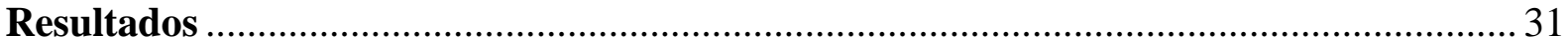

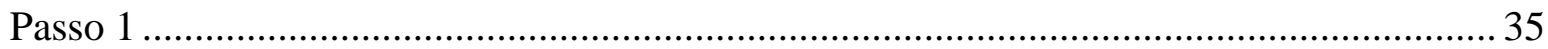

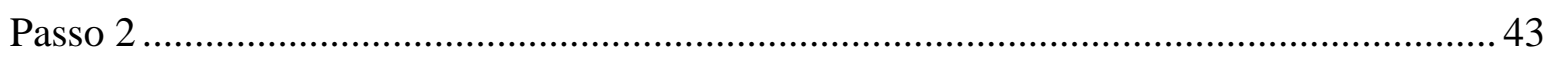

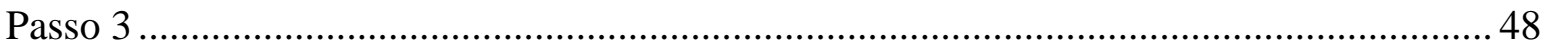

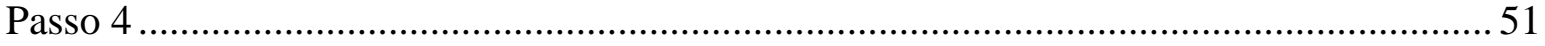

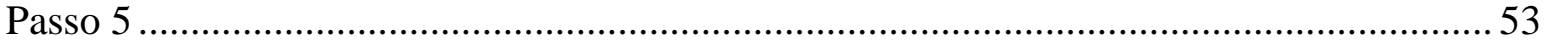

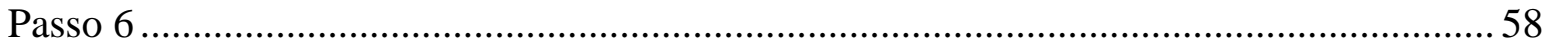

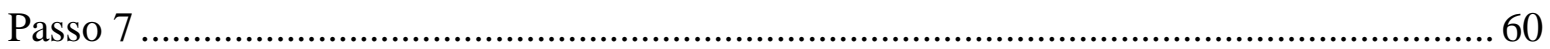

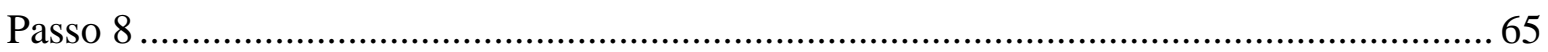

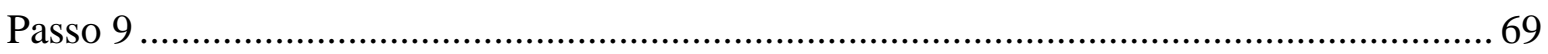

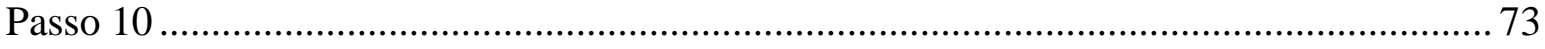

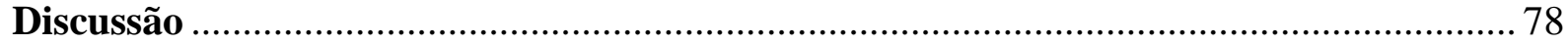

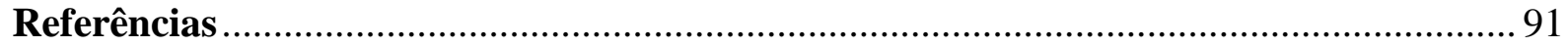

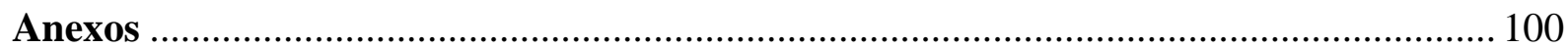

Anexo A - Critérios ou questões-chaves da Ferramenta de Autoavaliação do Governo Local (LGSAT) utilizados para avaliar as providências estabelecidas para cada um dos 10 passos da Campanha de cidades resilientes .................................................................. 100

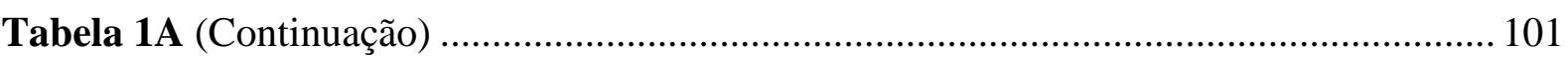

Anexo B - Dados obtidos da cidade de Campinas-SP, nos dois ciclos da Campanha, seguidos das notas de autoavaliação dos critérios da ferramenta LGSAT 


\section{Agradecimentos}

Agradeço, em primeiro lugar, aos meus pais, Alcinet e Gerardo, que sempre confiaram nos desafios aos quais me lancei e me deram a oportunidade e o apoio necessário para enfrentá-los. Não posso deixar de repetir o clichê: as minhas conquistas jamais seriam possíveis sem vocês.

Aos meus irmãos, Natália e Vitor, pelo companheirismo, compreensão, amizade e suporte. A nossa relação é um enorme orgulho para mim!

Ao meu amor, Luiz Gustavo, que, desde os primeiros meses, viveu ao meu lado todas as dificuldades desse período e cresceu tanto junto comigo. Estendo os agradecimentos à toda a sua família, que me presenteou com uma convivência amorosa e me amparou muitas vezes.

À Lara Rodrigues, minha referência de história em Brasília e de apoio na vida. E, ainda, à Karen Mororó, a minha melhor descoberta dos últimos anos. A parceria com essas duas me proporcionou os momentos mais felizes desses dois anos e a experiência de família necessária para uma intensa adaptação. Levo vocês para a vida inteira!

Ao meu terapeuta, Frederico Veloso, que me ensinou o significado mais genuíno de acolhimento e transformou os dias mais sombrios em oportunidades para reencontrar sonhos e descobrir novas perspectivas.

Às amigas Adriana Miranda, Izabel Vale, Flávia Hauck e Olívia do Vale, que tanto compartilharam comigo durante esse período, suprindo a minha privação afetiva nordestina, ao construir laços verdadeiros de amizade.

Às amigas Ingrid, Thaís, Carol, Juliana, Ana Paula, Nara, Natália Braga, Samara e Sylvia, e ao amigo Adriano Ludovice, que me acompanham ao longo de toda a minha jornada, demonstrando compreensão, apoio e torcida incondicional. 
Ao Thassio Queiroz, um velho amigo que voltou à minha convivência diária e que demonstrou solidariedade quando precisei. Espero que nossa amizade seja alimentada de companheirismo e muitas alegrias.

À minha orientadora, Prof ${ }^{a}$ Dra. Laércia Abreu Vasconcelos, por compartilhar comigo seu conhecimento e experiência nas reuniões e nas revisões atentas ao meu trabalho.

Aos professores Eileen Flores, Carlos Cançado, Raquel Aló, Jorge de Oliveira Castro, Goiara Castilho, Luciano Buratto e Domingos Coelho por ampliar significativamente o meu conhecimento sobre Análise do Comportamento e metodologia de pesquisa.

À turma de Fundamentos em Análise do Comportamento de 2016.1, que vivenciou junto comigo a experiência mais desafiadora e mais recompensadora durante o curso. Aprendi muito sobre minha competência com vocês.

Ao Sidnei Furtado, por colaborar com o repasse de relevantes bibliografias sobre desastres e com a sua disponibilidade valiosa para esclarecer dúvidas.

À Coordenação de Aperfeiçoamento de Pessoal de Nível Superior (CNPq) pelo apoio financeiro à minha pesquisa.

Aos membros da banca, Prof. Dr. Airton Bodstein de Barros, Prof. Dr. Elizeu Batista Borloti e Profa. Dra. Ana Rita Coutinho Xavier Naves, por aceitarem meu convite. 


\section{Lista de Figuras}

Figura 1. Descrição das prioridades estabelecidas pelos três marcos mundiais de referência para Redução de Risco de Desastres.

Figura 2. Fases do processo de planejamento estratégico de uma cidade para implementação da Campanha "Construindo Cidades Resilientes - Minha Cidade Está se Preparando".

Figura 3. Adesões de cidades brasileiras à "Campanha Construindo Cidades Resilientes - Minha Cidade Está se Preparando", entre os anos de 2011 a 2016.

Figura 4 Nível de Progresso Alcançado nos 41 critérios da Ferramenta LGSAT em Campinas nos dois ciclos da "Campanha Construindo Cidades Resilientes - Minha Cidade Está se Preparando".

Figura 5. Metacontingência Cidades Resilientes.

Figura 6. Passo 1 - Metacontingência Quadro Institucional e Legislativo.

Figura 7. Passo 2 - Metacontingência Financiamento e Recursos.

Figura 8. Passo 2 - Metacontingência Investimentos Financeiros em Campinas.

Figura 9. Passo 3 - Painel com Metacontingência Mapeamento de Risco e Ameaças Múltiplas e Metacontingência de Divulgação de Informação Sobre Riscos

Figura 10. Passo 4 - Painel com Metacontingência Proteção, Melhoria e Resiliência da Infraestrutura e Metacontingência CIMcamp.

Figura 11 Passo 5 - Painel com Metacontingência Proteção de Serviços Essenciais: Educação e Metacontingência Proteção de Serviços Essenciais: Saúde

Figura 12. Passo 6 - Metacontingência de Construção de Regulamentos e Planos de Uso e Ocupação do Solo.

Figura 13. Passo 7 - Painel com Metacontingência Treinamento e Sensibilização Pública e

Metacontingência Educação Ambiental.

Figura 14. Passo 8 - Metacontingência Proteção Ambiental e Fortalecimento de Ecossistemas.

Figura 15. Passo 9 - Metacontingência Preparação e Sistema de Alerta

Figura 16. Passo 10 - Metacontingência Recuperação e Reconstrução de Comunidades.

Figura 17. Relações entre as metacontingências dos 10 passos essenciais para construir cidades resilientes.

Figura 18. Os 10 passos essenciais para construir cidades resilientes e as fases de gerenciamento de desastre. 


\section{Lista de Tabelas}

Tabela 1 Os 10 passos essenciais para construir cidades resilientes

Tabela 2 Distribuição dos 16 estados com 921 cidades que aderiram à "Campanha Construindo Cidades Resilientes - Minha Cidade Está se Preparando" e avançaram para o $2^{\circ}$ ciclo, contemplando as regiões norte, nordeste, centro-oeste, sudeste e sul.

Tabela 3 Lista das principais legislações municipais de Campinas relacionada às medidas de redução de desastres

Tabela 4 Grupos de agentes que participam do Passo 2 da Campanha Cidades Resilientes na cidade de Campinas, $\mathrm{SP}$ - secretarias municipais ligadas à prefeitura e outros parceiros ....... 44

Tabela 5 Os 10 passos essenciais para construir cidades resilientes e legislação de apoio. 


\section{Lista de Abreviaturas}

ASIC

BPC

CACD

CAE:

CCPDC

CEASA

CEPAGRI

CFA

CFG

CGE

CIESP

CIIAGRO

CIMcamp

$\mathrm{CMC}$

CMDA

CME

CMPD

COMDEMA

CONGEAPA

CONSEGS

CPAT

CPFL

CPTEC

CPTM

CRAS

CREAS

CVDC

DAE
Associação Comercial e Industrial de Campinas

Benefício de Prestação Continuada da Assistência Social

Curso de Aperfeiçoamento de Voluntários em Defesa Civil

Coordenadoria de Arquitetura Escolar

Centro de Capacitação de Proteção e Defesa Civil

Centrais de Abastecimento de Campinas

Centro de Pesquisas Meteorológicas e Climáticas Aplicadas à

Agricultura

Formação de Agente de Proteção e Defesa

Formação de Gestores de Proteção e Defesa Civil

Centro de Gerenciamento de Emergências de São Paulo

Centro das Indústrias do Estado de São Paulo

Centro integrado de informações agrometeorológicas

Central Integrada de Monitoramento de Campinas

Conselho Municipal de Cultura

Conselho Municipal de Defesa Animal

Conselho Municipal de Educação

Conselho Municipal da Pessoa com Deficiência

Conselho Municipal de Meio Ambiente

Conselho Gestor da Área de Proteção Ambiental de Campinas

Conselhos Comunitários de Segurança

Centro Público de Apoio ao Trabalhador

Companhia Paulista de Força e Luz

Centro de Previsão de Tempo e Estudos Climáticos

Serviço Geológico do Brasil

Centro de Referência da Assistência Social

Centro de Referência Especializado de Assistência Social

Curso de Capacitação de Voluntário de Defesa Civil

Departamento de Apoio à Escola 
DAS

DDC

DIDC

DIRDN

DOAS

DPJ

DSAN

EIRD

EMDEC

FUNDAG

FUNDAP

GAE

GAMESP

GODC

GTALPS

IAC

IMA

INPE

IPMET

IPT

LUOS

MDS

MJ

NUDECs

PCJ

PETI

PNPDEC

PROAMB

PRONASCI

RRD

SAISP
Departamento de Assistência Social

Departamento de Defesa Civil

Departamento de Informação, Documentação e Cadastro

Década Internacional para Redução dos Desastres Naturais

Departamento de Operações da Assistência Social

Departamento de Parques e Jardins

Diretoria de Segurança Alimentar e Nutricional

Estratégia Internacional para Redução de Desastres

Empresa Municipal de Desenvolvimento de Campinas

Fundação de Apoio à Pesquisa Agrícola

Fundo de Apoio à População de Sub-habitação Urbana

Grupo de Atendimento de Emergência

Gabinete Metropolitano de Gestão Estratégica de Segurança Pública

Gerenciamento de Ocorrências de Defesa Civil

Grupo de Trabalho de Apoio ao Licenciamento de Projetos de Serviços

Municipais

Instituto Agronômico de Campinas

Informática de Municípios Associados

Instituto Nacional de Pesquisas Espaciais

Instituto de Pesquisas Meteorológicas

Instituto de Pesquisas Tecnológicas

Lei De Uso e Ocupação do Solo

Ministério do Desenvolvimento Social e Combate à Fome

Ministério da Justiça

Núcleos Comunitários de Defesa Civil

Piracicaba, Capivari e Jundiaí

Programa de Erradicação do Trabalho Infantil

Política Nacional de Proteção e Defesa Civil

Fundo de Recuperação, Manutenção e Preservação do Meio Ambiente

Programa Nacional de Segurança Pública Com Cidadania

Redução de Risco de Desastre

Sistema de Alerta a Inundações do Estado de São Paulo 
SAMU

SANASA

SDEST

SEHAB

SEINFRA

SEMAJ

SENAC

SENAI

SENASP

SENAT

SEPLAN

SETEC

SFA

SIADEC

SIMPDEC

SMC

SMCASP

SMCEL

SMCGP

SME

SMPED

SMS

SMSP

SMTR

SVDS

UAI

UNDRO

UNISDR
Serviço de Atendimento Móvel de Urgência

Sociedade de Abastecimento de Água e Saneamento

Secretaria Municipal de Desenvolvimento Econômico, Social e

Turismo

Secretaria Municipal de Habitação

Secretaria Municipal de Infraestrutura

Secretaria Municipal de Assuntos Jurídicos

Serviço Nacional de Aprendizagem Comercial

Serviço Nacional de Aprendizagem Industrial

Secretaria Nacional de Segurança Pública

Serviço Social de Aprendizagem do Transporte

Secretaria Municipal de Planejamento e Desenvolvimento Urbano

Serviços Técnicos Gerais

Setor de Fiscalização Ambiental

Sistema de Alerta da Defesa Civil de Campinas

Sistema Municipal de Proteção e Defesa Civil

Secretaria Municipal de Comunicação

Secretaria de Cooperação de Assuntos de Segurança Pública

Secretaria Municipal de Cultura, Esporte e Lazer

Secretaria Municipal de Chefia de Gabinete do Prefeito

Secretaria Municipal de Educação

Secretaria Municipal dos Direitos da Pessoa com Deficiência e

Mobilidade Reduzida

Secretaria Municipal de Saúde

Secretaria Municipal de Serviços Públicos

Secretaria Municipal de Trabalho e Renda

Secretaria Municipal do Verde, Meio Ambiente e Desenvolvimento

Sustentável

Unidade de Acolhimento Institucional

United Nations Disaster Relief Office

Escritório das Nações Unidas para a Redução do Risco de Desastres 


\section{Resumo}

Desastres são produzidos a partir da interação entre ameaças naturais com aspectos físicos e sociais, sendo passíveis de estudo por uma ciência do comportamento. A Análise do Comportamento, por meio do conceito de metacontingência, pode contribuir para a área de desastres, pois permite o planejamento e intervenção em práticas culturais, com alteração de comportamentos em larga escala. Em 2010, o Escritório das Nações Unidas para a Redução do Risco de Desastres (UNISDR) lançou uma campanha mundial para a construção de cidades resilientes a desastres, com a elaboração de um protocolo internacional para a atuação integrada de equipes multissetoriais. Neste trabalho, realizou-se uma pesquisa documental com o objetivo de analisar funcionalmente a implementação da Campanha "Construindo Cidades Resilientes - minha cidade está se preparando" em Campinas, São Paulo. A regulamentação da ONU e informações de bancos de dados oficiais do município entre os anos de 2011 e 2014 foram interpretadas a partir da Análise do Comportamento, com a identificação de metacontingências. Em Campinas há consistência entre o previsto e a descrição das implementações, com níveis de progresso na escala de autoavaliação LGSAT, com variação em uma escala de 4 e 5 pontos. Ademais, a partir dos dados obtidos, foram identificadas 15 metacontingências cuja interação resulta na redução de risco de desastres, com a diminuição de perdas humanas e materiais, um produto agregado (PA) primário comum a todos esses arranjos. O vasto quadro legislativo, que pode ser estímulo antecedente para contingências comportamentais entrelaçadas (CCEs) ou PAs, o apoio do prefeito, a informatização dos sistemas de comunicação e a programação de consequências individuais (e.g., isenção de impostos a uma empresa) e culturais (prêmios nacionais e internacionais) selecionadoras da ação articulada de muitos indivíduos são destaques na maioria dos 
entrelaçamentos identificados no município. O modelo disponibilizado por Campinas torna-se estímulo para outras ações a serem implementadas em outras cidades brasileiras.

Palavras-chave: Análise do Comportamento; Metacontingência; desastres; cidades resilientes; Campinas 


\begin{abstract}
Disasters are brought about by the interaction between natural threats with physical and social features, being thus amenable to study by a science of behavior. Behavior Analysis, through its concept of metacontingency, can contribute to the field of disasters, for it allows planning and intervention in cultural practices, with changes in behavior on a great scale. In 2010, the United Nations System for Disaster Risk Reduction (UNISDR) launched a worldwide campaign for the development of cities that are resilient to disasters, with the preparation of an international protocol for the integrated action of multisectoral teams. This work carried out a documentary research which aimed to perform a functional analysis of the application of the campaign "Building Resilient Cities - My city is preparing itself" in Campinas, São Paulo. UN's regulation and information from official database of Campinas between the years 2011 and 2014 have been interpreted according to Behavior Analysis, while metacontingencies have been identified. In Campinas there is consistency between what had been anticipated and the description of implementations, with progress levels in the selfevaluation scale LGSAT varying between 4 and 5. Furthermore, from the data gathered in the research, 15 metacontingencies have been identified whose interaction results in the reduction of the risk of disasters, while decreasing human and material losses, a primary aggregate product (AP) common to all of those arrangements. The broad legislative framework, which can be an antecedent stimulus to interlocking behavioral contingencies (IBCs) or an aggregate product (AP) - the mayor's support -, the computerization of the communication systems and the programming of consequences, both individual (tax exemption) and cultural (national and international prizes), which select the articulated action of several individuals are highlighted in most interlockings identified in the city of Campinas. The model offered by Campinas becomes a stimulus for other actions to be implemented in other Brazilian cities.
\end{abstract}


Keywords: Behavior Analysis; Metacontigency; Disasters; Resilient cities; Campinas. 
Desastres são responsáveis por um alto número de prejuízos sociais, econômicos e ambientais (Tominaga, Santoro \& Amaral, 2009). A Organização das Nações Unidas (ONU) estima que entre 2005 e 2015, a ocorrência de desastres afetou mais de 1,5 bilhões de pessoas, entre mortos, feridos e desabrigados, e promoveu perda econômica total de mais de US\$1,3 trilhões (UNISDR, 2015). No Brasil, embora não ocorram com frequência desastres de grande porte, como vulcões e terremotos, de acordo com o Atlas Brasileiro de Desastres Naturais, entre 1990 e 2012, somaram-se 38.996 registros de ocorrências (CEPED - UFSC, 2013; Tominaga Santoro \& Amaral, 2009). Ademais, o país apresenta números significativos de acidentes decorrentes de deslizamentos e inundações e está entre os países mais afetados por desastres de origem natural ${ }^{1}$ (CRED \& UNISDR, 2016; Kill, 2016; Tominaga Santoro \& Amaral, 2009).

As alterações climáticas ocasionadas pelo aquecimento global têm resultado em fenômenos naturais extremos, que provocam mudanças nos ecossistemas e têm o potencial de aumentar a intensidade, a duração e a frequência global dos desastres. Dados globais do EMDAT (CRED \& UNISDR, 2016) mostram que, entre 2005 e 2015, cerca de 90\% dos desastres registrados tiveram em sua origem eventos relacionados com o clima (e.g., aumento do nível dos oceanos, secas e ondas intensas de calor, aumento de áreas áridas, alterações das correntes marítimas, ciclones e precipitações de grande intensidade (Kill, 2016; Schinko, Mechler \& Hochrainer-Stigler, 2016; Siebert, 2012; Thompsom, 2010).

Historicamente a interação entre a maneira que os espaços foram ocupados pela população e os eventos climáticos provocou muitas situações de perdas humanas e materiais

\footnotetext{
${ }^{1}$ Bodstein, De Lima e De Barros (2012) defendem a substituição da terminologia "desastres naturais", utilizado por alguns veículos formais e midiáticos brasileiros, por "desastre de origem natural", seguindo recomendações da ONU, posição que também será adotada neste trabalho.
} 
(Carmo \& Anazawa, 2014). De acordo com a UNISDR (2010), atualmente, mais da metade da população mundial reside em centros urbanos e a tendência mundial do aumento da concentração populacional nas cidades pode acarretar impactos nocivos ao meio natural. A interação entre infraestrutura, rede de serviços deficientes e ocupações irregulares de espaços transformam as cidades em geradoras de riscos de desastres (Carmo \& Anazawa, 2014). Portanto, o uso abusivo dos recursos naturais e as atividades humanas que desrespeitam os limites da natureza no processo de urbanização são variáveis que potencializam os riscos de ocorrência de desastres (Siebert, 2012).

Um desastre, portanto, é produto da interação de ameaças naturais com aspectos físicos e sociais. É um evento que causa uma intensa interrupção no funcionamento de uma comunidade, resultando em perda de vidas humanas e/ou perdas materiais, econômicas e ambientais, advindo da combinação entre ameaças naturais, vulnerabilidade e incapacidade da comunidade de lidar e reduzir as potenciais consequências de riscos (UNISDR, 2009; Ximenes, Freitas \& Cerutti, 2014). Dessa forma, o seu risco de ocorrência depende do grau de vulnerabilidade e de exposição do local às ameaças naturais e da capacidade da comunidade de resistir aos impactos (Gallego-Lopez \& Essex, 2016).

Embora o termo vulnerabilidade seja central para a compreensão de desastres, apresenta definições distintas que dependem do contexto em que é utilizado (e.g., vulnerabilidade social, vulnerabilidade econômica, vulnerabilidade institucional) (Pereira, Szlafsztein \& Araújo 2016; Martins, Tavanti \& Spink, 2016). Diante da pluralidade de usos do conceito, a Organização das Nações Unidas (ONU) (UNISDR, 2015) propôs uma terminologia oficial que define vulnerabilidade como "processos ou condições determinadas por fatores físicos, sociais, econômicos e ambientais que aumentam a suscetibilidade de uma comunidade ao impacto dos perigos" (p. 31). A vulnerabilidade de um sistema resulta da 
coordenação de muitos fatores, tais como as condições de infraestruturas urbanas, o comportamento humano e a elaboração de políticas públicas voltadas para a gestão de riscos, sendo a pobreza um dos principais aspectos relacionados à vulnerabilidade de um local (Gonçalves, 2012).

O reconhecimento de que aspectos sociais influenciam na ocorrência de desastres sugere que uma ciência do comportamento tenha papel fundamental no enfrentamento de problemas ambientais. Segundo Alavosius e Mattaini (2011), o engajamento em comportamentos em larga escala que contribuam para a degradação ambiental pode ser alvo de estudos científicos e intervenções aplicadas. No mesmo sentido, Heward e Chance (2010) alertam para a necessidade do estudo de fenômenos ambientais em pesquisas e intervenções analítico-comportamentais, as quais têm potencial de alterar comportamentos de riscos ou produtos sociais adversos resultantes das ações de um grande número de pessoas. Thompson (2010), um pesquisador de destaque internacional na área de aquecimento global, sinaliza a mudança de comportamento como a principal solução para reduzir as taxas de aquecimento global, pois assim haveria tempo hábil para que novos recursos tecnológicos pudessem ser desenvolvidos.

O Behaviorismo Radical é a filosofia base da ciência da Análise do Comportamento, que possibilita o estudo do comportamento humano a partir da compreensão das relações funcionais entre organismo e ambiente. Para explicar como repertórios comportamentais são desenvolvidos, Skinner (1981) propôs o modelo de seleção pelas consequências, que envolve três níveis de determinação. O modelo reconhece a variação e seleção de fenômenos comportamentais em contingências relacionadas à sobrevivência da espécie, em contingências de reforçamento individual e em contingências culturais, nas quais práticas culturais variam e culturas evoluem. Dessa maneira, os padrões comportamentais são selecionados e fortalecidos 
por condições contextuais antecedentes à resposta, que estabelece ocasião para que ela ocorra, e pelas consequências que ela produz. Ou seja, de acordo com Skinner (1957), o organismo age sobre o mundo, modificando-o e sofre efeitos recíprocos que alteram a probabilidade futura da recorrência das determinadas ações implementadas.

Segundo Heward e Chance (2010), a Análise Aplicada do Comportamento tem como principal objetivo o desenvolvimento de tecnologias para melhorar comportamentos socialmente significantes. Gusso e Sampaio (2011) identificam a ficção social Walden II como a produção pioneira da Análise do Comportamento, na qual se identifica preocupação com a sustentabilidade. O ideal de sociedade presente em Walden II,

Inclui em seu planejamento cultural cuidados necessários para que as práticas desenvolvidas sejam mais sustentáveis, que contemplem contínua avaliação experimental dos resultados produzidos, de forma a aumentar as chances de sobrevivência da cultura e conservação do ambiente que propicia as condições de vida aos membros desse grupo (Gusso \& Sampaio, p. 12).

Segundo os atores, nesse contexto, sustentabilidade pode ser compreendida como a manutenção de um estilo de vida capaz de promover a sobrevivência dos organismos envolvidos e de suas práticas culturais compartilhadas. Em Walden II, Skinner (1972) propõe uma organização social ideal, cujo uso racional dos recursos naturais e qualidade de vida e bem-estar orientam o planejamento cultural. Assim, Skinner abordava o tema, ainda que não houvesse discussões sistemáticas sobre sustentabilidade nos anos 1970.

A partir da década de 1970, houve grande quantidade de publicações sobre intervenções analítico-comportamentais em problemas ambientais, apesar de as taxas de publicações nesse campo não continuaram crescendo com a mesma intensidade nas décadas seguintes (Heward \& Chance, 2010; Lehman \& Geller, 2004). Há registros sobre analistas do comportamento contribuindo para o tema de aquecimento global e sustentabilidade, desenvolvendo estudos relacionados ao controle de poluição (e.g., Bacon-Prue, Blount, 
Pickering, \& Drabman, 1980; Geller, Farris, \& Post, 1973), reciclagem (Jacobs, Bailey, \& Crews, 1984; Keller, 1991/2010) e redução de consumo de energia (Winett et al., 1982). Ademais, considerando a temática de desastres, foram desenvolvidos estudos que contribuíram para ampliar a compreensão sobre impactos de eventos radioativos em padrões comportamentais de organismos humanos e não-humanos (Brandão, 2012; Vasconcelos, 1995; Vasconcelos \& Gimenes, 1999) e estudos que propuseram contribuições behavioristas para a detecção de falhas estruturais nos sistemas de segurança, vulneráveis a ataques terroristas, assim como redes de comunicação e organização para a recuperação após um evento desse porte (Alavosius et al,, 2002; Alavosius, Houmanfar \& Rodriquez, 2005).

Lehman e Geller (2004) chamam atenção para os principais tipos de intervenção propostos por analistas do comportamento para aumentar comportamentos pró-ambientais e reduzir comportamentos de degradação. Intervenções típicas dessa área de estudo baseiam-se numa filosofia externalista, por meio da qual se promove mudanças no comportamento a partir de planejamento e rearranjos específicos de contingências. Alguns estudos na área demonstram que estratégias de manipulação de variáveis antecedentes ao comportamento tem o potencial de alterar a probabilidade de ocorrência de comportamentos pró-ambientais (Austin et al., 1993; Brothers, Krantz \& McClannahan, 1994; DeLeon \& Fuqua, 1995; Grantt, 2014; McMakin et al., 2002; Staats et al., 2000; Thompson \& Stoutmeyer, 1991; Werner et al., 1995). Essas variáveis (e.g. instruções verbais, apresentação de modelos a serem seguidos e introdução de objetos no ambiente que facilitam comportamentos pró-ambientais) estabelecem ocasião para que os organismos emitam respostas específicas, podendo sinalizar as consequências de seus comportamentos.

Outros estudos propõem estratégias que visam a manipulação das consequências das respostas individuais, a fim de alterar a probabilidade de sua ocorrência futura (Dwyer et al., 
1993; Geller et al., 1982; Hayes \& Cone, 1981; Schroeder et al., 2004; Shultz 1998). As intervenções descritas nessas pesquisas utilizaram reforço positivo na tentativa de tornar mais provável a emissão de respostas pró-ambientais, com o fornecimento de cupons de troca (e.g. objetos, ingresso de cinema e dinheiro) e o fornecimento de feedbacks que informam os efeitos de seu comportamento (e.g., boletins informativos periódicos sobre impactos econômicos advindos de altas taxas de reciclagem).

Esses estudos apresentam estratégias voltadas para a disposição de contingências visando a mudança individual de comportamento. No entanto, segundo Sampaio e Gusso (2011), no manejo dos problemas causados por ameaças naturais, faz-se importante, também, propor intervenções em um nível que extrapola o individual, por meio de mudanças culturais. O arranjo de contingências disposto na cultura ocidental cria um ambiente social que torna mais prováveis classes de consumismo exacerbado, valorização de resultados financeiros e do contato com consequências imediatas de nossos comportamentos, com impactos nocivos a longo prazo dessas ações. Isso aumenta a probabilidade de que estejam em alta frequência e larga escala comportamentos que dificultam a sobrevivência das culturas a longo prazo. Intervenções analítico-comportamentais com potencial de alterar práticas culturais abordam o gerenciamento de leis (Biglan, 2009) e incentivos econômicos para organizações que se comprometeram com metas sustentáveis (Heward \& Chance, 2010).

Fenômenos culturais vêm sendo amplamente estudados na área por meio do conceito de metacontingência, o qual foi apresentado por Glenn (1986) e surgiu como uma proposta de unidade de análise para o processo de seleção e manutenção de práticas culturais. Esse conceito possibilitou a ampliação do conhecimento sobre de que maneira contingências de reforçamento socialmente organizadas poderiam resultar em fenômenos de impacto cultural, e de que forma ocorreria sua manutenção ao longo de gerações (Martone \& Todorov, 2007). 
De acordo com a sua definição mais recente, uma metacontingência refere-se à relação entre contingências comportamentais entrelaçadas (CCEs) recorrentes que geram um produto agregado (PA) e condições culturais selecionadoras (Glenn et al., 2016). Ou seja, diz respeito ao entrelaçamento de comportamentos operantes emitidos por vários organismos, que, além de produzir consequências individuais, produzem também consequências comuns para as ações integradas de todos os agentes envolvidos (CCEs). Essa nova definição descreve, portanto, a relação entre, no mínimo, dois termos, CCEs $\rightarrow$ PA - também denominado de culturante - e um ambiente que selecionará esse arranjo ou não. É importante ressaltar que não é necessário, portanto, que haja consequências selecionadoras atuando diretamente sobre cada um dos comportamentos individuais dos participantes das CCEs, mas o ambiente selecionador atua em nível cultural, selecionando o culturante. Em alguns casos, o PA, além de efeito ambiental gerado pelas CCEs, também pode adquirir função selecionadora (Glenn et al., 2016).

O contexto antecedente também pode participar de uma metacontingência como um termo com efeito evocativo de culturantes. Isso quer dizer que a relação entre o culturante e sua consequência cultural selecionadora pode estar sob controle de estímulos antecedentes, ao especificar uma contingência - entrelaçamentos de comportamentos esperados e seus efeitos (regra ou instrução), ou apresentando função modificadora do valor reforçador de um efeito ambiental (Sacconato \& Andery, 2013; Vieira, Andery \& Pessôa, 2016).

Segundo Glenn et al. (2016) numa metacontingência, pode haver variação na recorrência das CCEs, que pode ser resultado de mudanças topográficas (que dizem respeito à forma) de comportamentos dos agentes participantes, da substituição de um ou mais desses indivíduos, ou ainda, de alterações na organização do entrelaçamento entre as contingências. Se essa variação for suficiente para alterar o PA, essa nova recorrência de CCEs poderá ser 
selecionada ou não. Ademais, mudanças ao longo do tempo no ambiente selecionador também podem alterar as contingências entrelaçadas (CCEs) e o produtos agregados (PAs).

Outro conceito central da Análise do Comportamento no estudo de práticas culturais é o de macrocontingência. Numa sociedade, é comum observar comportamentos operantes semelhantes, que foram socialmente aprendidos pelos seus membros. Esses macrocomportamentos são mantidos por consequências individuais, mas, como estão presentes no repertório comportamental de muitos indivíduos de uma comunidade, podem gerar um efeito cumulativo não contingente, com impactos ambientais importantes. Uma macrocontingência é a relação entre comportamentos operantes controlados por contingências individuais, com as quais se pode ter também CCEs de outras metacontingências, produzindo um efeito cumulativo que pode ter alta significância social (Glenn et al., 2016).

No transcorrer do desenvolvimento do conceito de metacontingência, pesquisas têm sido desenvolvidas de forma a evidenciar a consistência interna das relações funcionais anunciadas e a validade externa, envolvendo diferentes contextos de investigação, com estudos experimentais e não experimentais, desenvolvidos em laboratórios e no ambiente natural. Pesquisas experimentais criam microculturas em laboratório, a fim de identificar variáveis controladoras de operantes (i.e., mantidos por contingências individuais) e culturantes (CCEs $\rightarrow$ PA, mantidos por metacontingências), analisando a transmissão de práticas culturais e a seleção produzida por consequências culturais (e.g., Baia et al., 2014; Caldas, 2009;; Gadelha, 2010; Leite 2009; Saconatto \& Andery, 2013; Toledo et al., 2015; Toledo, T. F. N., \& Benvenuti Franceschini et al., 2012; Vichi \& Tourinho, 2012; Vasconcelos \& Todorov, 2015; Vichi, 2005; Vichi, Andery \& Glenn, 2009).

Pesquisas não experimentais - observacionais, exploratórias ou documentais - a partir de dados descritivos têm aplicado o conceito de metacontingência em diferentes áreas, tais 
como na política, economia, mídia, organizações e legislação, com o objetivo de analisar contingências sociais (Lamal, 1991; Rakos, 1991; Lamal \& Greenspoon, 1992; Bastos, 2015). No Brasil, já há um conjunto relevante de pesquisas com análises de contingências e metacontingências em leis (e.g., Cabral \& Todorov, 2016; Carvalho, 2013; Fava, 2014; Kill, 2016; Martins, 2009; Prudêncio, 2006; Todorov, 1987) e outras fontes documentais (e.g., Bastos, 2015; Fonseca, 2012; Vale, 2016).

Bastos (2015) utilizou os conceitos de metacontingência e macrocontingência para analisar os comportamentos de um grupo de cinco servidores de um subsistema de uma organização bancária pública, assim como os efeitos cumulativos e produtos agregados (PAs) de suas interações (CCEs) para a empresa, comparando-os com as exigências definidas por ela. A análise de documentos de atividades do setor e entrevistas com os servidores permitiram identificar a elaboração de documentos específicos e seu repasse ao banco como PAs resultantes da ação coordenada desses servidores. Cada servidor do grupo de trabalho (e.g., agente de área, técnico, gerente) responsabilizava-se por tarefas com alto grau de especialização, o que tornava necessário o entrelaçamento de seus comportamentos para que os PAs fossem de fato produzidos. Nesta Metacontingência, o banco aceita ou rejeita os documentos enviados, sendo, portanto, o sistema que libera a consequência cultural (i.e., o ambiente que seleciona as contingências comportamentais entrelaçadas e seus resultados, produtos agregados (CCEs $\rightarrow$ PAs).

As análises de Bastos (2015) revelaram que o culturante (CCEs $\rightarrow$ PAs) dessa metacontingência estava adequado às contingências de controle, atribuindo isso a três fatores: (1) Há contiguidade entre o culturante e as consequências culturais dispostas pelo banco, que dá um feedback após 2 ou 3 dias sobre o aceite dos documentos, justificando a recusa de qualquer variação operacional; (2) Historicamente, erros operacionais foram gravemente 
penalizados, pois se trata de um subsistema que atende demandas legais do banco; e (3) Repetidos processos seletivos ocorreram, selecionando CCEs muito específicas.

$\mathrm{Na}$ área de desastres, uma pesquisa documental foi desenvolvida por Kill (2016), na qual a lei $\mathrm{n}^{\circ}$ 12.608/12, que regulamenta a Política Nacional de Proteção e Defesa Civil (PNPDEC) e institui as diretrizes nacionais para o gerenciamento e gestão de desastres, foi analisada a partir dos conceitos de contingência e metacontingência. Utilizando o modelo de análise funcional de textos legais proposto por Todorov (1987, 2005; Todorov, Moreira, Prudencio \& Pereira, 2004), Kill (2016) identificou que a PNPDEC é o principal PA produzido, descrito em $23 \%$ dos artigos. Na análise dos 31 artigos da lei, o autor encontrou metacontingências principais que os apoiam, dentre as quais estão: (1) representantes dos municípios, estados, união, entidades públicas, privadas e da sociedade civil (CCEs) em interação para produzir a redução de perdas humanas, materiais e patrimoniais por desastres (PAs); e (2) A ação coordenada de representantes do municípios, estados e união, nas tarefas de prevenção, mitigação, preparação, resposta e recuperação de desastres (CCEs), resultam em produto agregado, o impedimento ou a redução de sua ocorrência de desastres.

Segundo Kill (2016), os artigos descrevem metacontingências incompletas, ou seja, que não incluem todos os componentes - CCEs, PAs e ambiente selecionador com a consequência cultural (CC) - em seu texto. A ausência de componentes nas metacontingências presentes na lei 12.608/12 diminui a efetividade das intervenções culturais no contexto de gestão de risco de desastres, já que compromete a sistematização e o monitoramento das regras estabelecidas pelo instrumento. Isso permite a pluralidade de interpretações do texto legal e a abstenção de órgãos, ou agentes do ambiente selecionador, responsáveis pela implementação da PNPDEC. 
Dessa forma, observa-se contribuições teóricas e metodológicas da análise do comportamento sobre fenômenos culturais para o estudo de fenômenos sociais complexos. A área de desastres, que envolve interação de múltiplos agentes, é um campo com relevante potencial a ser explorado. Esse potencial é especialmente relevante ao considerar os impactos à saúde mental dos indivíduos sobreviventes de uma situação de desastres e os danos causados por um acontecimento desse porte. De acordo com Albuquerque e Zacarias (2016), os primeiros registros de psicólogos atuando junto a vítimas de desastres remontam a 1992, após o acidente com césio-137 na cidade de Goiânia - GO, tratando-se, portanto, de uma inserção recente da Psicologia nessa área. No entanto, a atuação de Psicólogos extrapola as contribuições junto a equipes durante a fase de resposta a uma emergência, ou na fase de reconstrução, oferecendo apoio psicológico junto a instituições ou abrigos. Noções desenvolvidas no arcabouço teórico - metodológico da Psicologia podem ser úteis para ações de caráter sistêmico anteriores à ocorrência de desastres, tais como: a identificação e o desenvolvimento de redes de apoio voltadas para enfrentar eventos adversos e o desenvolvimento de estratégias de coping diante de violência gerada por um desastre; colaboração com equipes multiprofissionais para educação comunitária voltada para desastres, contribuindo para uma cultura de redução de riscos; e realização de estudos para otimizar a prevenção e a resposta com o envolvimento de diferentes atores nos planos liderados pela Defesa Civil.

Diante da importância da inserção da atuação de Psicólogos nas atividades relacionadas à área de desastres, o Conselho Federal de Psicologia (CFP) divulgou uma nota técnica sobre a atuação desses profissionais em situações de emergências, enfocando seu compromisso ético de contribuir para que as redes de serviço estejam preparadas para essas ocorrências: Para que isso aconteça, é necessário que os profissionais e as redes de serviço, 
especialmente de Defesa Civil, SUS, SUAS, Segurança Pública, Educação, iniciativas privadas e complementares, entre outras, contribuam para um plano de contingência articulado intersetorialmente com a Defesa Civil e/ou com os conselhos, as coordenadorias e os núcleos comunitários de Defesa Civil (Nudec), evitando-se ações isoladas, desintegradas e improvisadas (Conselho Federal de Psicologia, 2013, p. 1)”. Diante disso, a produção de conhecimento que contribua para a área de gestão de risco de desastre deve ser encorajada, o que justifica a importância do presente estudo, que vai ao encontro de uma atuação intersetorial e interdisciplinar para reduzir os impactos danosos provocados por situações catastróficas.

\section{Evolução das Estratégias Internacionais no Enfrentamento de Desastres}

Os anos 1960/1970 foram marcados por intervenções por parte da Organização das Ações Unidas (ONU) caracterizadas como reativas e emergenciais a desastres. No entanto, essas ações demonstraram-se insuficientes, levando à necessidade de estratégias de planejamento pré-desastre, com atenção à prevenção para reduzir seus efeitos e minimizar os seus danos (Brasil, 2016). Desse modo, em 1971, o "United Nations Disaster Relief Office (UNDRO)" foi criado com o objetivo de centralizar um escritório permanente de assuntos de socorro, capaz de estabelecer medidas sistemáticas e coordenadas de ajuda internacional. Ademais, desde a década de 1990, a Organização tem apresentado iniciativas sistemáticas que tornaram mais ampla a abordagem a desastres e a elaboração de marcos mundiais de referência no enfrentamento de desastres, como mostra a Figura 1.

A Assembleia Geral da ONU, em 1989, estabeleceu a década de 1990 como a Década Internacional para Redução dos Desastres Naturais (DIRDN), por meio da aprovação da Resolução 44/236, com o objetivo de estimular a cooperação internacional para promover a 
redução de perdas humanas e danos materiais e econômicos causadas por desastres, especialmente nos países em desenvolvimento (Brasil, 2016). Nesse contexto, ocorreu a I Conferência Mundial Sobre a Redução dos Desastres Naturais, em 1994, que contou com a participação de representantes de 155 países e territórios. Esse encontro gerou o documento intitulado "Estratégia e Plano de Ação de Yokohama Para um Mundo Mais Seguro", o primeiro marco de referência mundial centrado no objetivo de salvar vidas humanas e proteger propriedades, com o estabelecimento de ações recomendadas em nível comunitário e nacional, regional e internacional no que se refere à redução de desastres (EIRD, 1994).

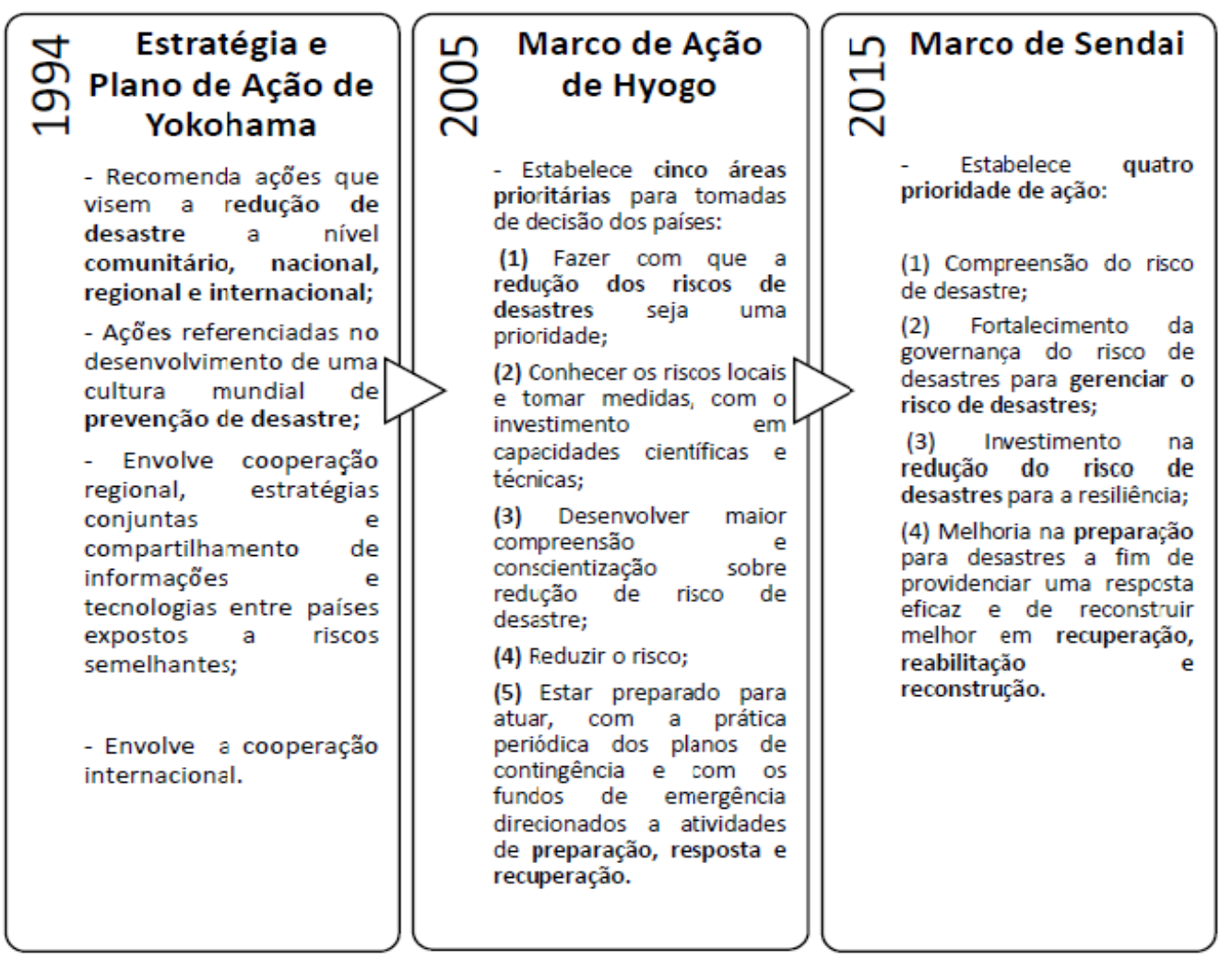

Figura 1. Descrição das prioridades estabelecidas pelos três marcos mundiais de referência para Redução de Risco de Desastres.

No entanto, apesar dos esforços despendidos entre os anos de 1960 e 2000, o aumento significativo na ocorrência, severidade e intensidade dos desastres nesse período (Rodrigues, 2010) demandaram a intensificação de estudos sobre suas causas e contribuíram para a criação de um secretariado permanente em Genebra, o Escritório das Nações Unidas para a 
Redução do Risco de Desastres (UNISDR), que deveria impulsionar a nova Estratégia Internacional para Redução de Desastres (EIRD) a partir dos anos 2000. A EIRD tinha como função dar continuidade às atividades desenvolvidas na DIRDN, ampliando a proteção contra os perigos para a gestão de risco, integrada ao desenvolvimento sustentável. A nova Estratégia demandou revisões do Plano de Ação de Yokohama e a incorporação de disposições da Cúpula Mundial sobre Desenvolvimento Sustentável, em 2002, que incluiu uma seção sobre um "enfoque integrado, global e multiameaças para tratar o tema da vulnerabilidade, a avaliação do risco e a gestão de desastres” (Silva, 2012).

Portanto, em 2005, realizou-se a II Conferência Mundial sobre Redução de Desastres, em Kobe, no Japão, onde foi aprovado o "Marco de Ação de Hyogo 2005-2015: Aumento da resiliência das nações e das comunidades frente aos desastres", o novo marco mundial de referência no enfrentamento de desastres. Nessa ocasião, 168 países comprometeram-se com o planejamento e a implementação de medidas para a redução dos riscos e da vulnerabilidade, e o aumento da resiliência das comunidades frente aos desastres, no contexto de desenvolvimento sustentável (UNISDR, 2005). Até esse momento histórico, os documentos oficiais da ONU tinham enfoque na redução de desastres, na mitigação de seus efeitos e no aumento da resistência das comunidades e países às ameaças naturais. No Marco de Ação e Hyogo, é possível notar a mudança de enfoque para a redução dos riscos de desastres e o aumento da resiliência das nações. Nesse sentido, o marco oferecia assistência às nações para que se tornassem mais resistentes às ameaças e conseguissem enfrentá-las de forma mais efetiva, indicando cinco áreas prioritárias para tomadas de decisões políticas (ver Figura 1).

O marco adotado foi um instrumento relevante para o aumento do compromisso político e da conscientização pública e institucional sobre a redução de riscos e levou a progressos dos países na gestão de risco de desastre. Coube à EIRD acompanhar o seu 
progresso de implantação, oferecendo apoio aos países e facilitando a coordenação de atividades em nível internacional e regional (continentes), por meio da criação da Plataforma Global, de estímulos para a criação de plataformas nacionais e do desenvolvimento da Campanha "Construindo Cidades Resilientes - minha cidade está se preparando" (UNISDR, 2015).

Ao longo dos dez anos seguintes à aprovação do Marco de Hyogo, números de impactos sobre pessoas afetadas por desastres somam 700 mil mortos, 1,4 milhão de feridos e 23 milhões desabrigados. A exposição das pessoas ao risco tem aumentado mais rapidamente do que a redução da vulnerabilidade, o que levou as autoridades a rever prioridades e metas traçadas no Marco de Hyogo, identificando lacunas nos meios e na execução de ações voltadas para a promoção da resiliência a desastres. Dessa maneira, em 2015, durante a III Conferência Mundial sobre a Redução do Risco de Desastres, no Japão, o Marco de Sendai foi aprovado, a partir da avaliação e revisão do Marco de Hyogo, considerando a experiência adquirida em sua implementação, no que diz respeito às modalidades de cooperação e estratégias, acordos, e planos regionais e nacionais adotados (Poterie \& Baudoin, 2015; GuhaSapir, Hoyois \& Below, 2014; UNISDR, 2015).

O novo marco estabelece o prosseguimento da cooperação internacional, regional e local para o aperfeiçoamento dos mecanismos existentes de implementação do marco, com especial apoio aos países em desenvolvimento, sem litoral, países africanos, ou que passam por desafios específicos, aumentando seus recursos e capacidades internas a partir de capacitação, apoio financeiro e técnico, além da transferência de tecnologia. No entanto, institui a necessidade de aumentar os esforços para a redução da exposição aos perigos e da vulnerabilidade aos desastres e pretende preencher lacunas presentes no Marco de Hyogo na 
abordagem aos fatores subjacentes aos desastres, na formulação de metas e prioridade de ação (UNISDR, 2015).

De acordo com o Marco de Sendai, os seguintes fatores subjazem aos desastres e requerem intervenções diretas para que seja possível a promoção da resiliência: a pobreza e desigualdade social, a variabilidade climática, a urbanização não planejada, a má gestão do solo, o uso abusivo de recursos naturais, os ecossistemas em declínio, a falta de regulamentação e incentivo para investimentos privados, a disponibilidade limitada de tecnologia, as políticas não informadas sobre o risco e as epidemias. Ademais, as medidas de prevenção de riscos de desastres devem ser integradas, inclusivas e centrar-se nas pessoas, com o envolvimento acessível da população na concepção e na implementação de políticas e planos (Aitsi-Selm \& Murray, 2014). O Marco sugere a ação focada nos âmbitos intrassetorial e intersetorial, promovida pelos Estados nos níveis local, nacional, regional e global em quatro prioridades, a saber: (1) Compreensão do risco de desastres; (2) Fortalecimento da governança do risco de desastres para gerenciar o risco de desastres; (3) Investimento na redução do risco de desastres para a resiliência; (4) Melhoria na preparação para desastres a fim de providenciar uma resposta eficaz e de Reconstruir Melhor em recuperação, reabilitação e reconstrução (UNISDR, 2015).

O termo resiliência aparece pela primeira vez em documentações oficiais relacionadas a desastre com a publicação do Marco de Ação de Hyogo e consta, de forma ainda mais frequente no Marco de Sendai, tanto nos principais objetivos de implementação quanto nas quatro áreas prioritárias de ação citadas acima (Poterie \& Baudoin, 2015). No contexto de desastres, é definido como a capacidade de resistência, absorção e reconstrução de um sistema ou comunidade que foi exposta a riscos, incluindo a restauração de suas estruturas e funções essenciais em tempo adequado (UNISDR, 2010). 
Nas últimas décadas, o termo resiliência tem sido abordado nos discursos políticos e acadêmicos nos temas de desenvolvimento internacional, bem como em círculos de profissionais, pesquisadores, organizações não-governamentais (ONGs), agências de financiamento e empresas privadas. Além disso, a promoção de resiliência tornou-se a prioridade das principais agendas mundiais de enfrentamento de adversidades, que propõem um conjunto de metas e objetivos que visam alcançar progressos na área de desastres, desenvolvimento sustentável e desafios humanitários (Marco de Sendai para a Redução do Risco de Desastres 2015-2030, Agenda de Desenvolvimento Sustentável 2030, Acordo de Paris sobre as Mudanças Climáticas - COP21 e Agenda da Cúpula Mundial Humanitária). Cada um desses quadros mundiais articulam a promoção a resiliência para as mudanças estimadas. É considerado, portanto, um conceito com potencial de integração entre instituições, setores e áreas de conhecimento, útil para a abordagem de diversos perigos e riscos que um país ou comunidade pode enfrentar (e.g., choques sociais, econômicos, culturais, físicos, ambientais e políticos) (Gaillard \& Jigyasu, 2016; Lovell, Bahadur, Tanner \& Morsi, 2016; Peters \& Thomas, 2016).

Em 2010, a EIRD, sob coordenação do Escritório das Nações Unidas para a Redução do Risco de Desastres (UNISDR) lançou, em nível global, a Campanha “Construindo Cidades Resilientes - minha cidade está se preparando", como uma estratégia para estimular governos locais na implementação de ações voltadas para tornar cidades resilientes a desastres. A Campanha, descrita na seção a seguir, foi proposta no contexto em que o Marco de Hyogo estava em vigor, mas com implementação também a partir das novas orientações do novo marco de Sendai, aprovado em março de 2015. 


\section{Campanha "Construindo Cidades Resilientes - minha cidade está se preparando"}

Diante de uma situação de desastre, as organizações locais são as que primeiro respondem às necessidades dos cidadãos, prestam-lhe serviços básicos e são responsáveis por gerir emergências. Portanto, ações de gestão de risco desenvolvidas em nível municipal têm alto potencial de reduzir os impactos físicos e sociais dos desastres. Assim, a ONU lançou a Campanha "Construindo Cidades Resilientes - minha cidade está se preparando", inserida na EIRD como uma estratégia para contribuir para a resiliência e a sustentabilidade urbana, a partir da: 1) sensibilização do governo e de civis sobre os benefícios de redução dos riscos urbanos; 2) identificação de recursos em planos municipais e sua alocação em iniciativas de redução de risco; e 3) inclusão da redução de risco de desastres no planejamento de desenvolvimento urbano (UNISDR, 2010). A adesão dos municípios deve partir do compromisso para implementação dos dez passos essenciais para construir uma cidade resiliente, apresentados na Tabela 1, os quais foram desenvolvidos com base nas cinco prioridades do Quadro de Ação de Hyogo.

As medidas de redução de risco de desastres, descritas nos 10 passos essenciais, estão relacionadas ao desenvolvimento de práticas locais sustentáveis que abrangem todas as etapas de gestão do risco e de gerenciamento de desastres (prevenção, mitigação, preparação, resposta e recuperação), que estão descritas na Lei $\mathrm{n}^{\circ}$. 12.608, de 10 de abril de 2012, que dispõe sobre a Política Nacional de Proteção e Defesa Civil (PNPDEC). A etapa de prevenção abrange ações prévias ao desastre, que diminuem as chances ou evitam a sua ocorrência, tais como identificação de riscos e vulnerabilidades locais e monitoramento de ameaças; urbanização sustentável, com desocupação de áreas críticas e ações de orientação à comunidade sobre prevenção de riscos e comportamentos de autoproteção. Quando não é possível evitar o desastre, ações mitigatórias devem ser desenvolvidas, que buscam diminuir 
a intensidade de seus impactos. Já na etapa de preparação, medidas de planejamento de intervenção pós-desastre visam aprimorar as ações de resposta e reconstrução, por meio de capacitações de equipes especializadas, elaboração de planos de contingência, desenvolvimento de sistemas de monitoramento e de alerta de ameaças, dentre outros.

\section{Tabela 1}

Os 10 passos essenciais para construir cidades resilientes (UNISDR, 2010, pp. 16-17).

(1) Estabeleça mecanismos de organização e coordenação de ações com base na participação de comunidades e sociedade civil organizada, por meio, por exemplo, do estabelecimento de alianças locais. Incentive que os diversos segmentos sociais compreendam seu papel na construção de cidades mais seguras com vistas à redução de riscos e preparação para situações de desastres;

(2) Elabore documentos de orientação para redução do risco de desastres e ofereça incentivos aos moradores de áreas de risco: famílias de baixa renda, comunidades, comércio e setor público, para que invistam na redução dos riscos que enfrentam;

(3) Mantenha informação atualizada sobre as ameaças e vulnerabilidades de sua cidade; conduza avaliações de risco e as utilize como base para os planos e processos decisórios relativos ao desenvolvimento urbano. Garanta que os cidadãos de sua cidade tenham acesso à informação e aos planos para resiliência, criando espaço para discutir sobre os mesmos;

(4) Invista e mantenha uma infraestrutura para redução de risco, com enfoque estrutural, como por exemplo, obras de drenagens para evitar inundações; e, conforme necessário, invista em ações de adaptação às mudanças climáticas;

(5) Avalie a segurança de todas as escolas e postos de saúde de sua cidade, e modernize-os se necessário;

(6) Aplique e faça cumprir regulamentos sobre construção e princípios para planejamento do uso e ocupação do solo. Identifique áreas seguras para os cidadãos de baixa renda e, quando possível, modernize os assentamentos informais;

(7) Invista na criação de programas educativos e de capacitação sobre a redução de riscos de desastres, tanto nas escolas como nas comunidades locais;

(8) Proteja os ecossistemas e as zonas naturais para atenuar alagamentos, inundações, e outras ameaças às quais sua cidade seja vulnerável. Adapte-se às mudanças climáticas recorrendo a boas práticas de redução de risco;

(9) Instale sistemas de alerta e desenvolva capacitações para gestão de emergências em sua cidade, realizando, com regularidade, simulados para preparação do público em geral, nos quais participem todos os habitantes;

(10) Depois de qualquer desastre, vele para que as necessidades dos sobreviventes sejam atendidas e se concentrem nos esforços de reconstrução. Garanta o apoio necessário à população afetada e suas organizações comunitárias, incluindo a reconstrução de suas residências e seus meios de sustento.

As etapas de resposta e reconstrução ocorrem após a ocorrência do desastre, com o acionamento de equipes especializadas para ações de socorro, o restabelecimento de serviços essenciais e a reconstrução da comunidade atingida (e.g., recuperação de unidades 
habitacionais, reconstrução de redes de infraestrutura), considerando a minimização dos danos de desastres futuros (Alves, 2015; Alves, Dos Santos \& Cartagena, 2011).

O governo municipal deve comprometer-se com iniciativa e liderança para implementar essas medidas, já que possui posição determinante na integração da agenda ao planejamento de desenvolvimento da cidade. No entanto, para uma abordagem plena de redução de risco de desastres, é necessário que haja o engajamento de vários agentes, cada um com ações específicas que, em interação, contribuirão para o aumento da resiliência do município. Deverão participar das ações sugeridas pela campanha representantes do governo federal, da comunidade internacional, do setor privado, de instituições de ensino, de organizações não-governamentais, associações comunitárias e da sociedade civil.

Assim, enquanto os prefeitos e gestores municipais devem estar em contato com a EIRD para apoiar a implantação da campanha em níveis locais e comunitários, governos nacionais devem fazer da redução de riscos uma prioridade nacional, fomentando plataformas nacionais de atuação multidisciplinar, garantindo orçamento para urbanização sustentável e para o desenvolvimento de políticas públicas de redução de risco e incentivando a economia de áreas rurais, de modo a reduzir a migração urbana acelerada. Às associações comunitárias, cabe a organização de atividades que promovam o engajamento de líderes comunitários à campanha, e a participação na formulação de projetos para tornar o local mais seguro, e na avaliação, planejamento e construção de mapas de risco, com base no seu conhecimento sobre a cidade. As ONGs, parceiras da campanha, devem se comprometer em apoiar os governos locais, desenvolvendo ferramentas e metodologias para a redução de risco, contribuindo para a ampliação da discussão local sobre o tema com a comunidade, assim como com o desenvolvimento de políticas públicas. Os representantes da iniciativa privada ou doadores devem participar com a aplicação de recursos em projetos de construção de cidades 
resilientes, evitando riscos de degradação do meio ambiente, além do financiamento de pesquisas e projetos sobre redução de riscos urbanos. As universidades devem contribuir a partir da disseminação do tema de planejamento urbano e processos de redução de risco em espaços acadêmicos e com o desenvolvimento de pesquisas voltadas para metodologia de avaliação de riscos, colocando suas produções à disposição do governo. Essa rede articulada entre agentes é característica fundamental para a construção de uma cidade resiliente.

Em 2012, visando apoiar processos decisórios e de organização para as atividades de redução de risco de desastre previstas pela campanha, a UNISDR publicou o Guia para Gestores Públicos Locais. O documento consiste na reunião de orientações para o desenvolvimento dos 10 passos e de boas práticas e ferramentas já aplicadas até aquele momento por algumas cidades. Ademais, sugere que seja feito um planejamento estratégico de desenvolvimento da campanha, o qual é relevante para que as autoridades locais avaliem os recursos dos quais o município já dispõe e quais fatores devem ser abordados para que se alcancem os resultados efetivos. É dividido em cinco fases (UNISDR, 2012), como mostra a Figura 2.

\section{MEDIDAS CONCRETAS DE REDUCÃO DE RISCOS DE DESASTRES}
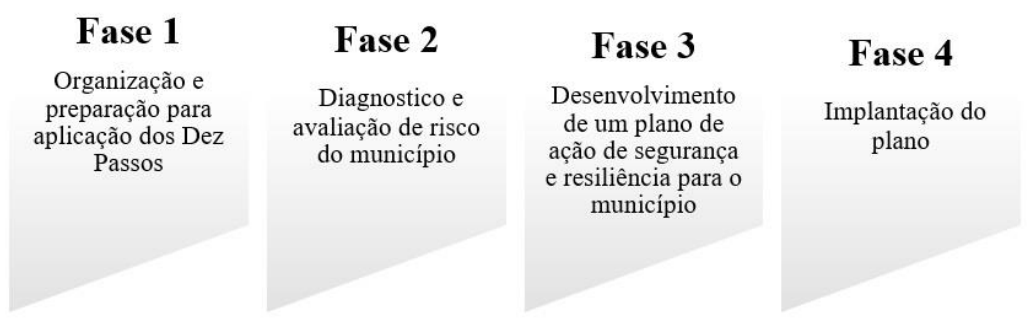

\section{Fase 5}

Monitoramento e
acompanhamento acompanhamento

Figura 2. Fases do processo de planejamento estratégico de uma cidade para implementação da Campanha "Construindo Cidades Resilientes - Minha Cidade Está se Preparando". 
A Fase 1 envolve a preparação do cenário institucional e a sensibilização da todos os envolvidos para cumprir os passos descritos para tornar o município resiliente a desastres, definindo lideranças, formalizando alianças, nomeando forças-tarefa de vários públicos de interesse e investindo em capacidades técnicas e orçamentárias para as atividades de redução de riscos. A Fase 2 requer o aumento do conhecimento a respeito das especificidades da localidade, com a realização de avaliações sobre vulnerabilidades e riscos de desastres, o estabelecimento de prioridades de ações estratégicas definidas em consenso com todos os participantes, e a identificação dos seus pontos fortes e fracos, dos recursos, participantes e públicos de interesse em relação à redução de risco de desastres. A Fase 3 refere-se ao desenvolvimento do plano de ação a ser implementado, a partir da definição dos objetivos, dos programas e projetos necessários, assim como da sua institucionalização, alinhando-o ao plano de desenvolvimento do município. Na Fase 4, o plano é colocado em ação, contanto com a mobilização de recursos e de estratégias que o tornem possível e de mecanismos institucionais que garantam a sua apropriação por todos os participantes. Encerrando o planejamento estratégico, a Fase 5 estabelece o monitoramento e a avaliação do plano de ação implementado, assim como estratégias de ampla comunicação sobre falhas e conquistas, que permita informar os participantes e receber seus comentários e sugestões (UNISDR, 2012).

De acordo com orientações do guia (UNISDR, 2012), a implementação de medidas concretas de redução de risco de desastres não deve ocorrer apenas na Fase 4. A atenção aos recursos e as capacidades locais que já existem é importante para que tais medidas estejam presentes em todo o processo de planejamento, cuja priorização pode conduzir a resultados visíveis rapidamente.

Como foi lançada em 2010, a Campanha voltada para cidades resilientes surgiu como uma estratégia de suporte para a implementação do Marco de Hyogo 2005-2015 no âmbito 
local. No entanto, com a aprovação do Marco de Sendai na III Conferência Mundial de Redução de Risco de Desastres em 2015, tornou-se necessário incorporar as prioridades de ação acordadas no novo marco para os próximos 15 anos $(2015$ - 2030). O documento do Marco de Sendai faz referência à Campanha Cidades Resilientes no contexto da prioridade de ação 1, "Compreensão dos Riscos", como uma das sugestões para o nível regional e global:

Desenvolver campanhas globais e regionais eficazes como instrumentos para a sensibilização e educação da sociedade, com base em campanhas já existentes (por exemplo, a iniciativa "Um milhão de escolas e hospitais seguros", a Campanha "Construindo cidades Resilientes - minha cidade está se preparando", o Prêmio Sasakawa das Nações Unidas para a Redução de Desastres e o Dia Internacional das Nações Unidas para a Redução de Desastres), a fim de promover uma cultura de prevenção de desastres, resiliência e cidadania responsável, gerar compreensão dos riscos de desastres, apoiar a aprendizagem mútua, compartilhar experiências. Incentivar as partes interessadas públicas e privadas a se engajar e participar ativamente de tais iniciativas e a desenvolver novas iniciativas nos níveis local, nacional, regional e global (UNISDR, 2015, p. 12).

De acordo com o site oficial do Ministério da Integração Nacional (MI) ${ }^{2}$, com a transição para o Marco de Sendai pretende-se alcançar uma maior coordenação entre os entes federativos e o alinhamento mais acurado da Campanha às políticas públicas federais. Enquanto, no período 2010-2015, a Campanha enfocou a sensibilização aos riscos, o reforçamento da liderança local e o aumento das iniciativas políticas para redução de risco de desastres, a segunda fase, iniciada em 2016, dedica-se à implementação dos compromissos assumidos pelos governos. Dessa maneira, o foco passou a ser o apoio ao engajamento de parceiros, às oportunidades de investimentos de cooperação, ao planejamento de ação local e ao monitoramento do progresso.

O procedimento de registro de um município como cidade resiliente na Campanha inicia com uma carta do poder executivo municipal ao UNISDR, comprometendo-se com as 10 providências previstas. O escritório da EIRD, então insere a cidade na lista das cidades

\footnotetext{
${ }^{2}$ Disponível em http://mi.gov.br/cidades-resilientes recuperado em 15 de agosto de 2016.
} 
participantes da Campanha e emite um certificado virtual de adesão ou entregue numa cerimônia de assinatura. A partir dessa confirmação, o governo local pode criar um perfil online no site, onde constará informações sobre as vulnerabilidades locais, as atividades para redução de risco de desastre e os progressos alcançados. ${ }^{3}$ Após inscrever-se na Campanha, o município inicia o compromisso com a definição prioridades específicas na área de gestão do risco de desastres que desenvolvam resiliência e os progressos e limites na implantação das ações de redução de risco de desastres serão medidos e avaliados, de modo a permitir que as cidades inscritas avancem para o segundo ciclo da Campanhas.

No Brasil, a Campanha foi lançada em 2011 pela Secretaria Nacional de Defesa Civil (SEDEC), do Ministério da Integração Nacional, durante a $7^{\text {a }}$ Semana Nacional de Redução de Desastres (10 a 15/10), com a adesão inicial de apenas uma cidade situada no estado de Santa Catarina ${ }^{4}$. A construção de cidades resilientes já é considerada em regulamentações oficiais. A Lei Federal $n^{\circ}$. 12.608, de 10 de abril de 2012, que dispõe sobre a Política Nacional de Proteção e Defesa Civil (PNPDEC), aponta, no Art. $5^{\circ}$ como um de seus objetivos:

VI - Estimular o desenvolvimento de cidades resilientes e os processos sustentáveis de urbanização;

Ademais, no relatório da II Conferência Nacional de Proteção e Defesa Civil ${ }^{5}$, um dos eixos que compõe as diretrizes que irão influenciar o desenvolvimento e implementação de políticas públicas para a área da proteção e defesa civil é:

IV - A mobilização e promoção de uma cultura de Proteção e Defesa Civil na busca de Cidades Resilientes

\footnotetext{
${ }^{3}$ Reunião de Trabalho Construindo Cidades Resilientes a partir do novo Marco de Sendai para a Redução do Risco de Desastres 2015-2030 - Apresentação Sidnei Furtado (março/2015).

${ }^{4}$ Disponível em http://www.defesacivil.sc.gov.br/index.php/ultimas noticias/1517-defesa-civil-estrategia-daonu-para-reducao-de-desastres-sera-adotada-no brasil.html recuperado em 20 de outubro de 1016.

${ }^{5}$ Disponivel em: http://www.mi.gov.br/documents/10157/3935871 recuperado em 22 de outubro de 2016.
} 
O Brasil é o país com o maior número de municípios participantes, com adesão de 921 cidades até novembro de 2016. Esse número representa 16,7\% do número total de municípios no território nacional ${ }^{6}$. Em 2013, a ONU certificou o município de Campinas -SP como cidade modelo de boas práticas na construção de resiliência para a redução de riscos e desastres $^{7}$. Ademais, o diretor da Defesa Civil municipal de Campinas, Sidnei Furtado, é um dos 25 promotores mundiais da Campanha. Em 2014, O Estado de São Paulo recebeu o certificado de Estado Modelo da Campanha Construindo Cidades Resilientes, sendo o primeiro Estado modelo do mundo reconhecido pela $\mathrm{ONU}^{8}$.

Estudos sobre práticas culturais, a partir da Análise do Comportamento, têm se expandido para diferentes fenômenos, como citado anteriormente. A área de desastres pode ser fortalecida com a contribuição de universidades, já prevista em regulamentações oficiais. Especificamente, com estudos científicos voltados para cidades brasileiras, de forma a contribuir para a redução de risco de desastres, evitando perdas sociais e econômicas expressivas.

Ao considerar a potencial contribuição de interpretações analítico-comportamentais (por meio dos conceitos de Metacontingência e macrocontingência) aplicadas em pesquisas documentais, o objetivo geral deste estudo foi analisar funcionalmente a implementação da Campanha "Construindo Cidades Resilientes - minha cidade está se preparando", numa cidade brasileira que aderiu à campanha e mostrou evolução nos dois ciclos previstos. Entre os objetivos específicos estão: (1) analisar o quadro geral brasileiro de adesão à campanha adesão de cidades, total de município nos dois ciclos (2) identificar as recomendações das

\footnotetext{
${ }^{6}$ No ranking dos países com maior número de cidades resilientes, a Áustria está em segundo lugar, com 280 adesões. Considerando o número total aproximado de municípios no território austríaco (1639 municípios), esse número de adesões representa $17 \%$ do seu total, o que se aproxima aos resultados encontrados no Brasil.

${ }^{7}$ Disponível em http://www.campinas.sp.gov.br/noticiasintegra.php?id=19648 recuperado em 18 de setembro de 2016.

${ }^{8}$ Disponível em http://www.saopaulo.sp.gov.br/spnoticias/lenoticia2.php?id=238718\&c=5330 recuperado em 18 de setembro de 2016.
} 
regulamentações que preveem a construção de cidades resilientes, a partir da campanha; e (3) analisar as metacontingências envolvidas na adesão à Campanha da cidade de Campinas São Paulo, apresentando análises do cumprimento das exigências estabelecidas no primeiro e segundo ciclo da campanha. 


\section{Método}

\section{Objeto de estudo}

As contingências comportamentais entrelaçadas (CCEs), os produtos agregados e o modo como esses culturantes foram selecionados na implementação da Campanha de cidades resilientes da ONU na cidade de Campinas, São Paulo, foi o alvo de análise deste estudo. O município apresenta avanços reconhecidos oficialmente pela ONU no enfrentamento de desastres, assim como premiações nacionais, o que motivou a sua escolha como objeto de análise. Foi realizada uma pesquisa documental, a qual, segundo Gil (2012), desenvolve-se a partir da análise de materiais que, em geral, não receberam tratamento analítico a priori, podendo envolver reportagens, diários, relatórios e documentos oficiais.

Portanto, a seleção da amostra foi por conveniência - considerando o banco de dados amplo de informações sobre implementação da Campanha em Campinas, nem sempre disponível no que diz respeito a outros municípios - além das premiações reconhecendo o nível de excelência dos trabalhos que têm sido desenvolvidos pela equipe na cidade.

\section{Fontes documentais}

Para cumprir os objetivos propostos, selecionou-se quatro fontes primárias documentos oficiais - publicadas na base de dados Preventioweb, lançada em 2007 pela UNISDR para colaborar com as necessidades de informação da comunidade sobre redução de risco de desastre. Duas dessas fontes são publicações da UNISDR que informam a respeito dos objetivos e características da Campanha e fornecem esclarecimentos e sugestões aos gestores locais para a sua implementação: Kit "Construindo Cidades Resilientes - Minha cidade está se preparando"; e o Guia "Como Construir Cidades Mais Resilientes - Um Guia para Gestores Públicos Locais. Uma contribuição à Campanha Global 2010-2015 Construindo 
Cidades Resilientes - Minha Cidade está se preparando". As outras duas fontes são os relatórios de progresso local na implantação dos 10 passos essenciais para construção de cidades resilientes, referentes ao primeiro (2011-2013) e segundo ciclo (2013-2014), elaborados pela equipe gestora de Campinas sobre medidas desenvolvidas no município, encaminhados ao UNISDR e publicados por ele no portal preventionweb para amplo acesso.

Os Relatórios de progresso local na implantação dos 10 passos essenciais para construção de cidades resilientes são produzidos a partir da Ferramenta de Autoavaliação do Governo Local (LGSAT), desenvolvida pela UNISDR, após consulta a parceiros, tais como representantes do governo local; da Rede Global de Organizações da Sociedade Civil para a Redução de Desastres (GNDR); e do Conselho Internacional para Iniciativas Ambientais Locais (ICLEI). Constitui-se em questionário composto por 41 questões-chave, ou critérios, elaborados a partir das áreas prioritárias enfocadas no Marco de Ação de Hyogo e dos 10 passos da Campanha. Uma equipe multidisciplinar local deve preencher o questionário, avaliando cada um dos critérios por meio de uma escala com variação de 1 a 5 pontos (UNISDR, 2012). Os 41 critérios estabelecidos para cada um dos dez passos são apresentados no Anexo A.

A cada dois anos, os governos locais devem realizar a autoavaliação, o que favorece a definição de avanços e fragilidades do município sobre as estratégias adotadas no enfrentamento de desastre, além de produzir dados passíveis de comparação entre governos locais. Os relatórios de progresso local na implantação dos 10 passos essenciais para construção de cidades resilientes, referentes ao primeiro (2011-2013) e segundo ciclo (20132014) da Campanha foram materiais de base para esta pesquisa, pois apresentam informações oficiais condensadas sobre as medidas realizadas em Campinas. As informações presentes nos 
relatórios foram confirmadas por conteúdos publicados pela imprensa local, consultados por meio do site oficial da cidade de Campinas (www.campinas.sp.gov.br).

Fontes documentais internas cedidas via e-mail pelo diretor da Defesa Civil de Campinas e Promotor da Campanha Cidades Resilientes no Brasil, Sidnei Furtado também foram utilizadas nesta pesquisa. Foram acessados cinco relatórios quantitativos com dados de municípios que aderiram à Campanha. Portanto, as fontes selecionadas, foram utilizadas de forma complementar nesse estudo.

\section{Procedimentos}

Inicialmente, Fase 1 consistiu da seleção e análise preliminar das fontes documentais encontradas, a fim de identificar a relevância do material escolhido para o cumprimento dos objetivos específicos propostos. Posteriormente, análises dos dados da Campanha do Brasil enviados via e-mail pelo promotor da Campanha no Brasil durante os meses de agosto e dezembro de 2016 permitiram a quantificação do total de adesões de município a cada ano, com a identificação da distribuição de municípios resilientes em cada uma das regiões do país, assim como a quantificação do número de cidades que avançaram para o segundo ciclo da Campanha.

Na Fase 2, o conteúdo das regulamentações oficiais da UNISDR (kit e guia de cidades resilientes) permitiu a identificação das principais providências a serem desenvolvidas pelo governo local para cada um dos dez passos para construir cidades resilientes, que foram sintetizadas em pequenos textos.

A Fase 3 consistiu na análise documental das ações implementadas em Campinas, SP nos dois ciclos da Campanha presentes nos relatórios de progresso local, com a sintetização das medidas implementadas referentes a cada um dos 41 critérios e a sua transposição para 
tabelas. Na tabela (ver Anexo A), abaixo de cada critério, foi exposto o nível de progresso alcançado e foram descritas as informações presentes no relatório referente ao primeiro ciclo da campanha e, logo abaixo, referente ao segundo ciclo. Em cada critério de cada um dos passos, os relatórios apresentavam links que levam a notícias publicadas no site oficial de Campinas, o que permitiu a conferência entre o conteúdo dos relatórios e informações noticiadas pela imprensa de Campinas.

$\mathrm{Na}$ Fase 4, as informações do primeiro passo, compiladas nas $\mathrm{t}$

Tabelas B1 a B10 (Anexo B), foram analisadas funcionalmente e descritas de acordo com contextos antecedentes, lista de agentes participantes, os produtos gerados por meio do entrelaçamento e as consequências selecionadoras. Essa leitura permitiu a sistematização de metacontingências e, em seguida, o mesmo foi repetido para os outros nove passos. 


\section{Resultados}

Desde o lançamento da Campanha "Construindo Cidades Resilientes - Minha cidade está se preparando" no Brasil, em 2011, o número de cidades do país que aderiram e se comprometeram com as providências de redução de risco de desastre, a cada ano, é expressivo, como mostra a Figura 3.

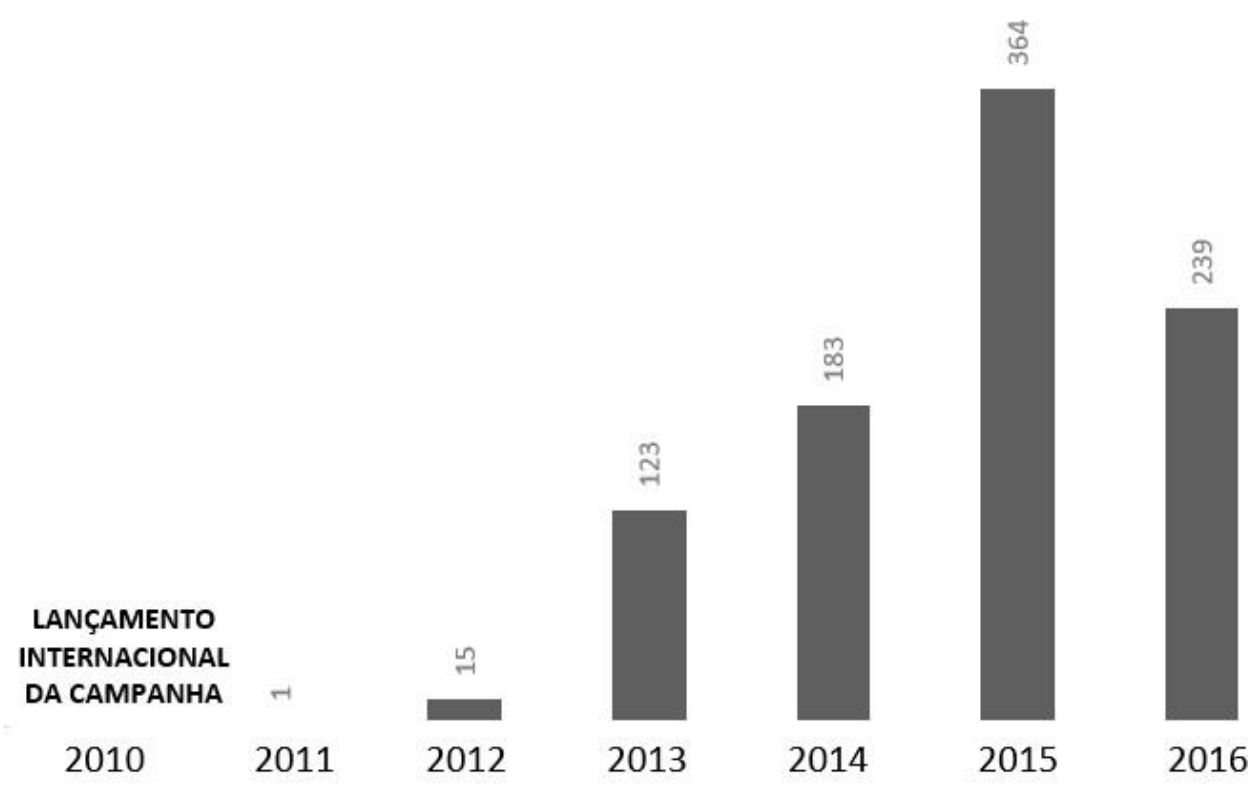

Figura 3. Adesões de cidades brasileiras à Campanha Construindo Cidades Resilientes - Minha Cidade Está se Preparando, entre os anos de 2011 a 2016.

Até outubro de 2016, um total de 921 cidades haviam aderido à Campanha, distribuídas por todas as regiões do país, com uma maior concentração na região sudeste e no Estado de São Paulo. Esse número representa por volta de $16 \%$ da quantidade total de municípios brasileiros, como mostra dados fornecidos pela Defesa Civil de Campinas ${ }^{9}$. Observa-se destaque para a região sudeste, seguida pela região sul, com significativas adesões nos estados de São Paulo e Paraná, respectivamente. Quanto à passagem para o segundo ciclo

\footnotetext{
${ }^{9}$ Disponível em http://www.unisdr.org/campaign/resilientcities/Home/advocateprofile/Advocate\%20Profile\%20Of\%20Sidnei/?id $\equiv 47689166$ recuperado em 30 de janeiro de 2017.
} 
da campanha, Pernambuco mostra 44,44\% de adesão, tendo 9 e 4 cidades, nos dois ciclos, respectivamente. E, São Paulo 24,35\%. Vale ressaltar que 8 estados em 4 regiões (norte, nordeste, centro-oeste e sudeste) não prosseguiram ao segundo ciclo da campanha. Esse dado que pode exigir investimentos estratégicos adicionais, ao investigar os fatores que estão contribuindo para a interrupção do avanço na campanha de cidades resilientes. Esses fatores podem ter valor explicativo também nos casos dos estados de Minas Gerais (115/1 ${ }^{\circ}$ Ciclo para $3 / 2^{\circ}$ Ciclo) e no Paraná (320/1 ${ }^{\circ}$ Ciclo para $3 / 2^{\circ}$ Ciclo). Atualmente, no total, 111 cidades encontram-se no segundo ciclo da Campanha, como mostra a Tabela 2.

\section{Tabela 2}

Distribuição dos 16 estados com 921 cidades que aderiram à "Campanha Construindo Cidades Resilientes - Minha Cidade Está se Preparando" e avançaram para o $2^{\circ}$ ciclo, contemplando as regiões norte, nordeste, centro-oeste, sudeste e sul.

\begin{tabular}{llcc}
\hline \multicolumn{1}{c}{ REGIÃO } & ESTADOS & $\begin{array}{c}\mathbf{N}^{\mathbf{0}} \text { DE CIDADES } \\
\text { TOTAL ADESOES }\end{array}$ & $\begin{array}{c}\mathbf{N}^{\mathbf{0}} \text { DE CIDADES } \\
\mathbf{2}^{\mathbf{0}} \text { CICLO }\end{array}$ \\
\hline NORTE & Acre & 2 & 0 \\
(04 cidades) & Amazonas & 1 & 1 \\
& Tocantins & 1 & 0 \\
\hline NORDESTE & Alagoas & 2 & 0 \\
$(\mathbf{1 2}$ cidades) & Bahia & 1 & 0 \\
& Pernambuco & 9 & 4 \\
\hline CENTRO-OESTE & Distrito Federal & 15 & 0 \\
(17 cidades) & Goiás & 1 & 0 \\
& Mato Grosso & 1 & 0 \\
\hline SUDESTE & Espírito Santo & 18 & 0 \\
(537 cidades) & Minas Gerais & 115 & 3 \\
& Rio de Janeiro & 22 & 4 \\
& São Paulo & 382 & 33 \\
\hline SUL & Paraná & 320 & 1 \\
$(\mathbf{3 5 1}$ cidades) & Rio Grande do & & 2 \\
& Sul & 16 & \\
\hline TOTAL & Santa Catarina & 15 & 111 \\
\hline
\end{tabular}

A seguir, serão apresentados os dados obtidos neste estudo, a partir da análise documental sobre as práticas de redução de risco de desastre, regulamentadas pelo Escritório 
das Nações Unidas para a Redução do Risco de Desastres (UNISDR) para a Campanha Global 2010-2015 “Construindo Cidades Resilientes - Minha cidade está se preparando”, que foram adotadas pela gestão municipal de Campinas-SP. Dados oficiais referentes aos dois ciclos da Campanha, presentes nos "Relatórios de progresso local na implantação dos 10 passos essenciais para construção de cidades resilientes" receberão interpretações analíticocomportamentais, a partir de metacontingências envolvendo as recorrentes práticas culturais e seus resultados no ambiente, e as consequências selecionadoras desses arranjos denominados de culturantes (CCES $\rightarrow$ PAs).

Desse modo, os 10 passos da Campanha "Construindo Cidades Resilientes - Minha Cidade está se Preparando" são apresentados nas Tabelas de B1 a B10 (ver Anexo B), as quais apresentam os dados obtidos da cidade de Campinas-SP, nos dois ciclos da Campanha, seguidos das notas de autoavaliação dos critérios da ferramenta $\operatorname{LGSAT}^{10}$. A partir dessas tabelas, as Figuras 5 a 16 apresentam as metacontingências que representam as ações coordenadas e seus resultados obtidos, bem como o ambiente que selecionou esses culturantes.

No município de Campinas, ao considerar os dois ciclos de implementação da Campanha, há consistência entre o previsto e a descrição das implementações, contando com altos níveis de progresso na escala de autoavaliação LGSAT. A Figura 4 mostra que a pontuação variou de 4 a 5, em geral, no transcorrer dos 10 Passos da Campanha. As descrições desses níveis são apresentadas a seguir:

Nível de progresso 4. Resultado significativo foi alcançado, mas com algumas deficiências já reconhecidas, em comprometimento, recursos financeiros ou capacidades operacionais.

Nível de progresso 5. Resultado completo foi alcançado, com compromisso e capacidade para apoiar esforços em todos os níveis.

\footnotetext{
${ }^{10}$ Grifos da autora foram feitos nas Tabelas B1 a B10, destacando centrais de controle e/ou agentes.
} 
De um total de 41 critérios, no transcorrer dos 10 Passos da Campanha, em apenas 4 critérios foi alcançado o nível 3, segundo o qual:

Nível de progresso 3: Existe algum compromisso institucional e capacidades para a redução de risco de desastres, mas o progresso não é abrangente ou substancial.

Ao considerar o ciclo 2, os Passos 3, 6, 9 e 10 sobressaíram-se alcançando nível 5. Como será detalhado a seguir, esses passos se referem a medidas de avaliação de risco, regulamentação para uso e ocupação do solo, sistemas de alerta e planos de reconstrução pósdesastre, respectivamente. Já nos Passos 2 e 7, que apresentam providências para ampliar a capacidade orçamentária municipal para atividades de redução de risco de desastre e o treinamento, sensibilização e educação pública sobre esse tema, alguns critérios alcançaram nível de progresso 3. A seguir, os dados obtidos dos 10 Passos da Campanha serão descritos e interpretados a partir da evolução de práticas culturais envolvendo múltiplos agentes, seus produtos na sociedade e a forma como esse arranjo envolvendo as ações desses agentes e seus resultados são fortalecidos ou selecionados, aumentando a probabilidade futura de ocorrência de intervenções ou ações que diminuam riscos de desastres em uma cidade resiliente brasileira.

NÍVEL DE PROGRESSO ALCANÇADO NA FERRAMENTA LGSAT

CAMPINAS $1 \%$ e $2 \circ$ CICLO

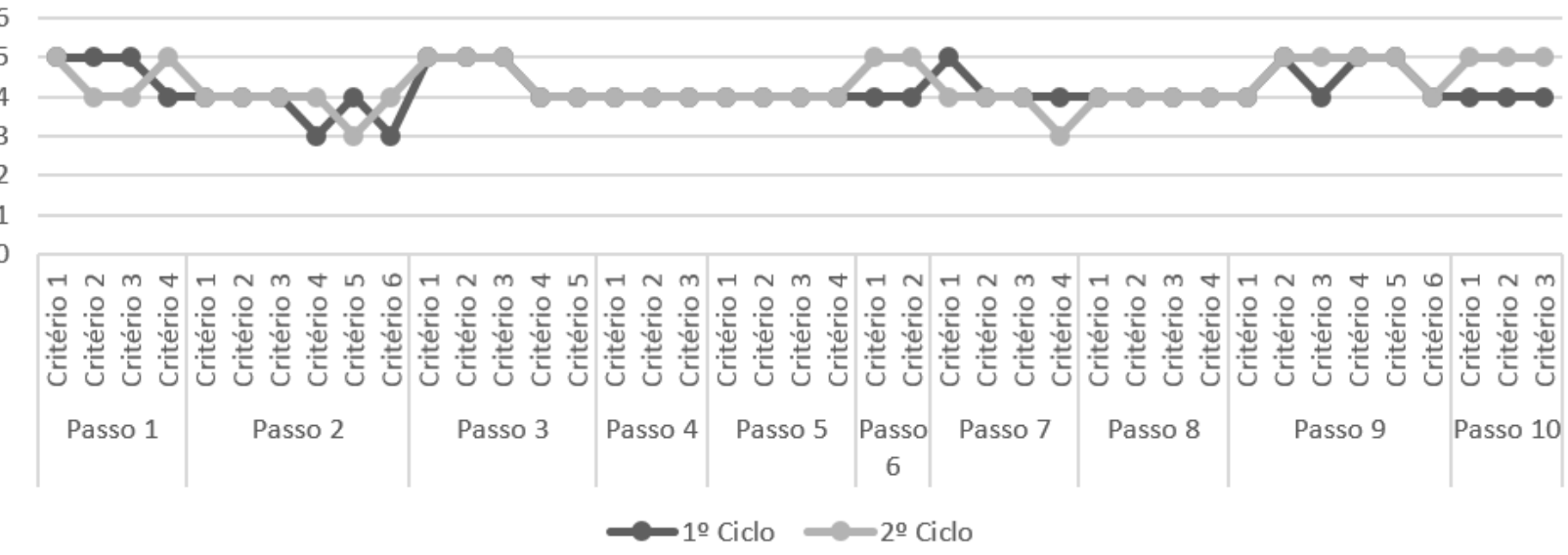

Figura 4. Nível de Progresso Alcançado nos 41 critérios da Ferramenta LGSAT em Campinas nos dois ciclos da "Campanha Construindo Cidades Resilientes - Minha Cidade Está se Preparando". 


\section{Passo 1}

A Tabela B1 (Anexo B) apresenta o Passo 1, o qual envolve pré-requisitos para a tomada de decisão, considerando: (1) capacidade institucional de aplicação das ferramentas de redução de risco e de coordenação das atividades realizadas no município, com atribuição de liderança a uma entidade ou escritório vinculado à administração pública local; (2) estabelecimento de um quadro legislativo (aperfeiçoar regulamentos, leis municipais, estatutos de apoio à redução de risco); e (3) desenvolvimento de alianças e parcerias (e.g., universidades, municípios vizinhos, ONGs, grupos de cidadãos e da sociedade civil e organizações técnico científicas), com trocas de experiências e ampliação da cooperação internacional, nacional e local (UNISDR, 2012). Tem como base, portanto, a criação de estratégias e/ou regulamentações que evoquem mudanças de comportamento voltadas para a prevenção de riscos de desastres.

Práticas culturais recorrentes envolvem dependência funcional entre as contingências que descrevem ações de múltiplos agentes envolvidos (CCEs) que participam de um determinado resultado social (PAs). Tais práticas e seus produtos agregados são, por sua vez, mantidas ou enfraquecidas por um ambiente selecionador denominado de consequência cultural.

A partir dos dados obtidos no município, uma metacontingência principal denominada de Metacontingência Cidades Resilientes foi descrita na Figura 5, destacando eventos antecedentes, como a ocorrência de desastres provocados por fatores naturais em CampinasSP e no Brasil, e as recomendações mundiais previstas no Marco de Ação de Hyogo 20052015. A ocorrência de desastres é uma operação estabelecedora que aumenta o valor reforçador de comportamentos com o potencial de diminuir os danos provocados por novos 
desastres e o Marco de Hyogo é um estímulo antecedente que especifica contingências (e.g., “se o município investir financeiramente em ações de risco de desastre, então estará preparado para uma situação de emergência e reduzirá o número de pessoas afetadas)”. A Figura 5 mostra também os agentes que atuam nas contingências comportamentais entrelaçadas, as ações desenvolvidas e os resultados das articulações, ressaltando os PAs. Nesta Metacontingência o comportamento de agentes do governo municipal, estadual e federal, organizações não governamentais (ONGs), organizações técnico-científicas; setor privado, comunidade internacional e instituições de ensino devem estar entrelaçados para produzir riscos de desastres de origem natural minimizado e perdas humanas, físicas e materiais reduzidas (PAs). Esses PAs são produzidos a partir do aperfeiçoamento de regulamentos (leis municipais, estatutos de apoio à redução de risco); estabelecimento de uma liderança local para coordenar as atividades de redução de risco de desastres; investimento financeiro paras as atividades de redução de risco; criação de instrumentos de medida de monitoramento climático e meteorológico; criação trocas de informação que resultam em rápida e efetiva ação preventiva e emergencial; e planejamento de estratégias de educação, capacitação e treinamento popular sobre redução de risco de desastre.

Quanto ao aperfeiçoamento de regulamentos, a Tabela 3 apresenta 3 decretos e 6 leis anteriores à adesão à Campanha da ONU de cidades resilientes. Em 2012, com a adesão à Campanha, outros 9 decretos, além de Resolução, Ordem de Serviço e 2 leis complementam e fortalecem a estrutura de funcionamento dos agentes envolvidos em redução de riscos de desastres no município de Campinas, São Paulo. Toda essa regulamentação da Tabela 3 será apresentada no transcorrer dos 10 Passos da Campanha. 


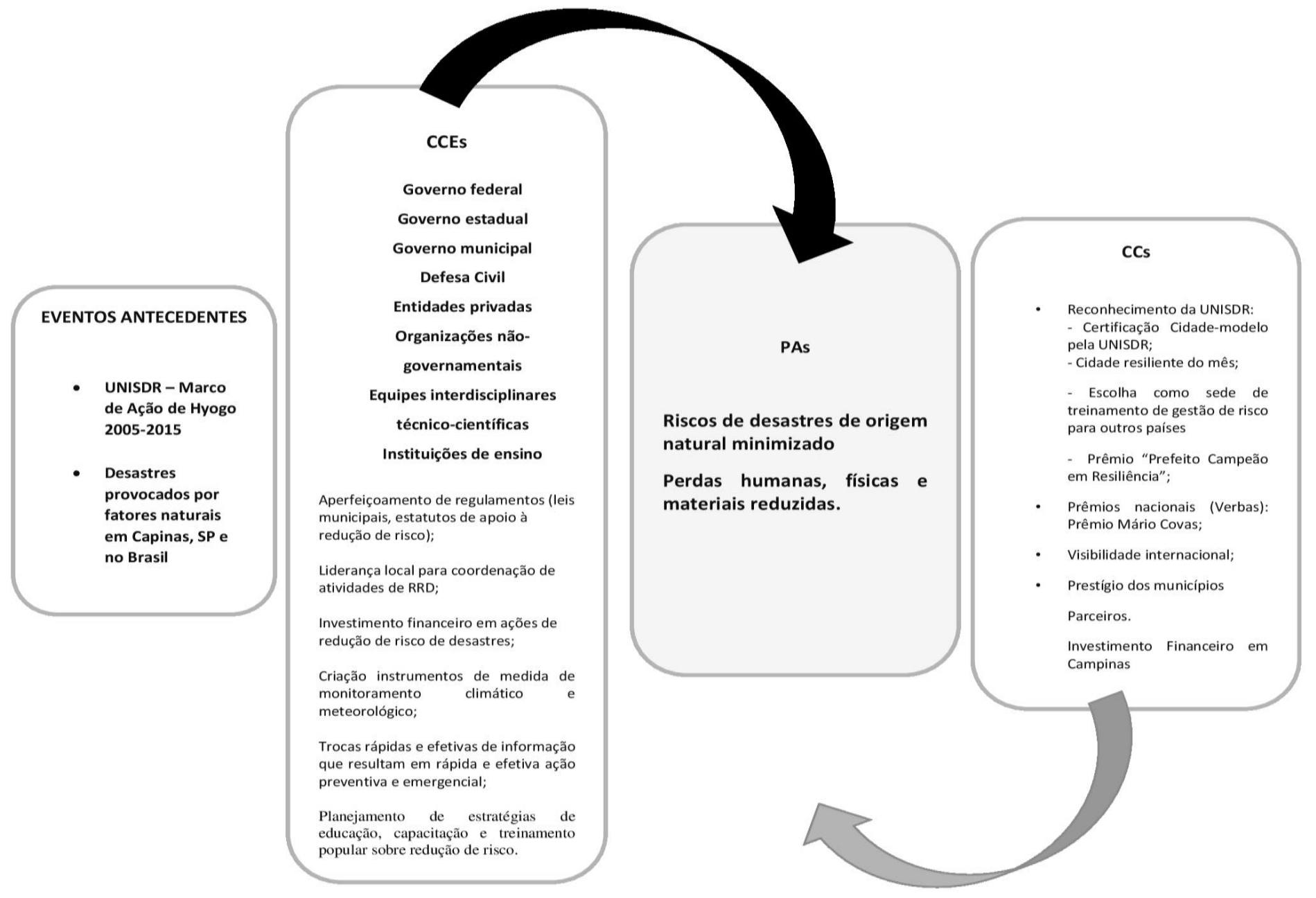

Figura 5. Metacontingência Cidades Resilientes.

As consequências culturais (CCs) que reforçam essas relações em Campinas (CCEs $\rightarrow$ PAs) figuram como prêmios nacionais, reconhecimento oficial pela ONU como uma cidade com boas práticas de redução de risco de desastres, no fortalecimento oferecido por outros municípios, e ainda, por representação reconhecida junto ao Ministério da Integração Nacional (MI) e Ministério da Cidades (MC). Em 2013, o município de Campinas recebeu destaque pela ONU, ao ser reconhecido como "cidade resiliente do mês"11 e, no mesmo ano, recebeu certificação de cidade modelo de boas práticas para construção da resiliência para redução de risco de desastres ${ }^{12}$. Ademais, em 2014, Campinas foi escolhida pela Organização

\footnotetext{
${ }^{11}$ Disponível em http://www.campinas.sp.gov.br/noticias-integra.php?id=18772 recuperado em 09 de setembro de 2016.

${ }^{12}$ Disponível em http://www.campinas.sp.gov.br/noticias-integra.php?id=19648 recuperado em 09 de setembro de 2016
} 
das Nações Unidas (ONU) como sede de um programa sobre gestão de riscos ministrado pela Defesa Civil municipal a técnicos de outros países de língua portuguesa ${ }^{13}$, e recebeu dois prêmios: (1) "Prêmio Mario Covas", de abrangência Nacional, na categoria Inovação em Gestão Estadual, com o projeto "Sistema Metropolitano de Defesa Civil"14; e (2) "Prefeito Campeão em Resiliência", destinado ao gestor público local, com reconhecimento pela ONU sobre como a cidade se tornou um centro nacional bem preparado para situações de desastre e de preparação de defesas civis de outras localidades ${ }^{15}$.

Essas premiações dão visibilidade nacional e internacional ao município, assim como colaboram para que receba verbas e investimentos financeiros. Portanto, são consequências culturais dispostas por organizações externas ao município, que têm função selecionadora dos entrelaçamentos e dos PAs produzidos em Campinas para as práticas de redução de risco de desastres. Nesse sentido, há consequências culturais para os relatórios de 2011-2013 e 20132014, além de consequências atuais em 2016. Vale ressaltar que as demais Figuras 6 a 17 podem ser apresentadas sem as consequências selecionadoras porque já foram aqui apresentadas no Passo 1, na Figura 5. Isto significa que, para todas as metacontingências identificadas em cada Passo, há consequências culturais selecionadoras dos arranjos entrelaçados entre os múltiplos agentes e seus respectivos produtos agregados resultantes.

\footnotetext{
${ }^{13}$ Disponível em ttp://correio.rac.com.br/_conteudo/2014/11/capa/campinas_e_rmc/222752-escolhida-pela-onucampinas-sedia-curso-de-gestao-de-riscos.html recuperado em 31 de agosto de 2016.

${ }^{14}$ Disponível em http://www.campinas.sp.gov.br/noticias-integra.php?id=23700 recuperado em 31 de agosto de 2016.

${ }^{15}$ Disponível em http://www.campinas.sp.gov.br/noticias-integra.php?id=24379 recuperado em 09 de setembro de 2016.
} 


\section{Tabela 3}

Lista das principais legislações municipais de Campinas relacionada às medidas de redução de desastres

\begin{tabular}{|c|c|c|}
\hline & LEGISLAÇÃO & DESCRIÇÃO \\
\hline \multicolumn{3}{|c|}{ ANTERIOR Á ADESÃO Á CAMPANHA DE CIDADES RESILIENTES } \\
\hline 1980 & Lei $\mathrm{n}^{\circ} 4985$ de 08 de maio de 1980 & $\begin{array}{l}\text { Cria o Fundo de Apoio à População } \\
\text { de } \quad \text { Sub-Habitação } \\
\text { (FUNDAP) }\end{array}$ \\
\hline 1988 & $\begin{array}{l}\text { Lei No } 6.031 \text { de } 29 \text { de dezembro de } \\
1988 \text { - Lei de Uso e Ocupação do } \\
\text { Solo (LUOS) }\end{array}$ & $\begin{array}{l}\text { Regulamenta o ordenamento } \mathrm{e} \\
\text { ocupação territorial de Campinas }\end{array}$ \\
\hline 1998 & $\begin{array}{l}\text { Lei } n^{\circ} 9.858 \text { de } 28 \text { de setembro de } \\
1998\end{array}$ & $\begin{array}{l}\text { Dispõe sobre a obrigatoriedade de } \\
\text { hospitais, prontos-socorros e } \\
\text { clínicas do município de Campinas } \\
\text { instalarem geradores de energia } \\
\text { elétrica }\end{array}$ \\
\hline 2003 & $\begin{array}{llllll}\text { Decreto } & n^{\circ} & 14.524 & \text { de } & 14 & \text { de } \\
\text { novembro de } & 2003\end{array}$ & \begin{tabular}{l}
\multicolumn{3}{l}{ Dispõe sobre o repasse de recursos } \\
financeiros às \\
educacionais públicas municipais \\
de Campinas (Programa Conta \\
Escola)
\end{tabular} \\
\hline 2003 & $\begin{array}{l}\text { Lei Complementar } N^{\circ} 09 \text { de } 23 \text { de } \\
\text { dezembro de } 2003\end{array}$ & $\begin{array}{l}\text { Dispõe sobre o código de obras e } \\
\text { edificações do município de } \\
\text { Campinas, estabelecendo } \\
\text { procedimentos necessários para o } \\
\text { licenciamento, fiscalização, projeto, } \\
\text { execução e preservação de obras e } \\
\text { edificações de órgãos ou serviços } \\
\text { públicos }\end{array}$ \\
\hline 2006 & $\begin{array}{l}\text { Lei Complementar } n^{\circ} 15 \text { de } 27 \text { de } \\
\text { dezembro de } 2006\end{array}$ & $\begin{array}{l}\text { Dispõe sobre plano diretor do } \\
\text { município de Campinas e define } \\
\text { diretrizes para as políticas setoriais } \\
\text { e para a gestão de todo o território }\end{array}$ \\
\hline 2007 & $\begin{array}{l}\text { Lei } n^{\circ} 13.197 \text { de } 14 \text { de dezembro de } \\
2007\end{array}$ & $\begin{array}{l}\text { Dispõe sobre a instituição do } \\
\text { Programa Auxílio Moradia e suas } \\
\text { modalidades. }\end{array}$ \\
\hline 2009 & $\begin{array}{l}\text { Lei } \mathrm{n}^{\circ} 13.658 \text { de } 17 \text { de agosto de } \\
2009\end{array}$ & $\begin{array}{l}\text { Autoriza o município de Campinas } \\
\text { a participar da constituição da } \\
\text { Fundação Agência das Bacias } \\
\text { Hidrográficas dos Rios Piracicaba, } \\
\text { Capivari e Jundiaí (PCJ) }\end{array}$ \\
\hline 2010 & $\begin{array}{l}\text { Decreto } n^{\circ} 16.920 \text { de } 8 \text { de janeiro } \\
\text { de } 2010\end{array}$ & $\begin{array}{l}\text { Cria o Grupo de Controle e } \\
\text { Contenção de Ocupações, } \\
\text { Parcelamentos Clandestinos e } \\
\text { Danos Ambientais no Município de } \\
\text { Campinas }\end{array}$ \\
\hline 2010 & $\begin{array}{l}\text { Lei } n^{\circ} 13.784 \text {, de } 04 \text { de março de } \\
2010\end{array}$ & $\begin{array}{l}\text { Altera a Lei } n^{\circ} 13.197 \text { de } 14 \text { de } \\
\text { dezembro de } 2007 \text {, que dispõe } \\
\text { sobre a instituição do Programa } \\
\text { Auxílio Moradia. }\end{array}$ \\
\hline \multicolumn{3}{|c|}{ POSTERIOR À ADESÃO Á CAMPANHA DE CIDADES RESILIENTES } \\
\hline 2012 & $\begin{array}{l}\text { Decreto } \mathrm{n}^{\circ} 17.536 \text {, de } 12 \text { de março } \\
\text { de } 2012\end{array}$ & $\begin{array}{l}\text { Dispõe sobre o Centro Integrado de } \\
\text { Monitoramento de Campinas } \\
\text { (CIMcamp) }\end{array}$ \\
\hline 2012 & $\begin{array}{l}\text { Decreto } n^{\circ} 17.576 \text { de } 02 \text { de maio de } \\
2012\end{array}$ & $\begin{array}{l}\text { Dispõe sobre o Programa Brigadas } \\
\text { de Prevenção e Combate a } \\
\text { Enchentes em Campinas }\end{array}$ \\
\hline
\end{tabular}




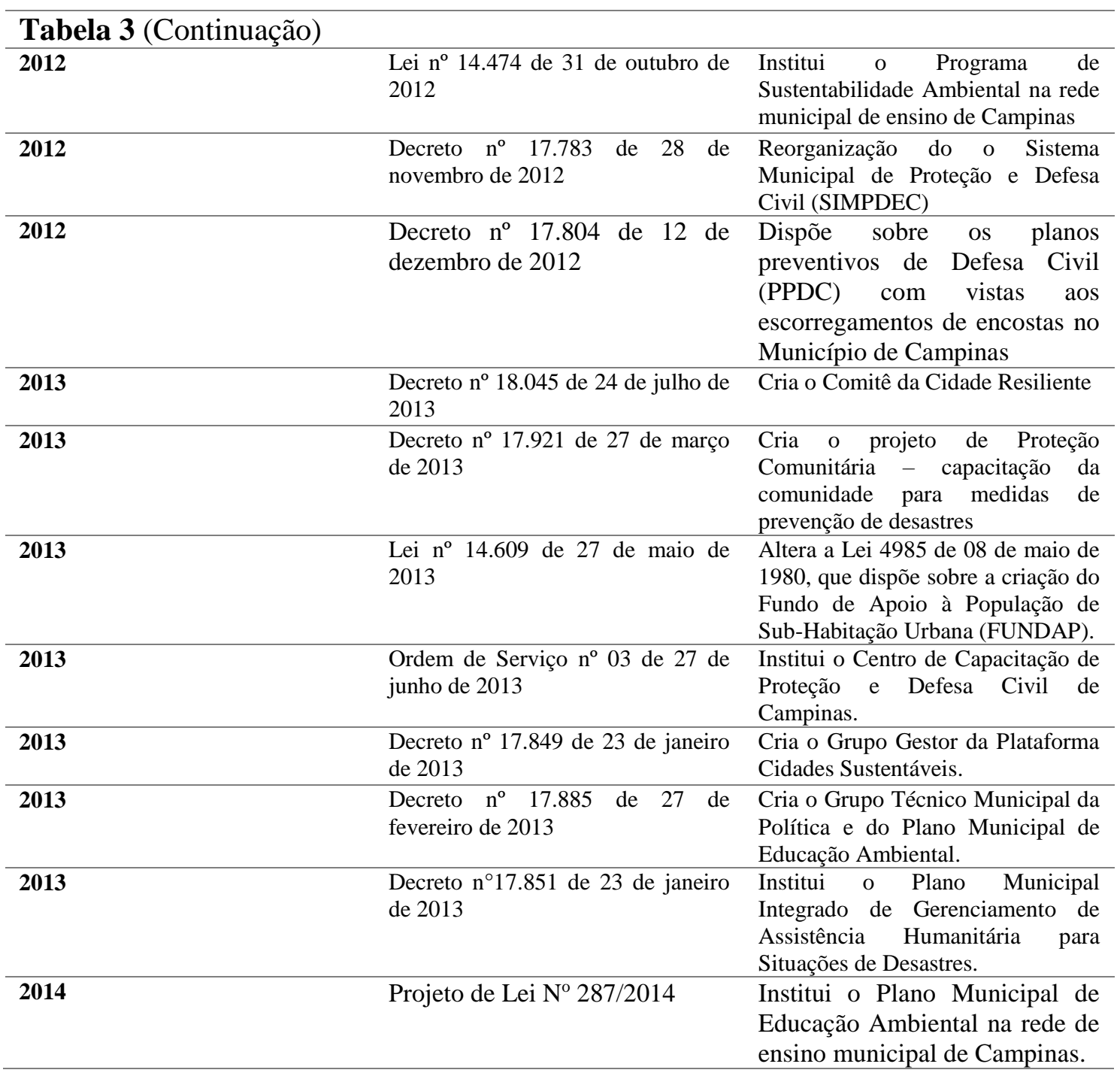

A Metacontingência Quadro Institucional e Legislativo do Passo 1 (ver Figura 6) é composta pelas medidas dos seus quatro critérios. No Critério 1 observa-se o entrelaçamento do comportamento de diferentes agentes, destacando-se, inicialmente, o apoio político e financeiro do prefeito junto à liderança da Defesa Civil local, sua equipe interdisciplinar, assim como, parcerias também anunciadas no Critério 2: biólogos, geógrafos, ecólogos, geólogos; estatísticos e programadores; setor público e privado tais como empresas de economia mista, autarquias; ONGs; instituições de ensino; e representantes da comunidade. A Defesa Civil de Campinas realiza a capacitação local para redução de riscos de desastres com a criação de novos instrumentos de medida de monitoramento climático e meteorológico - 
instalação de 42 sensores, 2 radares meteorológicos; instalação de sensor de enchente comunitário, acoplado ao sistema de alarme central, monitorando situações que exigem rápida saída de moradores de área de inundação. E ainda, na área de limpeza urbana, a SMSP realizou instalação de ecopontos minimizando o impacto negativo do lançamento de resíduos em locais públicos. Além disso, Campinas desenvolve também um sistema de bancos de dados que facilitam o acompanhamento local e nacional do monitoramento de áreas de risco, diminuindo os riscos de desastres por fatores naturais. Entre as bases estão o TerraMA2 Monitoramento, Análise e Alerta, e o Gerenciamento de Ocorrências da Defesa Civil (GODC). Quanto à capacitação, cursos têm sido programados, tendo como alvo a formação de competências em servidores e na comunidade em geral, envolvendo um total de 32 municípios do estado de São Paulo.

O município foi a primeira cidade brasileira a reorganizar o Sistema Municipal de Proteção e Defesa Civil (SIMPDEC), responsável por executar a Política Nacional de Proteção e Defesa Civil (PNPDEC) em esfera local ${ }^{16}$. Suas reorganizações ocorreram por meio de decretos, os quais descrevem contingências prescritas a serem planejadas de modo que a rede municipal de apoio à redução de risco de desastres seja mais articulada e atue de forma sistêmica. Foi a partir da reorganização do Sistema ocorrida em 2012 que houve o estabelecimento do apoio administrativo da Secretaria Municipal de Chefia do Gabinete (SMCGP) ao Departamento de Defesa Civil. A criação do Comitê Cidades Resilientes foi também uma medida importante estabelecida pela nova regulamentação, pois, além de promover a integração dessa rede, criou reservas de informação que garantem a recorrência de CCEs relevantes para a redução de risco de desastres, e, desse modo, a manutenção de práticas culturais efetivas nesse campo, ainda que mude a gestão da Prefeitura. As CCEs desta

\footnotetext{
${ }^{16}$ Disponível em http://www.campinas.sp.gov.br/noticias-integra.php?id=30244 recuperado em 14 de setembro de 2016.
} 
metacontingência geram uma equipe municipal bem capacitada em gestão do risco de desastres, sistemas de alerta bem equipado e atividades de RRD em pleno funcionamento. As premiações nacionais e internacionais já citadas no texto (Certificação Cidades Resilientes; "cidade resiliente do mês" e Prêmio Mario Covas") são consequências culturais selecionadoras das práticas de redução de risco descritas nesse Passo.

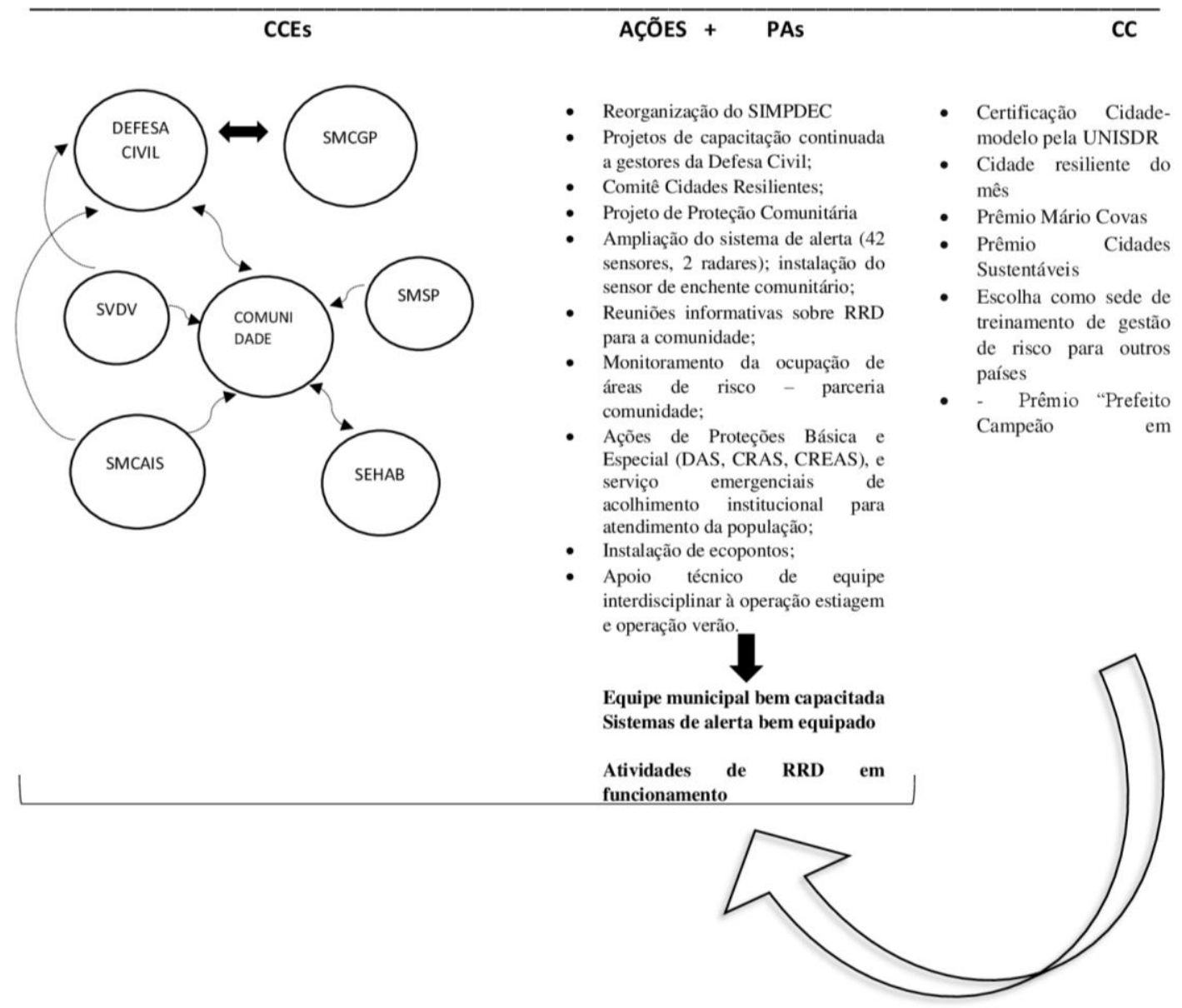

Figura 6. Passo 1 - Metacontingência Quadro Institucional e Legislativo.

SMCGP: Secretaria Municipal de Chefia de Gabinete do Prefeito

SMSP: Secretaria Municipal de Serviços Públicos

SVDS: Secretaria Municipal do Verde, Meio Ambiente e Desenvolvimento Sustentável

SEHAB: Secretaria Municipal de Habitação

SMCAIS: Secretaria Municipal de Cidadania, Assistência e Inclusão Social

SIMPDEC: Sistema Municipal de Proteção e Defesa Civil

RRD: Redução de Risco de Desastre

DAS: Departamento de Assistência Social

CRAS: Centro de Referência da Assistência Social

CREAS: Centro de Referência Especializado de Assistência Social 


\section{Passo 2}

A Tabela B2 apresenta o Passo 2 com medidas de ampliação da capacidade orçamentária do município para as atividades de redução de risco de desastre, contemplando as etapas de prevenção, mitigação, preparação, resposta e recuperação. O governo local deve integrar as ações de redução de risco ao seu plano orçamentário e buscar complementação em fundos de apoio estaduais e nacionais, organizações externas, parcerias público-privadas ou em recursos de cooperação técnica. Desse modo, deve garantir ações que contemplem: (1) incentivos financeiros para aqueles que apoiam padrões de segurança; (2) penalidades para ações que ampliem o risco e a degradação ambiental; (3) reserva orçamentária para necessidades pós-desastres; (4) capacitação e treinamento de equipes, com a manutenção de serviços de resposta a emergências bem equipados; e (5) financiamentos comunitários (UNISDR, 2012).

Metacontingências do Passo 2 abrangem a cooperação entre os três níveis de governo, considerando que o Município necessita de apoio financeiro do Estado e da União, além de envolver o entrelaçamento entre membros da prefeitura municipal, equipes técnicas, empresas locais, e comunidades vulneráveis. Os agentes envolvidos totalizam 18 grupos, apresentados na Tabela 4, a seguir.

A Figura 7 mostra a Metacontingência Financiamento e Recursos, com linhagens culturo-comportamentais (ou denominadas de linhagens de culturantes) que produzem recursos operacionais e financiamento para redução de risco de desastres, a partir dos Critérios 1 e 2:

Critério 1: Até que ponto o governo local tem acesso a recursos financeiros adequados para realizar as atividades de redução de risco?

Critério 2: Até que ponto o governo local aloca recursos financeiros suficientes para realizar atividades de redução de risco de desastres, incluindo resposta efetiva a desastres e recuperação. (Relatório de progresso local na implantação dos 10 Passos Essenciais para Construção de Cidades Resilientes 2013-2014) 


\section{Tabela 4}

Grupos de agentes que participam do Passo 2 da Campanha Cidades Resilientes na cidade de Campinas, SP - secretarias municipais ligadas à prefeitura e outros parceiros

1. Secretaria Municipal de Infraestrutura (SEINFRA)

2. Secretaria Municipal de Habitação (SEHAB)

3. Secretaria Municipal de Planejamento de Desenvolvimento Urbano (SEPLAN)

4. Sociedade de Abastecimento de Água e Saneamento (SANASA)

5. Secretaria Municipal de Cidadania, Assistência e Inclusão Social (SMCAIS)

6. Secretaria Municipal de Cooperação nos Assuntos de Segurança Pública (SMCASP)

7. Secretaria Nacional de Segurança Pública do Ministério da Justiça (SENASP/MJ)

8. Ministério de Desenvolvimento Social e Combate à Fome (MDS)

9. Secretaria Municipal de Serviços Públicos (SMSP)

10. Secretaria Municipal de Trabalho e Renda (SMTR)

11. Secretaria Municipal de Desenvolvimento Econômico, Social e Turismo (SDEST)

12. Empresa Chinesa

13. Empresa Brasileira

14. Loja de Departamentos

15. Companhia brasileira na área de biotecnologia

16. Associação Comercial e Industrial de Campinas

17. Centro das Indústrias do Estado de São Paulo

18. Banco Itaú e outras agências bancárias

Um total de cinco secretarias (ver Tabela 4 e Figura 7) estão envolvidas nesses entrelaçamentos de ações (CCEs) nos quais há recorrência, repetição e transmissão dessas linhagens (CCES $\rightarrow$ PAs), resultando em descentralização de alocação de recursos e oferta de serviços. Algumas secretarias possuem fundos ou reservas orçamentárias próprias de financiamento tais como a SEPLAN (R\$ 270 mil) e SEINFRA (R\$ 390 milhões), porém vale ressaltar que todas potencialmente contam com verbas expressivas da prefeitura. $\mathrm{O}$ apoio financeiro também pode ser realizado a partir de convênios dessas secretarias com instâncias federais, como os ministérios da Justiça $(\mathrm{MJ})$ e do Desenvolvimento Social e Combate à Fome (MDS). Portanto, essas linhagens culturo-comportamentais envolvem relações entre a prefeitura e suas secretarias, por meio de auxílio financeiro, assim como destas secretarias com órgãos da união.

As CCEs do Passo 2, com a reserva de aplicação de recursos financeiros e operacionais na diminuição de riscos de desastres, resultam no PA destacado na Metacontingência Financiamento e Recursos, "atividades de redução de risco de desastres 
suficientemente financiadas pelo município". Os recursos financeiros são utilizados para desenvolver planos de ação para obras (e.g., drenagem), medidas de redução de risco (e.g., monitoramento de áreas de risco preventivo, vistorias emergenciais, implementações de macrozonas, e mobilizações técnicas em território) e financiamento de programas socioassistenciais, que auxiliam comunidades vulneráveis após a ocorrência de um desastre.

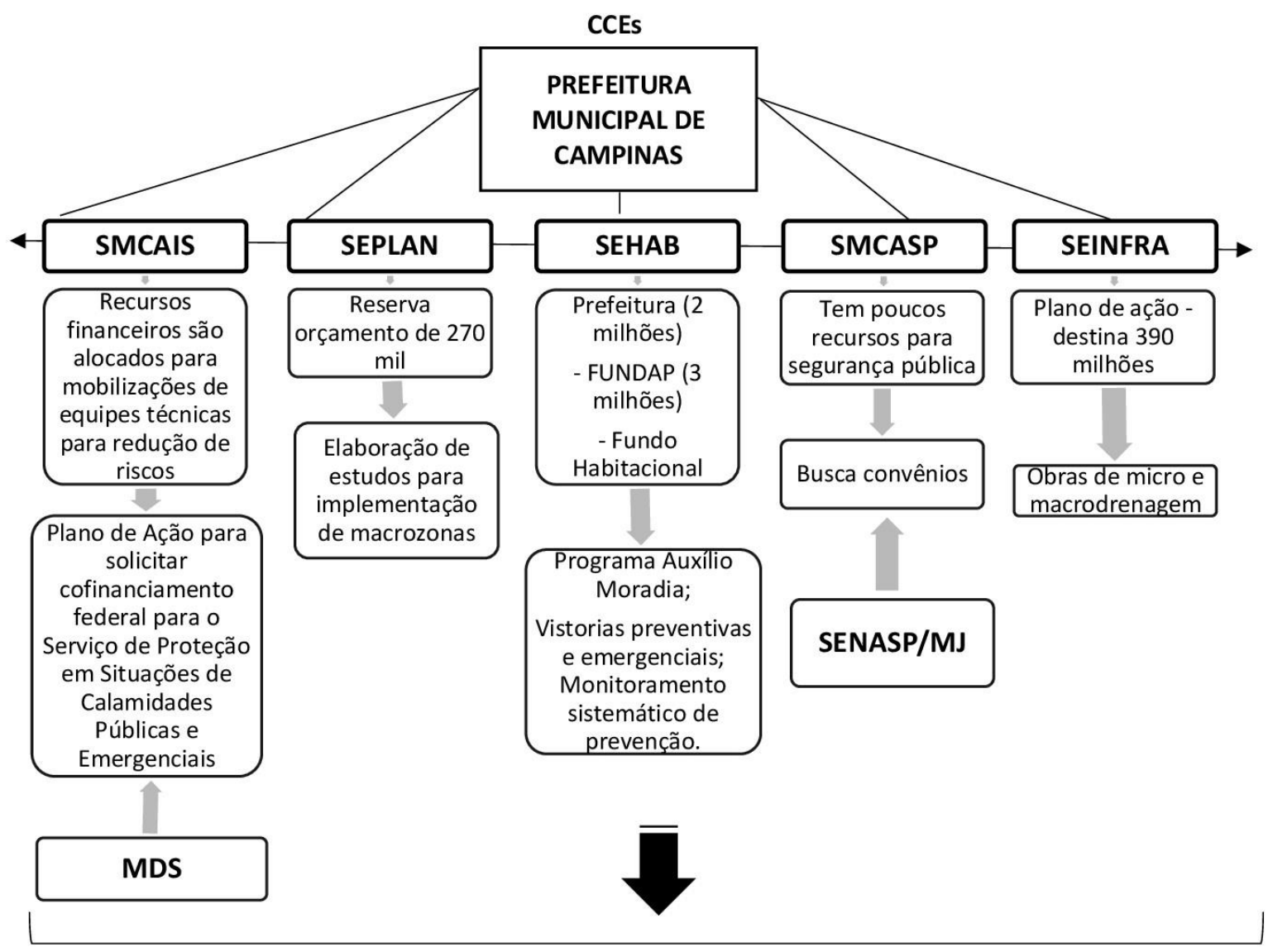

PA: atividades de redução de risco de desastres suficientemente financiadas pelo município

270 mil (SEPLAN)

2 milhões (Prefeitura)

3 milhões (FUNDAP)

390 milhões (SEINFRA)

Convênios federais de cofinanciamento

Figura 7. Passo 2 - Metacontingência Financiamento e Recursos

SMCAIS: Secretaria Municipal de Cidadania, Assistência e Inclusão Social

SEPLAN: Secretaria Municipal de Planejamento e Desenvolvimento Urbano

SEHAB: Secretaria Municipal de Habitação

SMCASP: Secretaria de Cooperação de Assuntos de Segurança Pública

SEINFRA: Secretaria Municipal de Infraestrutura

FUNDAP: Fundo de Apoio à População de Sub-habitação Urbana

MDS: Ministério do Desenvolvimento Social e Combate à Fome

SENASP: Secretaria Nacional de Segurança Pública

MJ: Ministério da Justiça 
O segundo conjunto de CCEs do Passo 2, dispostos na Figura 8, compõe a Metacontingência Investimentos Financeiros em Campinas e conta com oito grupo de agentes - algumas secretarias, associações, centro empresarial, empresas brasileiras e estrangeiras e instituições bancárias. A interação desses agentes promove um Produto Agregado comunidades vulneráveis economicamente capacitadas principalmente no que se refere à possibilidade de recuperação e reconstrução no cenário pós-desastres. Esse PA é gerado por outros produtos agregados, como os programas de transferência de renda permanentes e temporárias, de oferta de linhas de crédito com taxas de juros reduzidas, a instalação de centros de incentivo e apoio ao trabalhador e a pequenas empresas, a adoção de estratégias que buscam investimentos produtivos para a cidade e a instalação de novos empreendimentos na cidade. Em outras palavras, o PA ocorre com a geração de emprego e renda em Campinas; e com investimentos financeiros na cidade.

De acordo com o "Relatório de progresso local na implantação dos 10 passos essenciais para construção de cidades resilientes (2014)", o Passo 2 mostra que o Município de Campinas alcançou resultado significativo (Nível de Progresso 4) no que se refere ao acesso a recursos financeiros satisfatórios e à sua alocação em atividades de redução de risco, assim como na oferta de serviços financeiros disponíveis para famílias instaladas em áreas de risco. Entretanto, nos dois ciclos, os Critérios 4, 5 e 6, apresentados abaixo, tiveram variações entre resultados satisfatórios e progresso pouco abrangente ou substancial no apoio e incentivo econômico para famílias e empresas investirem na redução de risco de desastres, como a concessão de prêmios de seguro reduzidos ou isenções fiscais.

Critério 4: Até que ponto o microfinanciamento, auxílio em dinheiro, empréstimos facilitados, garantias de empréstimos, etc. estão disponíveis para que as famílias afetadas possam reiniciar os meios de subsistência após os desastres?

Critério 5: Como os incentivos econômicos para investir na redução de riscos de desastres para as famílias e empresas (prêmios de seguros reduzidos para as famílias, isenções fiscais para as empresas) são estabelecidos? 
Critério 6: Até que ponto as associações empresariais locais, como câmaras de comércio e similares, apoiam empenhos às pequenas empresas para continuidade dos negócios durante $\mathrm{e}$ após os desastres?

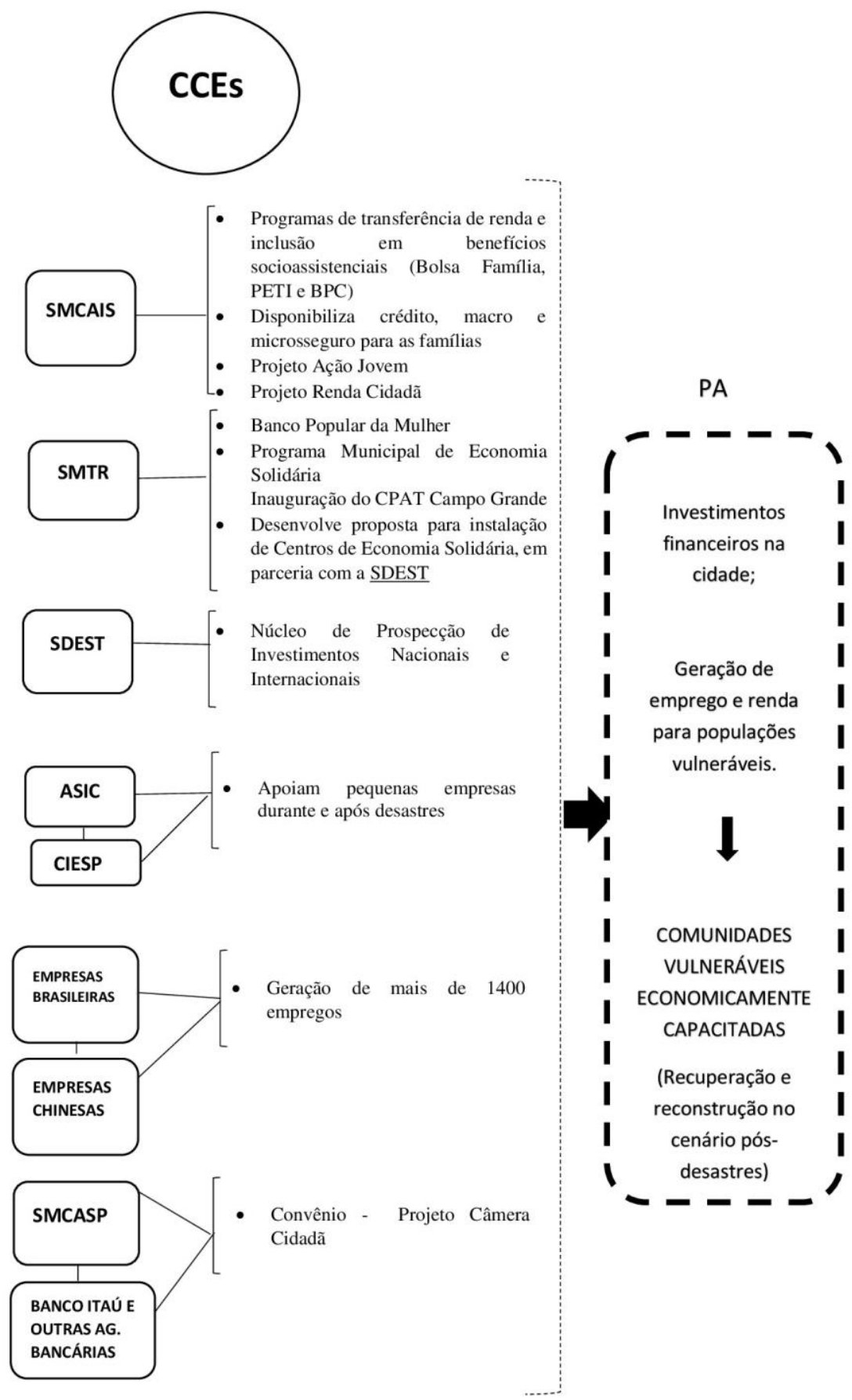

Figura 8. Passo 2 - Metacontingência Investimentos Financeiros em Campinas.

SMCAIS: Secretaria Municipal de Cidadania, Assistência e Inclusão Social SMTR: Secretaria Municipal de Trabalho e Renda CPAT: Centro Público de Apoio ao Trabalhador SMCASP: Secretaria Municipal de Cooperação de Assuntos de Segurança Pública SDEST: Secretaria Municipal de Desenvolvimento Econômico, Social e Turismo CIESP: Centro das Indústrias do Estado de São Paulo
BPC: Benefício de Prestação Continuada da Assistência Social PETI: Programa de Erradicação do Trabalho Infantil ASIC: Associação Comercial e Industrial de Campinas 


\section{Passo 3}

Na Tabela B3, a partir do Passo 3 busca-se conhecer os riscos, vulnerabilidades e exposição da sociedade local a desastres, para um planejamento eficaz da redução de riscos de desastres, adequando as tomadas de decisões, a priorização de projetos e as medidas de redução de risco às legítimas necessidades locais. Dessa maneira, o governo local deve preparar avaliações de risco que envolvam dados históricos sobre desastres e o cenário de perda atual, considerando: (1) classificação das ameaças de acordo com a sua intensidade localização e probabilidade; (2) os graus de vulnerabilidade e de exposição a essas ameaças; (3) os recursos e capacidades institucionais dos municípios; e ainda, (4) as ações corretivas e os planos de redução de risco. O governo local deve assegurar que as informações sobre os riscos serão de fácil acesso à população, à comunidade técnica e científica e ao setor produtivo (e.g., agricultura, comércio e turismo). Para tanto, poderá ser criado um sistema de informações geográficas e monitoramento que disponibilize dados atualizados (UNISDR, 2012).

O esforço da gestão municipal de Campinas no investimento em mapeamento de riscos foi uma das razões citadas pelos líderes da UNISDR para o seu reconhecimento como Cidade Modelo da Campanha ${ }^{17}$. A certificação foi uma consequência cultural (CC) com função selecionadora de culturantes (CCES $\rightarrow$ PAs) da Metacontingência de Mapeamento de Risco e Ameaças Múltiplas do Passo 3, exposta na parte superior no painel da Figura 9. Representantes do Departamento de Defesa Civil, de secretarias municipais (e.g., SVDS, SEPLAN, SEHAB, do Instituto de Pesquisas Tecnológicas (IPT) e do Serviço Geológico do Brasil (CPRM) são os agentes (CCEs) envolvidos no mapeamento de áreas urbanas e rede hidrográfica do município, que alimenta bancos de dados, facilitando a identificação de áreas

\footnotetext{
${ }^{17}$ Disponível em: https://nacoesunidas.org/onu-reconhece-lideranca-de-campinas-na-reducao-do-risco-dedesastres/ recuperado em 10 de setembro de 2016.
} 
de riscos e atividades potencialmente perigosas. Para que "áreas municipais de risco mapeadas" (PA) seja produzido como efeito, deve ocorrer interação entre os resultados da ação de agentes de: (1) centros tecnológicos estaduais e federais responsáveis por catalogar áreas de risco de inundação, enchente, alagamento e erosão do território e a delimitação de áreas de alto risco de enchentes e movimentos de massa do município; (2) Secretarias municipais que desenvolvam mapeamento da rede hidrográfica do município e sua sobreposição à malha urbana, implementação de macrozonas no território municipal, vistorias preventivas de atividades potencialmente perigosas; (3) instituições de ensino que desenvolvam estudos para subsidiar futuras remoções de famílias que moram em áreas de risco; e (4) um departamento de defesa civil capacitado para coordenar um banco de dados de avaliação de risco do município junto aos agentes citados.

A Metacontingência Mapeamento de Risco e Ameaças Múltiplas do Passo 3, torna-se uma ocasião (ou um estímulo antecedente discriminativo) para a ocorrência da Metacontingência de Divulgação de Informação Sobre Riscos, envolvendo articulação de diversos setores (e.g., Defesa Civil, secretarias municipais e empresas de economia mista) e gerando a ampla divulgação dos dados para públicos de interesse e contribui para a o desenvolvimento de planos de desenvolvimento alinhados aos riscos locais (ver Figura 9). E ainda, nesta Metacontingência de Divulgação de Dados, os Conselhos Comunitários de Segurança (CONSEGs), Gabinete Metropolitano de Gestão Estratégica de Segurança Pública (GAMESP), e o Programa Nacional de Segurança Pública com Cidadania (PRONASCI) também fazem parte do contexto antecedente, uma vez que apresentam regulamentações com integração entre as diretrizes nacionais de estratégias de segurança pública e as demandas locais, estabelecendo controle verbal sobre as ações de segurança serem desenvolvidas no município. 
Na Metacontingência de Divulgação de Informações Sobre Riscos, o compartilhamento das informações sobre os riscos do município de Campinas ocorre por meio das seguintes CCEs: medidas constantes das operações da Defesa Civil junto à sociedade, com a participação de representantes de secretarias e órgãos da administração indireta em seu grupo executivo (e.g., Operação Verão e Operação Estiagem); modernização do serviço de atendimento ao público do Departamento de Informação, Documentação e Cadastro (DIDC) da Secretaria de Planejamento e Desenvolvimento Urbano (SEPLAN), com a instalação de um totem interativo que possibilita consultas visuais no mapa da cidade e a localização de informações do interessado. Dessa forma, esses dados estão disponíveis tanto aos cidadãos como aos responsáveis por desenvolver planos de gestão do crescimento urbano do município e de operações voltadas para redução de risco de desastres.

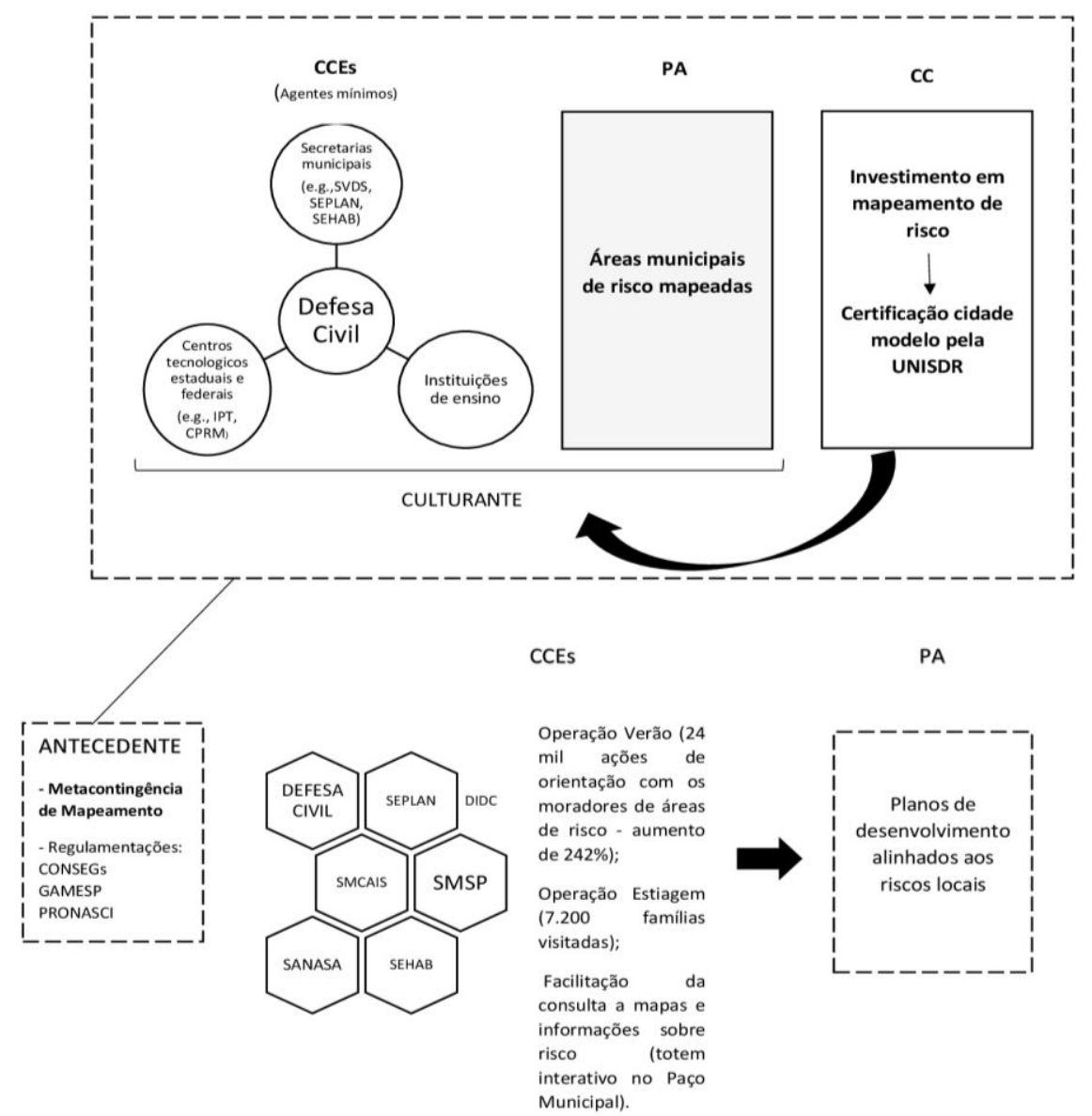

Figura 9. Passo 3 - Painel com Metacontingência Mapeamento de Risco e Ameaças Múltiplas e Metacontingência de Divulgação de Informação Sobre Riscos 


\section{Passo 4}

No Passo 4, sintetizado na Tabela B4, observa-se o desenvolvimento de projetos urbanos relacionados à gestão de risco de desastres. Nestes, contempla-se a instalação e manutenção de uma infraestrutura urbana para prevenir ou minimizar os riscos, considerando os fenômenos naturais típicos da localidade e as mudanças climáticas. Ações de prevenção estabelecidas por políticas municipais, planos estratégicos e padrões de resiliência, segurança e acessibilidade para construção podem minimizar ou evitar riscos e impedir a interrupção das estruturas. Desse modo, a infraestrutura crítica, que inclui a rede de transportes, de energia, de telecomunicações, o fornecimento de água e saneamento, e serviços essenciais (hospitais e escolas), deve ser submetida a avaliações dos riscos e vulnerabilidade, que serão base para estratégias de fortalecimento, com reforma ou substituição de infraestrutura. Além disso, fazse necessário investir e projetar infraestruturas sustentáveis com padrões fixos de segurança, capazes de manter funcionamento efetivo durante um desastre (UNISDR, 2012).

Algumas secretarias da Prefeitura Municipal de Campinas, empresas de economia mista e autarquias estão envolvidas nas CCEs da Metacontingência Proteção, Melhoria e Resiliência da Infraestrutura do Passo 4 (ver Figura 10). Esses agentes desenvolvem estudos específicos sobre impactos de grandes empreendimentos; fornecem licenças para instalação de equipamentos públicos, obras e edificações em solos públicos e privados, fiscalizando e avaliando risco e segurança dos mesmos (e.g., obras de pavimentação, iluminação pública e recuperação ambiental, evitando possíveis riscos aos usuários); e autorizam intervenções em áreas de alto risco e de preservação permanente. Além disso, para as ações de proteção de instalações públicas e infraestruturas críticas, o poder público local conta com a colaboração de uma central que o auxilia por meio das informações obtidas por suas ferramentas de monitoramento das instalações municipais e de ocorrências de emergência, como a Central 
Integrada de Monitoramento de Campinas (CIMcamp). O CIMcamp é um sistema integrado de monitoramento formado por representantes de seis diferentes áreas (ver Figura 10), cuja integração permite que o diagnóstico e as providências, diante de ocorrências nos diversos âmbitos envolvidos sejam feitos de forma mais rápida e efetiva. Por meio do sistema de câmeras e radares, do sistema de radiocomunicação e da central telefônica, sua atuação está voltada para a segurança no trânsito, criminalidade, uso e ocupação ordenada do solo, qualidade no transporte e prevenção de desastres naturais. Sua utilização produz monitoramento das instalações municipais, um PA da Metacontingência Proteção, Melhoria e Resiliência da Infraestrutura.

As ações envolvidas no Passo 4 são dependentes das estabelecidas no Passo 3, uma vez que medidas de avaliação de risco precedem tomadas de decisões sobre redes municipais de infraestrutura. A complexidade desse fenômeno é representada pelas metacontingências de avaliação de risco e divulgação dessas informações, do Passo 3, que criam ocasião para a ocorrência da Metacontingência de Proteção, Melhoria e Resiliência da Infraestrutura do Passo 4. Nesta, observa-se o PA: construção e manutenção de infraestrutura resiliente a desastres.

Entre os anos de 2005 e 2013, houve a redução de 64\% das áreas de risco de inundação e deslizamentos em Campinas ${ }^{18}$. Esse resultado também é um produto da Metacontingência Infraestrutura, a qual envolve medidas preventivas que podem evitar inundações, deslizamentos, desabamentos e suas consequências sociais, sanitárias e econômicas. Esse PA não seria produzido caso não houvesse articulação intersetorial das metacontingências dos Passos 3 e 4. Além disso, tem função de consequência cultural, selecionando os culturantes desta metacotingência.

\footnotetext{
${ }^{18}$ Reunião de Trabalho Construindo Cidades Resilientes a partir do novo Marco de Sendai para a Redução do Risco de Desastres 2015-2030 - Apresentação Sidnei Furtado (março/2015).
} 


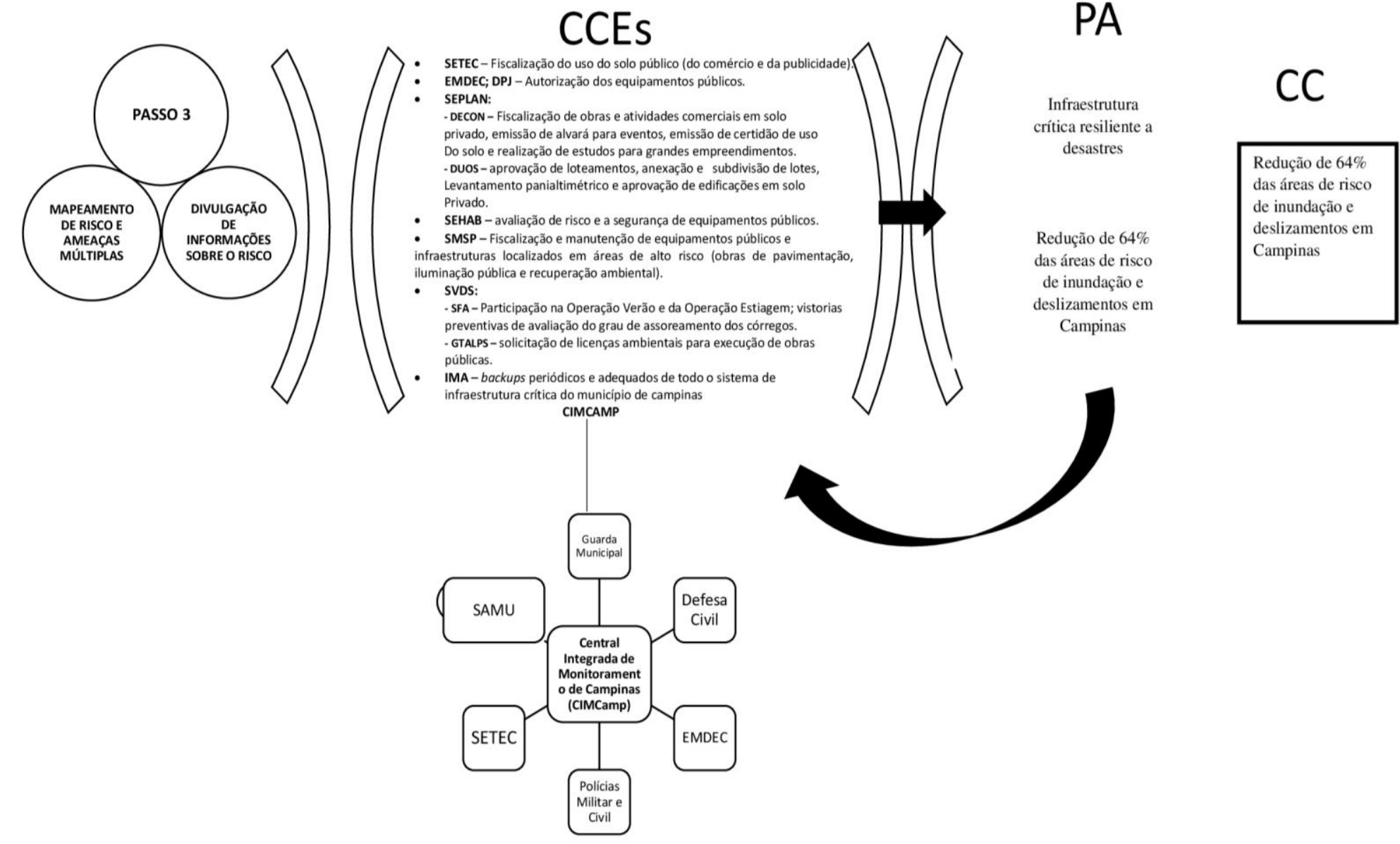

Figura 10. Passo 4 - Painel com Metacontingência Proteção, Melhoria e Resiliência da Infraestrutura do Passo 4 e Metacontingência CIMcamp.

SETEC: Serviços Técnicos Gerais

EMDEC: Empresa Municipal de Desenvolvimento de Campinas

DPJ: Departamento de Parques e Jardins

SMSP: Secretaria Municipal de Serviços Públicos

SDVS: Secretaria Municipal do Verde, Meio Ambiente e Desenvolvimento Sustentável

SFA: Setor de Fiscalização Ambiental

GTALPS: Grupo de Trabalho de Apoio ao Licenciamento de Projetos de Serviços Municipais

IMA: Informática de Municípios Associados

SAMU: Serviço de Atendimento Móvel de Urgência

\section{Passo 5}

No Passo 5, apresentado na Tabela B5, são estabelecidos direcionamentos para que escolas e centros de saúde, instituições que prestam serviços essenciais à população, continuem operacionais em situação de desastres ou retornem rapidamente ao seu funcionamento efetivo. Diante de uma emergência, ambos têm papel complementar de apoio nas fases de resposta e recuperação, a fim de: (1) funcionar como abrigo para os sobreviventes 
e promover o restabelecimento da normalidade; e (2) evitar repercussões sociais e psicológicas dos desastres. O poder público municipal deve garantir a segurança das instalações públicas de educação e saúde ao implantar planos de ação que estabeleçam avaliações periódicas de risco e vulnerabilidades das unidades; programas permanentes de manutenção; reforma de unidades mais críticas; e assegurar o cumprimento dos padrões de segurança na construção de novas estruturas. Deve também mobilizar topógrafos, engenheiros e a comunidade para o trabalho de redução de risco, e formalizar parcerias com instituições privadas, incentivando-as a colaborar com o resgate e com a prestação de serviços complementares, durante uma situação de desastre (UNISDR,2012).

Em Campinas, vistorias e avaliações de risco na rede municipal de ensino são feitas pela Secretaria Municipal de Educação (SME), por meio da Coordenadoria de Arquitetura Escolar (CAE) do Departamento de Apoio à Escola (DAE), responsável por supervisionar a construção, manutenção e reformas necessárias nas unidades educacionais. A CAE encarregase da identificação de áreas para implantação de novas unidades educacionais, da elaboração de projeto e memorial descritivo dessas novas escolas e da reforma das escolas existentes, principalmente no período de chuvas intensas. As escolas municipais contam, ainda, com o Programa Conta Escola, por meio do qual recebem recursos da prefeitura, a cada três meses, destinados a investimentos, reparos, melhorias na infraestrutura e compras de materiais. Esse programa promove a autonomia financeira das unidades, permitindo que a própria equipe gestora das escolas definam suas prioridades.

Ademais, no município são desenvolvidos ações, cursos e projetos com o objetivo de investir nas fases de preparação, resposta e recuperação do funcionamento escolar e do ensino diante de situação de desastres (e.g., simulado de situações de emergência, Projeto Defesa 
Civil Mirim, cursos de prevenção de acidentes e primeiros socorros e estudos para aplicação do Manual "Requisitos Mínimos para a Educação: Preparação, Resposta e Reconstrução").

O painel superior da Figura 11 mostra a Metacontingência Proteção de Serviços Essenciais: Educação que envolve ações da prefeitura, isto é, agentes da SME, DAE e CAE que interagem para produzir infraestrutura resiliente nas escolas municipais, e ainda, a Defesa Civil, a Guarda Municipal, o Corpo de Bombeiros, e a rede municipal escolar com seus alunos e profissionais, os quais colaboram em projetos que preparam a comunidade escolar para situação de desastres, minimizando os riscos ou potencializando a recuperação do seu funcionamento. Esses entrelaçamentos são responsáveis pela redução do número de escolas afetadas por temporais (PA). Enquanto, em 2003 um total de 25 escolas foram afetadas, desde 2008 nenhuma atividade escolar foi paralisada por ocorrências relacionadas a desastres. Decisões de técnicos da prefeitura sobre repasse de verbas diante de avanços como citado acima podem ser consequências culturais (CCs) com efeito selecionador desse arranjo de contingências entrelaçadas e produtos agregados. Em 2010, a administração municipal de Campinas aumentou a verba investida no Programa Conta Escola em R $\$ 1,2$ milhão ${ }^{19}$.

Quanto à proteção de instituições de saúde de Campinas, alguns agentes contribuem para que a rede hospitalar se mantenha operacional, caso o fornecimento de energia seja interrompido por um desastre (ver painel inferior da Figura 11). Ademais, a Companhia Paulista de Força e Luz (CPFL) confere prioridade no reestabelecimento de energia elétrica, diante de uma eventual interrupção, e a legislação municipal (Lei n ${ }^{\circ} 9.858$ de 28 de setembro de $1998^{20}$ ) prevê a obrigatoriedade de instalação de geradores em equipamentos dessa rede. Os grupos de geradores instalados no hospital Dr. Mário Gatti, instituição pública municipal

\footnotetext{
${ }^{19}$ Disponível em http://www.campinas.sp.gov.br/noticias-integra.php?id=820 recuperado em 10 de outubro de 2016.

${ }^{20}$ Disponível em: http://cm-campinas.jusbrasil.com.br/legislacao/329319/lei-9858-98 recuperado em 12 de outubro de 2016.
} 
com grande cobertura de atendimento, passam por vistorias diárias por técnico eletricista e vistorias mensais pela empresa fabricante. A Lei $n^{\circ} 9.858$ apresenta instrução para que a CPFL, o setor de manutenção do hospital, a empresa de geradores e técnicos eletricista contratados pelo hospital produzam a manutenção da energia elétrica e a continuidade dos serviços médicos durante uma emergência.

A simulação de situações críticas que envolve grande número de vítimas consiste em uma estratégia importante frequentemente desenvolvida pela Defesa Civil de Campinas, a qual envolve outras equipes, tais como o Serviço de Atendimento Móvel de Urgência (SAMU) da cidade e de outros municípios, equipes das áreas de trânsito (Polícia Rodoviária) e de segurança (Polícia Civil, Política Militar, CIMCamp), Corpo de Bombeiros, e voluntários para figuração. As relações funcionais dos agentes envolvidos no simulado colaboram para equipes mais preparadas para uma situação real de emergência e a identificação de falhas de segurança dos serviços de saúde. A Metacontingência Proteção de Serviços Essenciais: Saúde envolve, portanto, duas linhagens culturo-comportamentais (rede hospitalar Mário Gatti e simulações de situações críticas de emergência) que garantem o funcionamento efetivo da estrutura hospitalar e das equipes de resgate e cuidado, produzindo o PA: unidades de saúde operacionais diante de situação de desastres. 


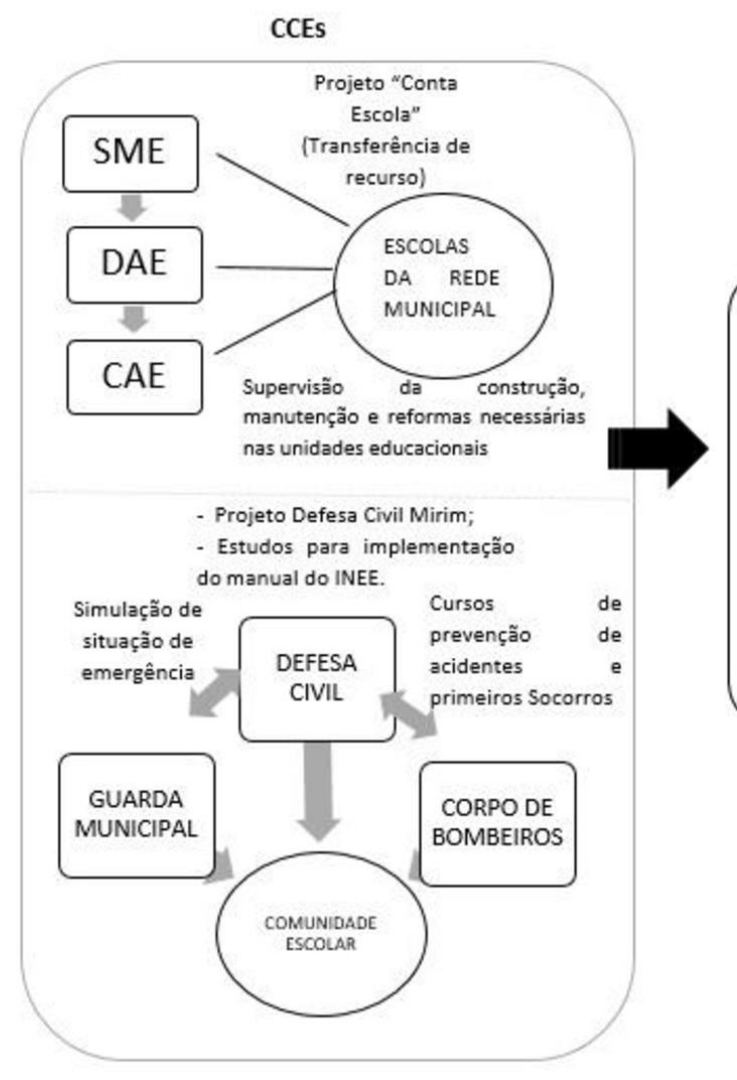

PAS

CCs

escolas afetadas

por temporais

diminui;

Escolas se

mantêm

operacionais após

desastre

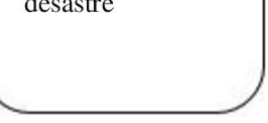

Prefeitura

aumenta o

repasse para 1,2

milhão.

Programa Conta

Escola
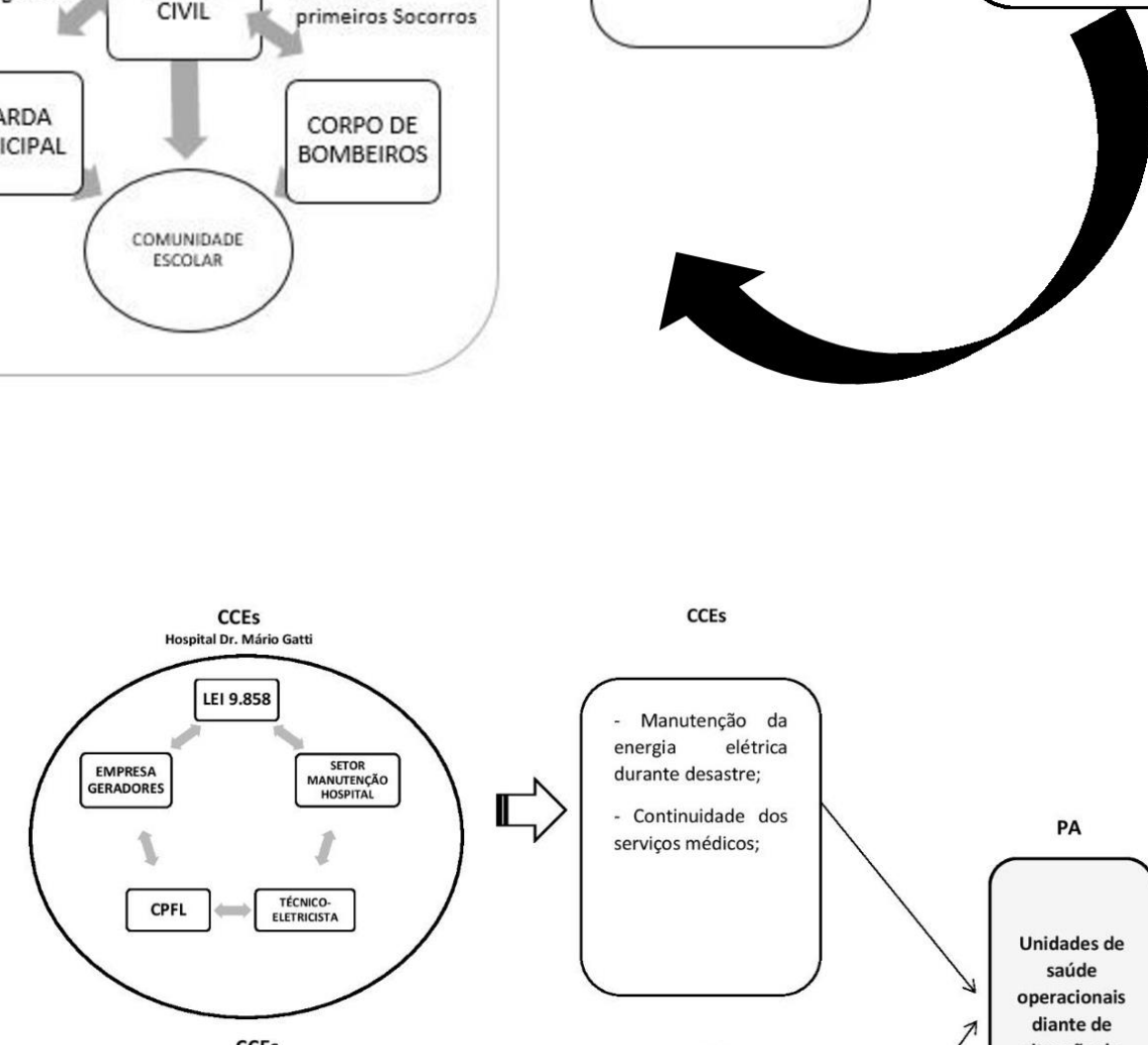

CCES
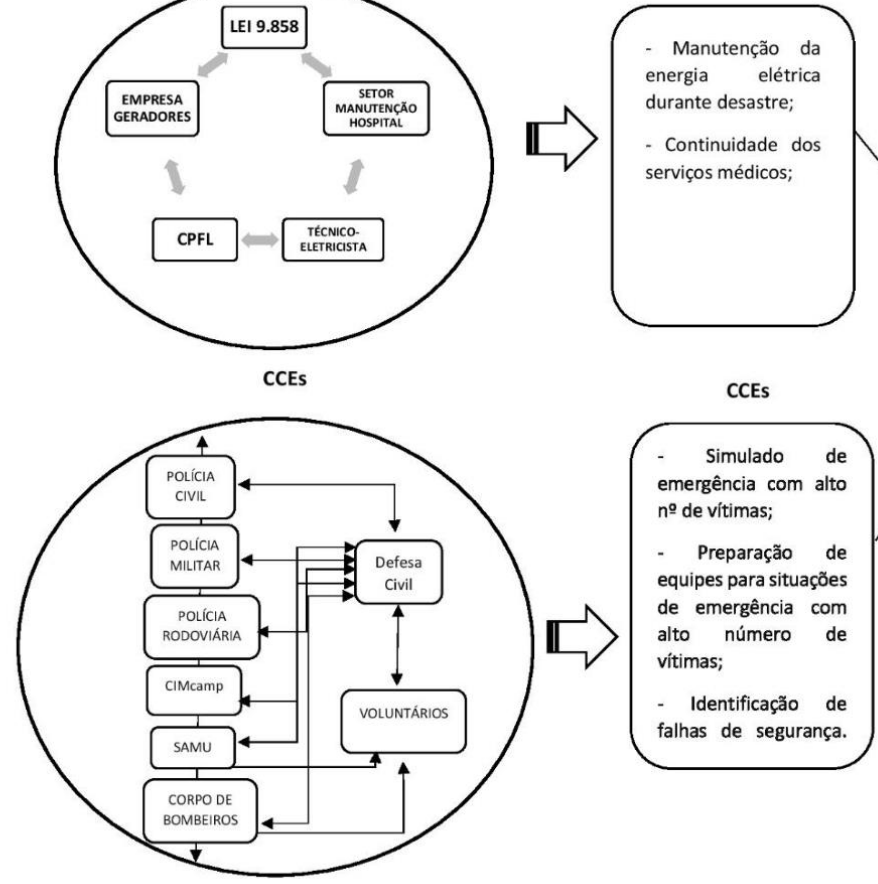

Figura 11. Passo 5 - Painel com Metacontingência Proteção de Serviços Essenciais: Educação e Metacontingência Proteção de Serviços Essenciais: Saúde

SME: Secretaria Municipal de Educação

CAE: Coordenadoria de Arquitetura Escolar

SAMU: Serviço de Atendimento Móvel de Urgência
DAE: Departamento de Apoio à Escola

CPFL: Companhia Paulista de Força e Luz

CIMcamp: Central Integrada de Monitoramento de Campinas 


\section{Passo 6}

O Passo 6 mostrado na Tabela B6 determina a aplicação de códigos de construção e regulamentações para o planejamento e monitoramento do uso e ocupação do solo urbano e rural. Minimização de risco de desastres e os impactos das mudanças climáticas devem ser incorporadas nessas legislações municipais. O plano de uso e ocupação do solo do município deve ser baseado em avaliações de risco de desastres, sendo necessário que se mantenha um banco de dados espacial de construções urbanas, para fins de monitoramento de áreas suscetíveis a ameaças naturais. Essas áreas devem ter o desenvolvimento controlado, por meio de planos que apresentem restrições quanto ao tipo, uso, ocupação e densidade das construções. No caso de ocupações irregulares, que não ocorreram com o acompanhamento de engenheiros, o governo deve realocar esses assentamentos para locais mais seguros. Caso não seja possível, deve garantir o fortalecimento dessas construções, buscando mecanismos participativos de redução de risco, compartilhando experiências e demonstrações técnicas em campanhas públicas e dispondo projetos que utilizem materiais disponíveis localmente e técnicas de baixo custo.

O governo municipal deve envolver agentes de segurança, construtores, comerciantes e cidadãos em geral na promoção do cumprimento dos regulamentos de uso de solo, na identificação e comunicação de práticas de construção inseguras e no desenvolvimento de planos e tecnologias inovadoras em construção. Assim, o governo deve promover ações que resultem em sensibilização pública; desenvolvimento de capacidade técnica e competência local; e motivação, de forma a aumentar o comprometimento (UNISDR, 2012).

Em Campinas, as regras de organização da ocupação do espaço urbano são estabelecidas principalmente pela Lei de Uso e Ocupação do Solo (LUOS), Lei $\mathrm{N}^{\circ} 6.031$ de 29 de dezembro de 1988 e Lei Complementar $N^{\circ} 09$ de 23 de dezembro de 2003, que dispõe 
sobre o código de obras e edificações do município. Essas legislações discorrem sobre os parâmetros a serem obedecidos na distribuição e ocupação territorial, regulamentando procedimentos necessários para o licenciamento, fiscalização, projeto, execução e preservação de obras e edificações em Campinas. Além disso, definem as seguintes competências ao governo municipal: (1) emitir licenças para execução de projetos; (2) fiscalizar a execução e manutenção das condições de segurança das obras e edificações; e (3) embargar obras que não atendam às exigências dispostas na legislação sobre edificações.

Na Metacontingência Construção de Regulamentos e Planos de Uso e Ocupação do Solo, da Figura 12, as CCEs envolvem cinco secretarias (SEPLAN, SEMAJ, SVDS, SEHAB e SETEC), uma empresa de fotografia e o Grupo de Controle e Contenção de Ocupações, Parcelamentos Clandestinos e Danos Ambientais - criado pelo Decreto $\mathrm{n}^{\mathbf{0}} 17.849$ de 23 de janeiro de 2013 e constituído pelas secretarias SEHAB, SEPLAN, SMCASP, SVDS e SMCGP. Essa metacontingência tem como eventos antecedentes a Lei $N^{\circ} 6.031$ de 29 de dezembro de 1988 (LUOS) e a Lei Complementar $N^{\circ} .09$ de 23 de dezembro de 2003, que sinalizam contingências a serem programadas para uso do território municipal.

Membros dessas entidades em CCEs desenvolvem serviços, tais como a emissão alvarás e licenças ambientais para uso do solo; certificação de conclusão de obras; autorização de instalação de equipamentos públicos e interdição e demolição de obras impróprias; projetos de lei que regulamentem ocupações clandestinas; estratégias de desburocratização do serviço que agilizam o acesso às informações sobre ocupação territorial do município (criação de mapas cartográfico da cidade, desenvolvimento de aplicativo de consulta de zoneamento e digitalização de patrimônio público). Assim, as CCEs da Figura 12 acarretam nos seguintes resultados sociais (PAs): (1) cadastro físico-territorial de Campinas atualizado; (2) 5.000 
obras de unidades residenciais do "Programa Minha Casa, Minha Vida" retomadas; e (3) diminuição de $30 \%$ solicitações presenciais de informação sobre zoneamento.

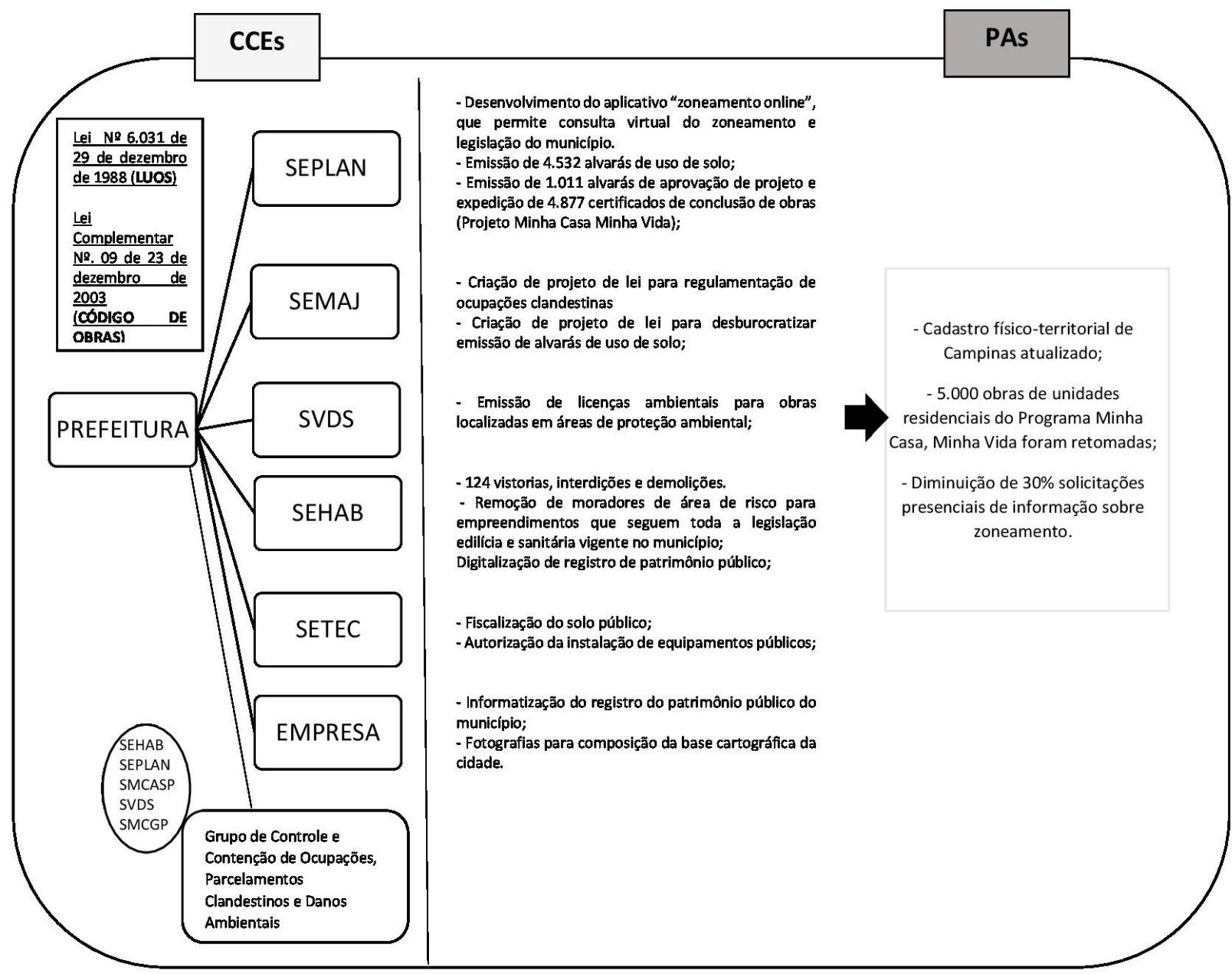

Figura 12. Passo 6 - Metacontingência de Construção de Regulamentos e Planos de Uso e Ocupação do Solo

LUOS: Lei De Uso e Ocupação do Solo

SEHAB: Secretaria Municipal de Habitação

SEPLAN: Secretaria Municipal de Planejamento e Desenvolvimento Urbano

SVDS: Secretaria Municipal do Verde, Meio Ambiente e Desenvolvimento Sustentável

SMCGP: Secretaria Municipal de Chefia de Gabinete do Prefeito

SMCASP: Secretaria de Cooperação de Assuntos de Segurança Pública
SEMAJ: Secretaria Municipal de Assuntos Jurídicos

SETEC: Serviços Técnicos Gerais

\section{Passo 7}

O Passo 7, descrito na Tabela B7, destaca a importância do estabelecimento da responsabilidade coletiva dos cidadãos na criação de uma cidade resiliente. A mobilização popular deve ser incentivada por meio de estratégias de sensibilização, educação e treinamento em redução de risco de desastres, proporcionando auxílio à população para que 
responda de forma eficiente aos alertas locais de desastres. O governo local deve: (1) conduzir campanhas de educação pública sobre redução de risco de desastres e efeitos de mudanças climáticas; (2) integrar o tópico aos programas formais de educação de todos os níveis, estabelecendo parceria com autoridades da área educacional, professores e estudantes; (3) desenvolver programas permanentes de treinamento em redução de risco de desastres para diversos agentes sociais importantes, tais como legisladores, equipes médicas de emergência e de resgate, lideranças comunitárias, educadores, iniciativa privada, e especialistas das áreas de engenharia, zoneamento, meio ambiente saúde e comunicação; e (4) organizar estratégias criativas de envolvimento popular na segurança a desastres, tais como organizar eventos de preservação da memória dos principais desastres e planejar participação nas comemorações do Dia Internacional de Redução de Desastres e outras datas relacionadas (e.g., Dia Mundial da Meteorologia, Dia Mundial da Saúde e Dia Mundial do Habitat) (UNISDR, 2012).

A gestão municipal de Campinas desenvolve e encoraja medidas de educação da sociedade sobre redução de risco de desastres, envolvendo o Departamento de Defesa Civil (DDC) e entidades parceiras, compondo, assim, a Metacontingência Treinamento e Sensibilização Pública (ver parte superior do painel da Figura 13). Durante a Operação Verão 2012/2013, 34.000 famílias foram orientadas sobre enfrentamento de desastres. Além disso, junto à Secretaria Municipal dos Direitos da Pessoa com Deficiência e Mobilidade Reduzida (SMPED), o DDC organizou o seminário Viver com Deficiência e Desastres, que contou também com a participação da Defesa Civil de outros municípios, o SAMU e a SANASA.

Em parceria com outras instituições municipais EMDEC, Corpo de Bombeiros, Guarda Municipal e SAMU), o Departamento de Defesa Civil desenvolveu ações de orientação e treinamento da comunidade, como o simulado de abandono de área de risco na Vila Brandina. Vale ressaltar o grande número de agentes atuando nesta metacontingência de 
forma integrada - mais de 13 centros de Defesa Civil e uma secretaria municipal específica produzindo um resultado social "comunidade local bem capacitada em redução de risco de desastres".

A Metacontingência Treinamento e Sensibilização Pública (ver painel superior da Figura 13) envolve também linhagens culturo-comportamentais voltadas para diferentes treinamentos de autoridades locais e líderes comunitários desenvolvidos pelo Centro de Capacitação de Proteção e Defesa Civil (CCPDC), órgão do Departamento da Defesa Civil de Campinas. O Centro foi criado com o objetivo de garantir a qualificação dos profissionais envolvidos nas ações de proteção e defesa civil, por meio da organização de cursos de formação (PAs), tais como: (1) o Curso de Formação de Agente de Proteção e Defesa Civil (CFA); (2) Curso de Formação de Gestores de Proteção e Defesa Civil (CFG); (3) Curso de Capacitação de Voluntário de Defesa Civil (CVDC); (4) Curso de Aperfeiçoamento de Voluntários em Defesa Civil (CADC); (5) Curso de Formação e Reciclagem de Brigadistas de Combate às Enchentes; (6) medidas de treinamento com membros dos Núcleos Comunitários de Defesa Civil (NUDECs); (7) medidas de capacitação de integrantes do Sistema Municipal de Proteção e Defesa Civil (SIMPDEC) na participação da Campanha Construindo Cidades Resilientes; assim como a (8) promoção de simpósios, congressos e palestras, incentivando pesquisas e estudos sobre redução de risco de desastres. Essas oito linhagens culturocomportamentais contam com um total de três decretos municipais de Campinas, que estabelecem uma significativa e variada formação de um grande número de agentes. Os produtos agregados, neste caso, envolvem um significativo número de diferentes cursos e de agentes expostos a uma variedade de formações específicas programadas pela Defesa Civil.

É possível depreender dessa metacontingência agentes fundamentais cujo entrelaçamento de suas ações resulta na capacitação da comunidade local: (1) um órgão com 
autonomia e conhecimento técnico deve ser o agente planejador da instrução, no caso de Campinas, o Departamento de Defesa Civil; (2) equipes técnicas da administração direta e indireta do município ou de um centro criado com a finalidade de capacitação; e (3) participantes locais a serem instruídos sobre redução de risco de desastres.

CCEs
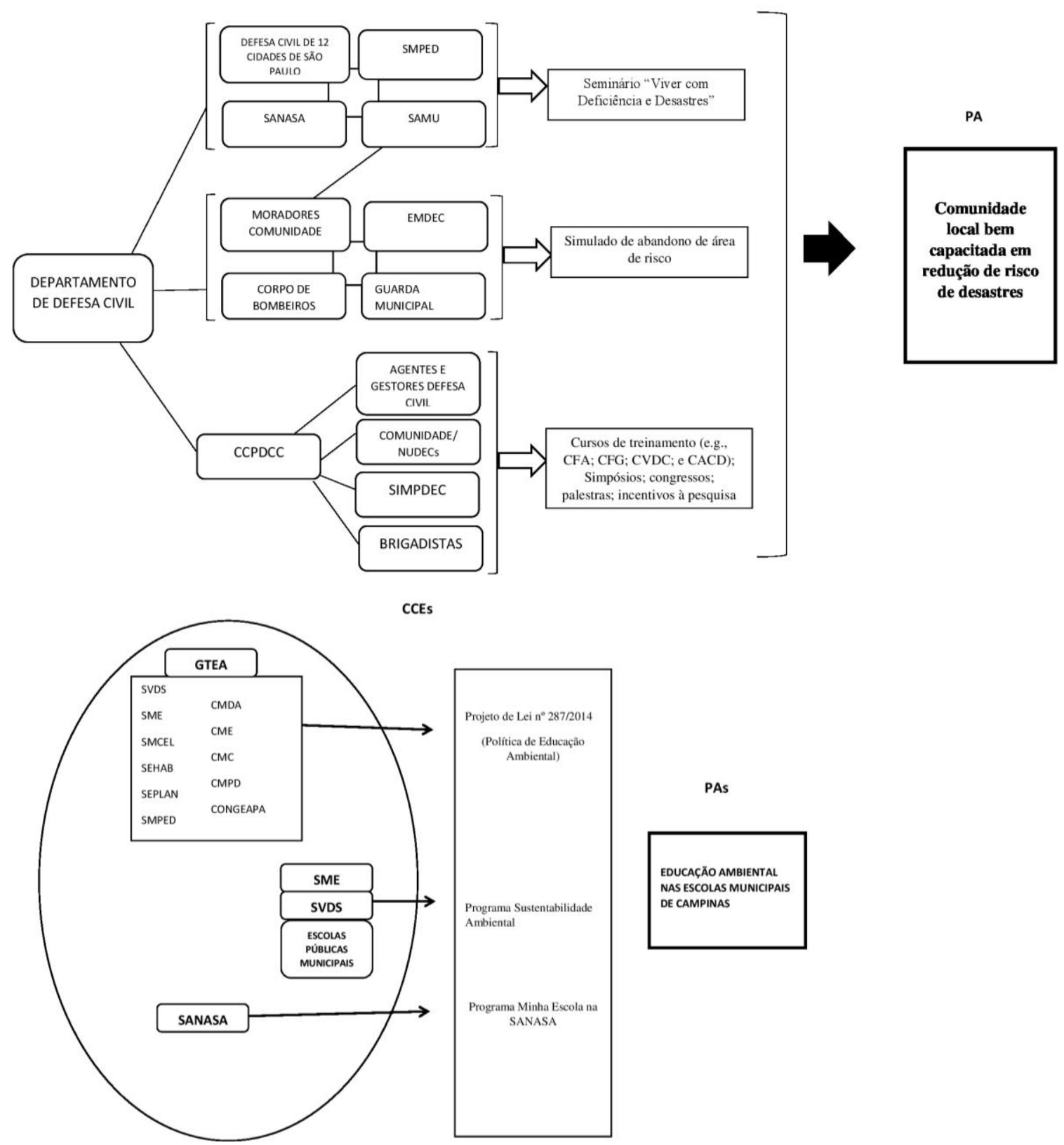

Figura 13. Passo 7 - Painel com Metacontingência Treinamento e Sensibilização Pública e Metacontingência Educação Ambiental. 
Ainda no Passo 7 a Metacontingência Educação Ambiental (ver inferior do painel da Figura 13) contém estratégias pontuais ou continuadas de educação ambiental que contribuem para a sensibilização sobre as implicações da degradação do meio ambiente e para a colaboração da população nessas ações. Em Campinas, a proposta de plano e política pública sobre educação ambiental foi desenvolvida pelo Grupo Técnico Municipal da Política e do Plano Municipal de Educação Ambiental (GTEA), instituído pelo Decreto nº 17.885, de 27 de fevereiro de 2013. O decreto, portanto, é evento antecedente para o entrelaçamento dos participantes do grupo, cujo entrelaçamento constituem as CCEs desta metacontingência. O grupo conta com representantes de secretarias e conselhos municipais, citados a seguir: SVDS, SME, SMCE, SEHAB, SMPED, SEPLAN, Conselho Municipal de Meio Ambiente (COMDEMA); Conselho Gestor da Área de Proteção Ambiental de Campinas (CONGEAPA); Conselho Municipal de Defesa Animal (CMDA); Conselho Municipal de Educação (CME); Conselho Municipal de Cultura (CMC); e Conselho Municipal da Pessoa Com Deficiência (CMPD).

O contato recorrente entre os integrantes do grupo promoveu a produção do Projeto de Lei $n^{\circ}$ 287/2014, que dispunha sobre a Política de Educação Ambiental no município de Campinas e prescreve contingências a serem desenvolvidas nesta área em Campinas. Ações voltadas para a educação ambiental foram desenvolvidas nas escolas do município, como o Programa Sustentabilidade Ambiental, que estabelece parceria entre essas instituições a SME e a SVDS, na promoção de atividades diversas (palestras, oficinas e ações) de conscientização de problemas ambientais da cidade. A SANASA também desenvolve o Programa Minha Escola na SANASA, cuja metodologia inclui visitas em Estações de Tratamento de Água (ETAs) e palestras educativas, que ressaltam a importância do saneamento para evitar poluição de água e o risco de enchentes. $\mathrm{O}$ entrelaçamento dos comportamentos desses agentes implica no 
principal impacto social desta metacontingência, a educação ambiental sendo abordada nas escolas municipais de Campinas.

\section{Passo 8}

O Passo 8, exposto na Tabela B8, ressalta a adoção de medidas de proteção e fortalecimento dos ecossistemas que, ao funcionar como barreiras naturais diante de ameaças, têm potencial de aumentar a resiliência da localidade a desastres. O governo deve promover a transição dos planos de desenvolvimento da cidade para a economia verde, apresentando iniciativas de sensibilização da sociedade quanto aos impactos da degradação dos ecossistemas e das mudanças climáticas no risco de desastres. Deve também integrar a gestão sustentável de ecossistemas às estratégias de redução de risco de desastre, considerando o reflorestamento, a restauração de bacias hidrográficas, o controle de processos de sedimentação e a proteção costeira. As medidas prescritas no Passo 8 preveem o estabelecimento de parcerias entre o governo municipal, gestores ambientais e representantes da iniciativa privada, a fim de ampliar a capacidade técnica municipal (e.g., avaliações de risco, avaliações ambientais e monitoramento científico) para uma gestão de risco de desastres multissetorial, e de obter recursos financeiros, garantindo que os investimentos ocorram de acordo com normas ambientais e de redução de risco (UNISDR, 2012).

A Metacontingência Proteção Ambiental e Fortalecimento dos Ecossistemas (Ver Figura 14) envolve CCEs com representantes de órgãos da prefeitura de Campinas com entidades estaduais de São Paulo (e.g., Secretaria de Estado do Meio Ambiente (SEMA), Rede Nossa São Paulo, Instituto Ethos e Rede Social Brasileira por Cidades Justas e Sustentáveis). Essas entidades estão à frente de agências e programas que oferecem diretrizes e capacitações técnicas para auxiliar os representantes do município a desenvolverem políticas 
e outras iniciativas voltadas para o desenvolvimento econômico e ambiental sustentável. A interação gera a execução de alguns programas em Campinas (e.g., Fundação Agência das Bacias Hidrográficas dos Rios Piracicaba, Capivari e Jundiaí; Programa Cidades Sustentáveis e Programa Município Verde Azul) e a prefeitura designa responsáveis por executá-los na localidade. Ao considerar as CCEs do Programa Cidades Sustentáveis, o Decreto nº 17.849 de 23 de janeiro de 2013 instituiu o Grupo Gestor da Plataforma Cidades Sustentáveis, formado pelos seguintes representantes: vice-prefeito, representantes da SVDS, SEPLAN e SMCAIS e SANASA. Ademais, a prefeitura reativou o Fundo de Recuperação, Manutenção e Preservação do Meio Ambiente (PROAMB), que dedica 7,8 milhões de reais para ações na área de meio ambiente e sustentabilidade.

A SVDS é um grupo de agentes de destaque nas CCEs da Metacontingência Proteção Ambiental e Fortalecimento dos Ecossistemas, pois o órgão é responsável por elaborar os seguintes planos de gestão de recursos naturais: Plano Municipal de Recursos Hídricos; Plano Municipal de Áreas Verdes; Plano Municipal de Educação Ambiental; Plano Municipal de Proteção Animal; Plano Municipal de Recuperação e Conservação da Mata Atlântica; Plano Municipal de Saneamento Básico; e Plano de Gestão Ambiental do Banco de Áreas Verdes. Esses planos são instruções dos entrelaçamentos necessários para que ocorra a gestão responsável dos bens naturais. Ademais, a SVDS promove ações de proteção florestal, com a criação de unidades de conservação, fornecimento de licenciamento ambiental de atividades impactantes e elaboração de Termos de Compromisso Ambiental; e proteção de zonas úmidas e dos recursos hídricos municipais. Utiliza a ferramenta e licenciamento ambiental online, que permite solicitações virtuais de licenciamento para empreendimentos de baixo impacto ambiental, assim como o pagamento e acompanhamento das solicitações. 
Outras secretarias municipais são agentes da Metacontingência Proteção Ambiental e Fortalecimento dos Ecossistemas, como a SANASA, que participa da gestão dos recursos hídricos, a SMSP, com ações voltadas para a arborização urbana e a SDEST, com iniciativas de orientação às empresas sobre a importância de seguir os parâmetros estabelecidos pelo Plano de Gestão Ambiental do Banco de Áreas Verdes. O conceito de metacontingência destaca a recorrência de práticas culturais e a dependência funcional entre as contingências que descrevem as ações de cada agente. Neste sentido, facilita a compreensão de fenômenos sociais complexos e da continuidade de determinadas práticas.

Os entrelaçamentos dessa metacontingência envolvem, ainda, representantes da população e do setor privado. Cidadãos podem colaborar com a proteção dos ecossistemas da cidade, denunciando casos de degradação ambiental aos órgãos competentes por meio do cadastro "156", e as empresas comprometem-se a cumprir os Termos de Compromisso Ambiental para a execução de seus empreendimentos. Além disso, tanto a comunidade quanto entidades privadas possuem representatividade no Conselho Municipal de Meio Ambiente (COMDEMA) e no Conselho Gestor da Área de Proteção Ambiental de Campinas (CONGEAPA), que estão envolvidos com a elaboração de políticas ambientais municipais (PA). Em 2014, após a criação da SVDS, tornou-se necessário realizar a revisão da Política de Meio Ambiente de Campinas, contemplando a nova estrutura e adequando os objetivos e instrumentos (PA).

A prefeitura vinculou o CONGEAPA à SVDS na regulamentação do Censo Verde, um cadastramento, desenvolvido pela Informática dos Municípios Associados (IMA), que possibilita que empresas, cidadãos e ONGs que de áreas afins de sustentabilidade consultarem e preencherem dados de suas ações, o que leva a uma maior visibilidade às iniciativas do município, contribuindo para o desenvolvimento de uma economia verde. O efeito ambiental 
gerado pelos resultados da ação coordenada desses agentes é a gestão sustentável de recursos naturais $(\mathrm{PA})$.

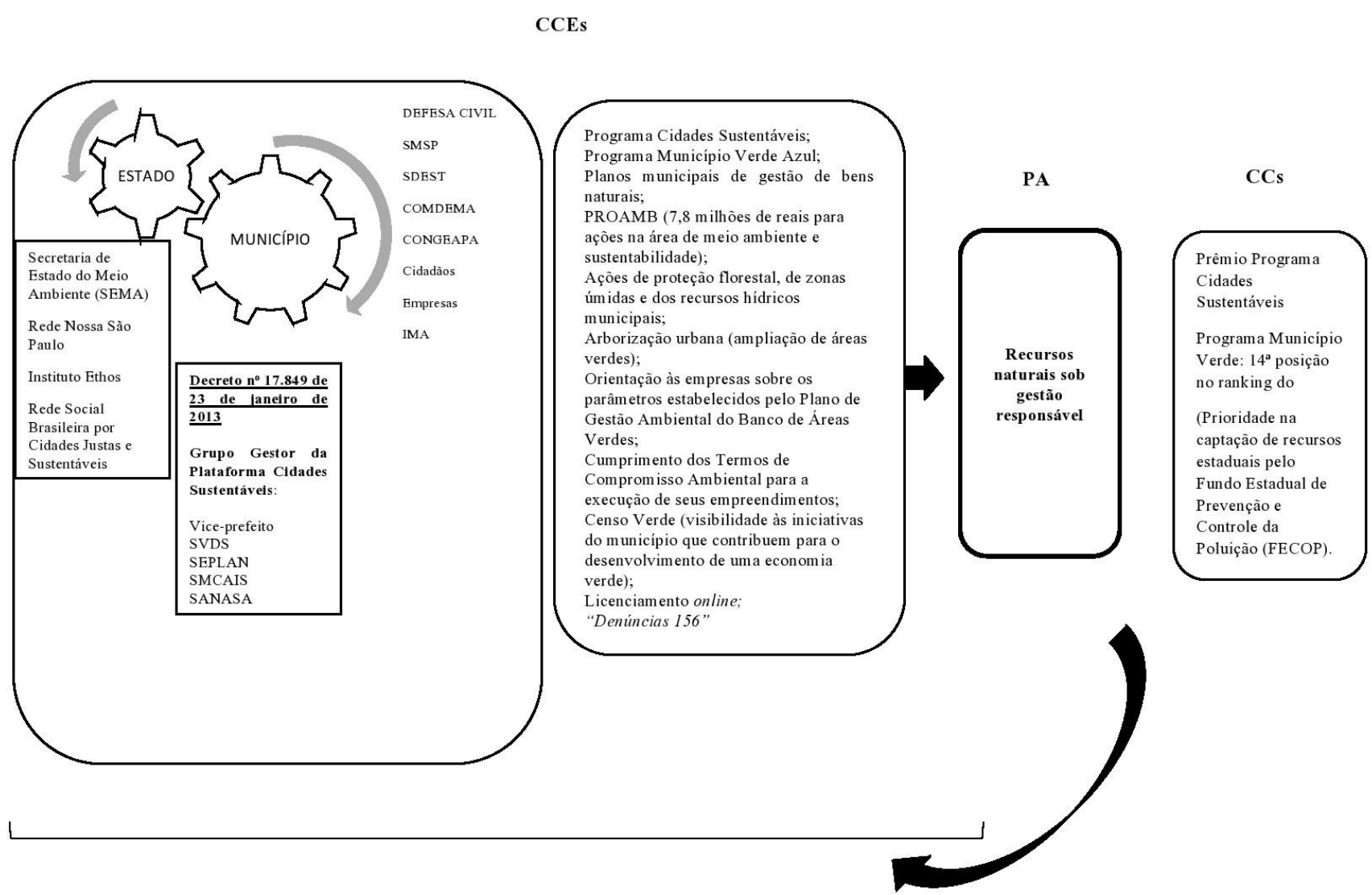

Figura 14. Passo 8 - Metacontingência Proteção Ambiental e Fortalecimento de Ecossistemas.

SVDS: Secretaria Municipal do Verde, Meio Ambiente e Desenvolvimento Sustentável SMCAIS: Secretaria Municipal de Cidadania, Assistência e Inclusão Social SMSP: Secretaria Municipal de Serviços Públicos COMDEMA: Conselho Municipal de Meio Ambiente

IMA: Informática dos Municípios Associados

PROAMB: Fundo de Recuperação, Manutenção e Preservação do Meio Ambiente
SEPLAN: Secretaria Municipal de Planejamento e Desenvolvimento Urbano SANASA: Sociedade de Abastecimento de Água e Saneamento SDEST: Secretaria Municipal de Desenvolvimento Econômico e Turismo CONGEAPA: Conselho Gestor da Área de Proteção Ambiental de Campinas PCJ: Piracicaba, Capivari e Jundiaí

Em 2014, Campinas recebeu um prêmio pela participação no Programa Cidades Sustentáveis e por ter alcançado a $14^{\mathrm{a}}$ posição no ranking do Programa Município Verde Azul, no qual havia alcançado a $220^{\mathrm{a}}$ posição no ano anterior. Isso garantiu à gestão municipal a prioridade na captação de recursos junto ao Governo do Estado, por meio do Fundo Estadual de Prevenção e Controle da Poluição (FECOP), consistindo no ambiente social selecionador (consequências culturais) das práticas de proteção de ecossistemas desenvolvidas 
Campinas. Além disso, a prefeitura programa incentivos econômicos para empresas inscreverem suas áreas nos Bancos de Área Verde (BAV), como a isenção sobre Imposto sobre a Propriedade Predial e Territorial Urbana (IPTU).

\section{Passo 9}

O Passo 9, descrito na Tabela B9, apresenta determinações para fortalecer a preparação do município e, assim, potencializar seu poder de resposta diante da ocorrência de desastres. Planos de preparação e resposta a situações de emergência devem estar integrados às políticas públicas do município, por meio de mecanismos legais que instituam o comprometimento de ampla rede institucional de órgãos públicos. Para tanto, precisam contar com sistemas aprimorados de comunicação, alerta e alarme locais para proporcionar resposta imediata e efetiva aos sobreviventes, reduzindo a dependência de recursos externos. Ademais, as estratégias de preparação para desastres devem ser embasadas nos resultados de avaliação de risco e devem ser medidas por meio de exercícios simulados de campo e treinamentos especializados, que envolvam bombeiros, policiais e organizações de gestão de emergências e órgãos de saúde e segurança. O planejamento da reconstrução deve ser anterior à ocorrência de desastre, com tempo hábil para pautar decisões, definir papéis e responsabilidades e outras providências sobre as metas e estratégias (UNISDR, 2012).

Os entrelaçamentos identificados nas ações de resposta a desastres em Campinas deram origem à Metacontingência Preparação e Sistemas de Alerta. Essa Metacontingência (Figura 15) envolve a articulação de ações de representantes de entidades nacionais, estaduais e municipais, em CCEs, no apoio à comunidade afetada por desastres, no que se refere à coordenação de sistemas de monitoramento, comunicação e alerta.

Para compor um banco de dados confiável capaz de orientar ações preventivas e de atendimento a ocorrência de emergências, o Departamento de Defesa Civil de Campinas 
utiliza os seguintes sistemas informatizados: (1) Central Integrada de Monitoramento de Campinas (CIMCamp); (2) Sistema Integrado de Alerta da Defesa Civil (SIADEC); (3) TerraMA2 - Monitoramento, Análise e Alerta; e (4) Gerenciamento de Ocorrências da Defesa Civil (GODC). A utilização desses sistemas permite o monitoramento do território municipal, a comunicação mais efetiva entre agentes responsáveis em situações de emergência e maior agilidade de resposta a desastres, produzindo um PA relevante, que é o aumento da probabilidade de predição e de resposta a ocorrências. A seguir, os quatro sistemas serão apresentados, com seus agentes e produtos agregados, atuando de forma entrelaçada.

A Central Integrada de Monitoramento de Campinas (CIMCamp), já descrita no Passo 4, é vinculado à Secretaria Municipal de Cooperação no Assuntos de Segurança Pública (SMCASP), a qual integra as CCEs da Metacontingência Preparação e Sistemas de Alerta deste Passo 9, junto a representantes da Empresa Municipal de Desenvolvimento de Campinas (EMDEC), Guarda Municipal, Polícia Militar, Corpo de Bombeiros, Serviço de Atendimento Móvel de Urgência (SAMU) e Defesa Civil. A ação conjunta desses agentes resulta no monitoramento de todo o território municipal, com 372 câmeras distribuídas em 143 pontos da cidade.

O Sistema de Alerta da Defesa Civil (SIADEC) foi desenvolvido pela Informática dos Municípios Associados (IMA) e conta com a colaboração de algumas entidades municipais (e.g., Centro de Pesquisas Meteorológicas e Climáticas Aplicadas à Agricultura - CEPAGRI), estaduais (e.g., Sistema de Alerta a Inundações do Estado de São Paulo - SAISP, Centro de Gerenciamento de Emergências de São Paulo - CGE, instituto de pesquisas meteorológicas IPMET e Centro integrado de informações agrometeorológicas - CIIAGRO) e nacionais (e.g., Centro de Previsão de Tempo e Estudos Climáticos - CPTEC e Fundação de Apoio à Pesquisa Agrícola - FUNDAG). Essas CCEs resultam na coleta e armazenamento diário de 
dados meteorológicos de Campinas de diversas fontes (e.g., estações meteorológicas automáticas, pluviômetros mecânicos e semiautomáticos, estações de monitoramento do ar, rede telemétrica, sensor comunitário de enchente, sistema de detecção de raios e câmeras de monitoramento).

Os dados coletados pelo SIADEC são transmitidos em tempo real para o TerraMA2, ferramenta desenvolvida pelo Instituto Nacional de Pesquisas Espaciais (INPE) e utilizada pelo município de Campinas. A interação entre esses dois sistemas permite a integração de dados climáticos, atmosféricos, hidrológicos, geotécnicos e demográficos, gerando o monitoramento de ocorrências de vários tipos (e.g., como abalos sísmicos, descargas elétricas, epidemias e homicídios). Portanto, essas CCEs geram ações preventivas de proteção, estabelecendo antecipadamente os limites para disparo de alertas.

O quarto sistema informatizado utilizado em Campinas, o Gerenciamento de Ocorrências da Defesa Civil (GODC), é um sistema web de atendimento de ocorrências de desastres criado pela Informática de Municípios Associados (IMA). O GODC permite o registro de ações da Defesa Civil, com o acompanhamento e elaboração de estatísticas das ocorrências de desastres em áreas da cidade, resultando em maior agilidade e eficiência no acionamento de equipes de socorro e na comunicação em tempo real entre os órgãos envolvidos.

A Região Metropolitana de Campinas (RMC) é a primeira metrópole da América Latina com estações meteorológicas em todas as suas cidades, resultando em $100 \%$ de controle para a prevenção de desastres de origem natural, o que configura um importante produto social (PA) do funcionamento desses quatro sistemas municipais citados anteriormente. Esse PA tornou-se possível com o entrelaçamento da Defesa Civil, com a 
colaboração do governo estadual, fornecendo recursos para a construção das estações, e do

Instituto Agronômico de Campinas (IAC), oferecendo serviços de manutenção (CCEs).

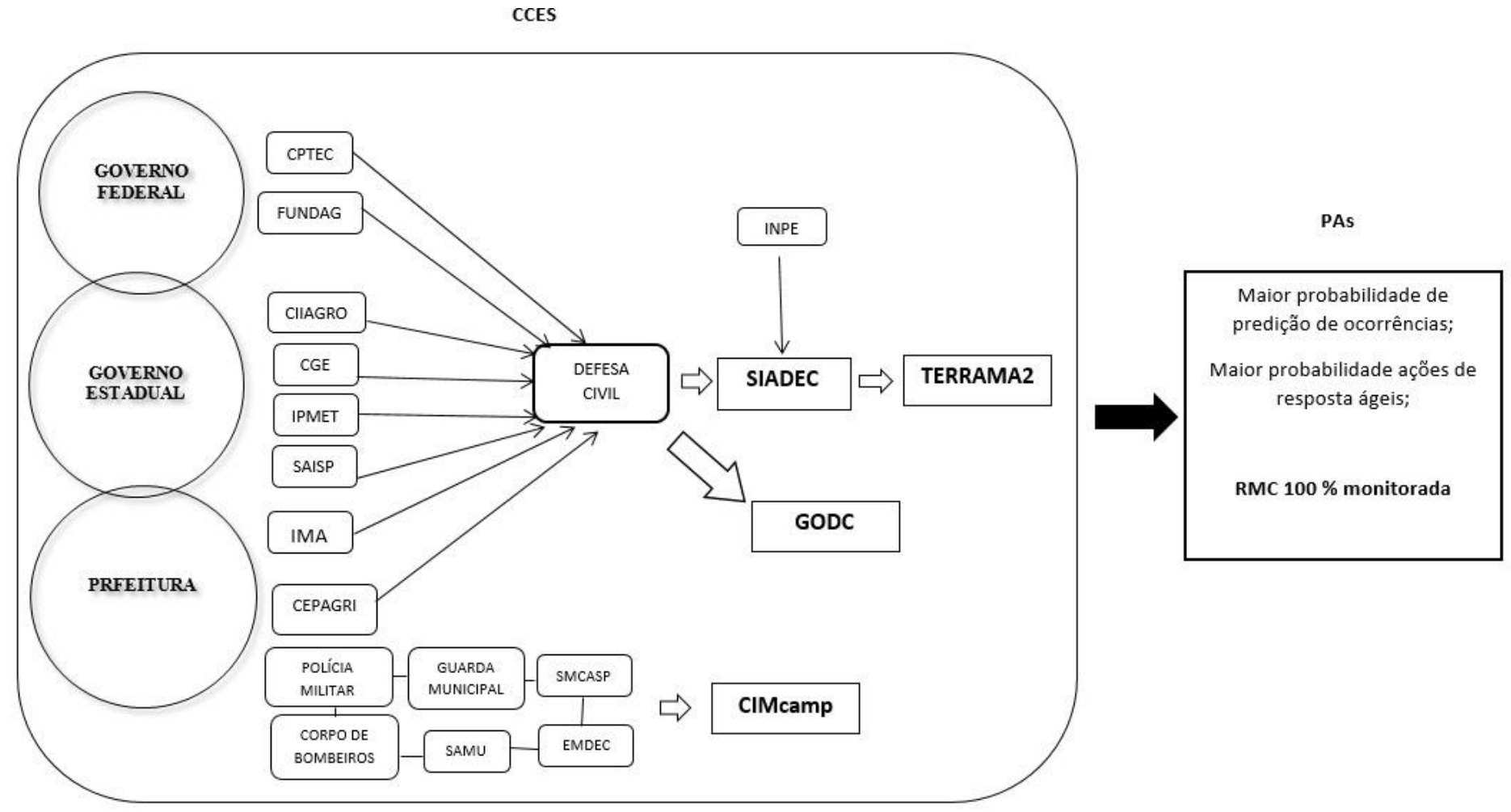

Figura 15. Passo 9 - Metacontingência Preparação e Sistema de Alerta

CEPAGRI: Centro de Pesquisas Meteorológicas e Climáticas Aplicadas à Agricultura FUNDAG: Fundação de Apoio à Pesquisa Agrícola IPMET: Instituto de Pesquisas Meteorológicas

SAISP: Sistema de Alerta a Inundações do Estado de São Paulo INPE: Instituto Nacional de Pesquisas Espaciais

SMCASP: Secretaria de Cooperação de Assuntos de Segurança Pública

GODC: Gerenciamento de Ocorrências de Defesa Civil

SIMPDEC: Sistema Municipal de Proteção e Defesa Civil

SETEC: Serviços Técnicos Gerais

SMCAIS: Secretaria Municipal de Cidadania, Assistência e Inclusão Social

DSAN: Diretoria de Segurança Alimentar e Nutricional

CEASA: Centrais de Abastecimento de Campinas
IMA: Informática dos Municípios Associados CPTEC: Centro de Previsão de Tempo e Estudos Climáticos CIIAGRO: Centro integrado de informações agrometeorológicas CGE: Centro de Gerenciamento de Emergências de São Paulo IAC: Instituto Agronômico de Campinas

SIADEC: Sistema de Alerta da Defesa Civil de Campinas

CIMcamp: Central Integrada de Monitoramento de Campinas EMDEC: Empresa Municipal de Desenvolvimento de Campinas GAE: Grupo de Atendimento de Emergência

DOAS: Departamento de Operações da Assistência Social

UAI Unidade de Acolhimento Institucional 


\section{Passo 10}

No Passo 10, apresentado na Tabela B10, são estabelecidas medidas de reconstrução e recuperação a serem tomadas após a ocorrência de desastres. O município deve contar com um processo de reconstrução planejado e participativo, com a previsão de necessidades, o desenvolvimento de mecanismos operacionais e o comprometimento de recursos. O governo local deve desenvolver uma gestão de recursos estratégica, fortalecendo e buscando convênios com órgãos e agências nacionais, internacionais e empresários. As necessidades da população afetada devem ser priorizadas, com o fornecimento de abrigos, aconselhamento e ações que propiciem o retorno à sua rotina, a reconstrução de suas vidas, casas e meios de subsistência (UNISDR, 2012).

A Metacontingência Recuperação e Reconstrução das Comunidades apresentada na Figura 16, descreve as relações funcionais referentes ao Passo 10, identificadas em Campinas. O município conta com um plano político instituído por decreto municipal que tem função de contexto antecedente para as ações de apoio aos cidadãos, na fase de recuperação de um desastre. O Plano Municipal Integrado de Gerenciamento de Assistência Humanitária para Situações de Desastres (Decreto $\mathrm{n}^{0} 17.851$ de 23 de janeiro de 2013) estabelece procedimentos de socorro às vítimas atingidas por situação de emergência ou estado de calamidade pública. A terminologia utilizada pelo segundo plano e a padronização de medidas a serem realizadas pelos órgãos envolvidos colaboram para que as suas ações, em articulação, produzam efetivo resultado social: recursos emergenciais de água, abrigo, alimentação e saúde após a ocorrência de desastres garantidos à população municipal atingida por um desastre (PAs).

As CCEs da Metacontingência Recuperação e Reconstrução das Comunidades contam com agentes dos órgãos integrantes do Sistema Municipal de Proteção e Defesa Civil 
(SIMPDEC), dentre os quais estão: Defesa Civil; Serviço de Atendimento Móvel de Urgência (SAMU); Serviços Técnicos Gerais (SETEC); Assistência e Inclusão Social (SMCAIS); Secretaria Municipal de Saúde (SMS); Departamento de Vigilância em Saúde, Secretaria Municipal de Comunicação (SMC); Secretaria Municipal de Chefia de Gabinete do Prefeito (SMCGP); Centrais de Abastecimento de Campinas (CEASA); Sociedade de Abastecimento de Água e Saneamento (SANASA); Corpo de Bombeiros e Empresa Municipal de Desenvolvimento de Campinas (EMDEC).

Na metacontingência do Passo 10, a Defesa Civil de Campinas promoveu também o desenvolvimento do Sistema de Gerenciamento de Ações Humanitárias (DONARE), que faz a gestão dos donativos recebidos e resulta nos PAs: (1) a centralização de uma base de dados com informações de voluntários e quantidade de vagas livres e ocupadas nos abrigos cadastrados; (2) atualização em tempo real das informações; e (3) distribuição dos donativos, de acordo com a prioridade de cada local afetado.

A administração dos entes estadual e federal participam das CCEs dessa Metacontingência Recuperação e Reconstrução das Comunidades por duas vias principais: (1) programas nacionais de apoio às comunidades vulneráveis ou em situação de risco (Programa Nacional de Acesso ao Ensino Técnico e Emprego, PRONATEC, e Programa Habitacional Minha Casa Minha Vida); e (2) suplementação de recursos.

Esses programas federais estabelecem parceria entre união, estados, municípios, empresas e entidades sem fins lucrativos (CCEs), sendo desenvolvidos em Campinas sob a responsabilidade de secretarias municipais (e.g., SMCAIS; SMTR; SEHAB e SME). Ao considerar o PRONATEC, essas secretarias estabelecem parceria com o Serviço Nacional de Aprendizagem Comercial (SENAC), Serviço Nacional de Aprendizagem Industrial (SENAI) e Serviço Social de Aprendizagem do Transporte (SENAT) na oferta de cursos de 
qualificação profissional para população vulnerável. Como produto agregado resultante da integração de agentes dessas entidades em CCEs, observa-se, em 2012, um total de 5.944 cidadãos qualificados profissionalmente, dentre os quais estão beneficiários do Bolsa Família, desempregados, matriculados na rede de ensino público, trabalhadores domésticos, cadastrados em programas sociais, trabalhadores informais e autônomos. E ainda, famílias removidas de áreas de risco e transferidas para novas moradias, em situação de desastre, são Produtos Agregados (PAs) resultante das ações do Programa Minha Casa Minha Vida. 


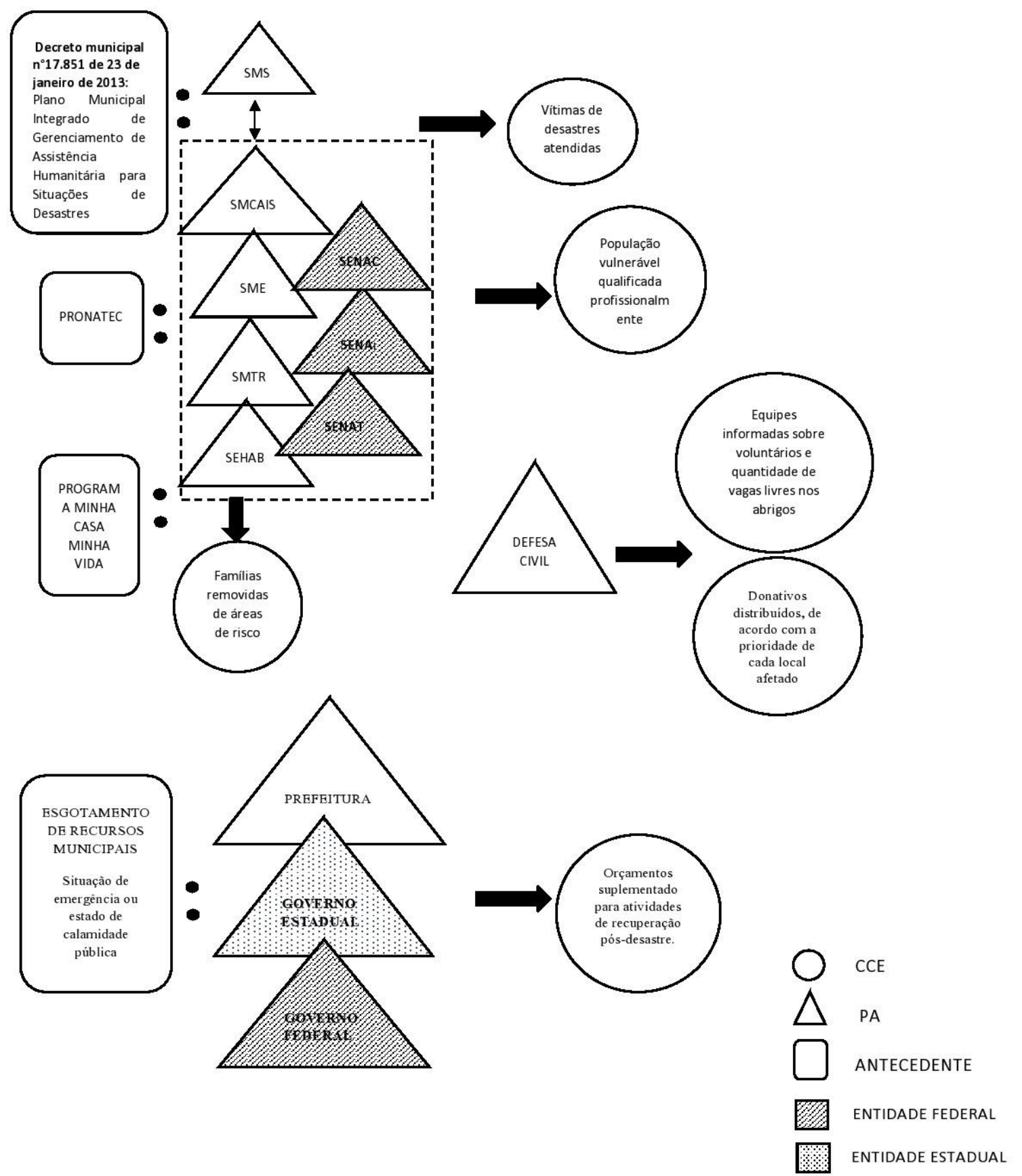

Figura 16. Passo 10 - Metacontingência Recuperação e Reconstrução de Comunidades.

SENAC: Serviço Nacional de Aprendizagem Comercial

SENAT: Serviço Social de Aprendizagem do Transporte

SMCAIS: Secretaria Municipal de Cidadania, Assistência e Inclusão Social

SEHAB: Secretaria Municipal de Habitação

SETEC: Serviços Técnicos Gerais

SMS: Secretaria Municipal de Saúde

SMCG: Secretaria Municipal de Chefia de Gabinete do Prefeito

SANASA: Sociedade de Abastecimento de Água e Saneamento
SENAI: Serviço Nacional de Aprendizagem Industrial SME: Secretaria Municipal de Educação

SMTR: Secretaria Municipal de Trabalho e Renda SIMPDEC: Sistema Municipal de Proteção e Defesa Civil

SAMU: Serviço de Atendimento Móvel de Urgência

SMC: Secretaria Municipal de Comunicação

CEASA: Centrais de Abastecimento de Campinas

EMDEC: Empresa Municipal de Desenvolvimento de Campinas

Além da responsabilização da execução em nível local dos programas citados, as quatro secretarias municipais (SMCAIS, SMTR, SEHAB e SME) desenvolvem outras 
atividades: (1) gestão dos benefícios dos programas de transferência de renda municipais, estaduais e federais; (2) demolição das residências e promoção da recuperação ambiental da área em consonância com os projetos habitacionais; e (3) sistematização e análise de informações territorializadas sobre as situações de vulnerabilidade e risco de famílias. Essas ações caracterizam serviços preventivos que agilizam o apoio a comunidades vulneráveis em situação pós-desastres, de forma a se obter CCEs e produtos que minimizem efeitos adversos em novas ocorrências de desastres.

As CCEs da Metacontingência Recuperação e Reconstrução das Comunidades ocorre também por meio da suplementação de recursos. O esgotamento de recursos municipais é um estímulo antecedente para CCEs de suplementação, pois o prefeito pode decretar situação de emergência ou estado de calamidade pública, e solicitar apoio suplementar ao governo estadual ou federal. Nessas CCEs pode participar ainda, a rede socioassistencial privada com o cofinanciamento de serviços, o que resultou, no ano de 2013, em 21.786 usuários atendidos nos serviços de Proteção Básica e Especial (CRAS e CREAS) (PA). 


\section{Discussão}

A contribuição da psicologia, especificamente da Análise do Comportamento, na interpretação de fenômenos culturais complexos, e ainda, a contribuição para planejamentos e/ou aperfeiçoamento de práticas culturais pode ser aplicada na área de desastres. Nesta, equipes multissetoriais atuam com suas diferentes competências, mas de forma integrada e seguindo protocolo internacional, nas diferentes fases de gerenciamento de desastre - da prevenção à recuperação (Daumal, Machado \& Franco, 2015; UNISDR, 2010; UNISDR, 2012).

A ênfase da Análise do Comportamento em análises funcionais que busquem pela função de determinados eventos ambientais sobre o comportamento humano contribui para o conhecimento sobre condições favoráveis ao desenvolvimento e manutenção de padrões de comportamento. Para essa área de conhecimento, a causa do comportamento não está apenas localizada no presente, mas em uma história de recorrência em determinados contextos, nos quais variáveis específicas atuam para seu fortalecimento ou enfraquecimento futuro. Entretanto, na cultura ocidental, tende-se a analisar comportamento de forma causal, imediata, e com destaque para explicações internas ao indivíduo ou mesmo estruturais como a mente ou outras estruturas corporais para as quais se atribui explicação (Carrara, 2004). Assim, desconsidera-se que essas estruturas (como a mente, cérebro, entre outras) também sofrem efeito da história de aprendizagem individual e de forças culturais (envolvendo a influência ou o controle de grandes grupos tais como a família, escola, profissão, religião e Estado - com seu sistema de governo e contexto socioeconômico) (Skinner, 1990).

No que tange ao planejamento de práticas culturais, destaca-se o papel de instruções e regras, as quais, segundo Matos (2001), são estímulos discriminativos que descrevem contingências, ou seja, variáveis que especificam um comportamento e suas consequências. 
Desse modo, a forma como um indivíduo se comporta pode depender das instruções que recebeu (Catania, 1999) e, ainda mudanças culturais podem ser promovidas por meio do estabelecimento de leis (Fava, 2014). O desenvolvimento de políticas e de regulamentações favorecem a implementação de novas práticas culturais, o que já foi demonstrado, como no caso do impacto internacional que levou à diminuição significativa do tabagismo entre jovens

(Biglan et al, 2000; Biglan, 2015).

\section{Tabela 5}

\section{Os 10 passos essenciais para construir cidades resilientes e legislação de apoio.}

(1) Estabeleça mecanismos de organização e coordenação de ações com base na participação de comunidades e sociedade civil organizada, por meio, por exemplo, do estabelecimento de alianças locais. Incentive que os diversos segmentos sociais compreendam seu papel na construção de cidades mais seguras com vistas à redução de riscos e preparação para situações de desastres;

Decreto $N^{\circ} 17.783$ de 28 de novembro de 2012 (Reorganização do SIMPDEC)

Decreto No 17.921 de 27 de março de 2013 (Projeto de Proteção Comunitária)

Decreto $N^{0} 18.045$ de 24 de julho de 2013 (Comitê Cidades Resilientes)

(2) Elabore documentos de orientação para redução do risco de desastres e ofereça incentivos aos moradores de áreas de risco: famílias de baixa renda, comunidades, comércio e setor público, para que invistam na redução dos riscos que enfrentam;

Lei $n^{\circ} 4985$ de 08 de maio de 1980 / Lei no 14.609 de 27 de maio de 2013 (Fundo de Apoio à População de Sub-Habitação Urbana (FUNDAP))

Lei $\mathrm{N}^{\circ} 13.197$ de 14 de dezembro de 2007 / Lei $\mathrm{n}^{\circ}$ 13.784, de 04 de março de 2010 (Programa Auxílio Moradia)

(3) Mantenha informação atualizada sobre as ameaças e vulnerabilidades de sua cidade; conduza avaliações de risco e as utilize como base para os planos e processos decisórios relativos ao desenvolvimento urbano. Garanta que os cidadãos de sua cidade tenham acesso à informação e aos planos para resiliência, criando espaço para discutir sobre os mesmos;

(4) Invista e mantenha uma infraestrutura para redução de risco, com enfoque estrutural, como por exemplo, obras de drenagens para evitar inundações; e, conforme necessário, invista em ações de adaptação às mudanças climáticas;

Lei No 6.031 de 29 de dezembro de 1988 (Lei de Uso e Ocupação do Solo (LUOS))

(5) Avalie a segurança de todas as escolas e postos de saúde de sua cidade, e modernize-os se necessário;

Lei $\mathbf{N}^{0} 9.858$ de 28 de setembro de 1998 (Geradores de energia elétrica em hospitais, prontossocorros e clínicas do município de Campinas)

Decreto $\mathbf{n}^{0} 14.524$ de 14 de novembro de 2003 (Programa Conta Escola)

(6) Aplique e faça cumprir regulamentos sobre construção e princípios para planejamento do uso e ocupação do solo. Identifique áreas seguras para os cidadãos de baixa renda e, quando possível, modernize os assentamentos informais;

Lei $\mathbf{N}^{\circ} 6.031$ de 29 de dezembro de 1988 (LUOS)

Lei Complementar $\mathbf{N}^{\circ} 09$ de 23 de dezembro de 2003 (código de obras e edificações do município) 


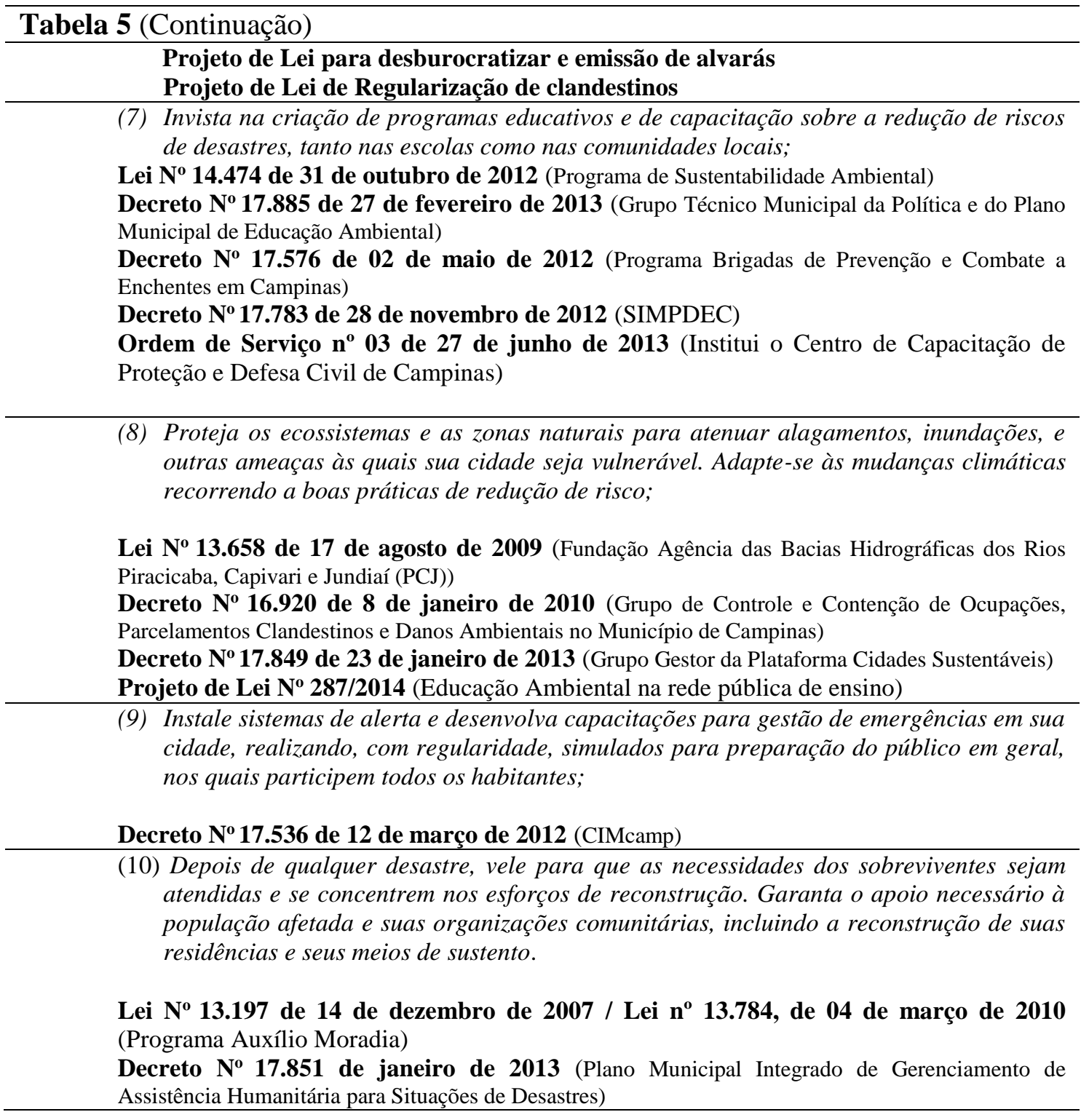

Ao considerar as regulamentações estabelecidas no transcorrer do cumprimento dos ciclos da Campanha (Tabelas 1 e 3; e Anexo 2 Tabelas 1B a 10B), observa-se que um total de 9 decretos, 2 leis, 1 projeto de lei e 1 ordem de serviço foram criadas na execução dos 10 Passos. A Tabela 5 mostra as principais regulamentações legais necessárias para o funcionamento de metacontingências que envolvem mudanças na construção de cidades resilientes para cada um dos passos da Campanha. O município de Campinas já contava com uma estrutura jurídica razoável no que diz respeito à regulamentação referente a infraestrutura 
e financiamento de providências que apoiam e/ou colaboram para a redução de risco de desastres (8 leis e 2 decretos).

Embora instruções, regras e regulamentações oficiais sejam necessárias em planejamentos culturais, essas variáveis não são suficientes para garantir a mudança de comportamento ou para manter comportamentos alvo, neste caso, ações direcionadas à redução de riscos de desastres. É necessário também planejar contingências de reforçamento, isto é, consequências para comportamentos individuais, formando competências específicas, ou classes de comportamento operantes em diferentes cursos e simulações, por exemplo. Em Campinas, nas realizações do Passo 8 da Campanha, a prefeitura programou incentivos que beneficiaram empresas com a isenção de IPTU, quando estas mostraram ações de inserção em Bancos de Área Verde (BAV). Assim, a empresa cumpre determinados parâmetros e contribui para uma gestão sustentável necessária para o planejamento urbano, visando a minimização de riscos de desastres. Essa programação de contingência de reforçamento positivo é inovadora e contrasta com consequências programadas por governos baseadas em contingências aversivas com punição para determinados comportamentos (e.g., multas e aumento de impostos).

Uma longa tradição de pesquisa voltada para estimulação aversiva mostra vários riscos para os quais se deve estar atento ao utilizar reforço negativo, punição positiva e negativa (Carvalho, Neto \& Gouveia Jr, 2015; Catania, 1999; Estes \& Skinner; 1941; Maier \& Seligman; 1976; Sidman, 2003). Com o reforço negativo, a probabilidade futura de ocorrência de um comportamento aumenta caso ele tenha função de interromper alguma consequência aversiva - estudar ou trabalhar em contextos coercitivos para não ser reprovado ou para não ser demitido, respectivamente. Nesses exemplos, o comportamento de estudar ou trabalhar não estaria sendo mantido por reforço positivo natural, intrínseco à leitura, discussão, em 
escolas e ambientes profissionais. Sentimentos de prazer e satisfação podem ser substituídos nesses ambientes de tensão por sentimentos de medo, raiva e outros que podem provocar adoecimento, fuga e esquiva. A punição positiva constitui também uma contingência aversiva que diminui a probabilidade futura de um comportamento pela apresentação de um estímulo aversivo - como uma multa produzida por dirigir em alta velocidade, ou ainda, uma multa por alta utilização da água. Na punição negativa, há retirada de um estímulo reforçador do ambiente do indivíduo, produzindo diminuição de uma resposta alvo - como no caso de uma prisão após uma ação classificada como crime; ou a retirada do estudante de sala de aula (Catania, 1999).

Assim, a análise funcional permite identificar eventos que assumem função de reforço, punição, ou estímulos antecedentes que acompanham tais consequências e assumem a função de estímulo discriminativo, ocasionando determinadas ações de acordo com as contingências de reforçamento ou de punição (Meyer, 2003). No caso de metacontingências, as quais envolvem maior complexidade, isto é, várias contingências de reforçamento envolvendo redes de interação, novamente, as consequências culturais mantêm ou enfraquecem um conjunto de contingências entrelaçadas, recorrentes que descrevem o comportamento de cada agente envolvido e o produto agregado que produzem.

O objetivo geral deste estudo foi analisar funcionalmente a implementação da Campanha "Construindo Cidades Resilientes - minha cidade está se preparando", a partir dos princípios da Análise do Comportamento, numa cidade brasileira que demonstrou evolução nas práticas de redução de risco de desastre. Uma pesquisa documental com análises do contexto aplicado da Campanha em Campinas-SP permitiu a sistematização de metacontingências envolvidas nas providências, ou Passos, previstos pela regulamentação do Escritório das Nações Unidas para a Redução do Risco de Desastres Escritório das Nações 
Unidas para a Redução do Risco de Desastres (UNISDR) e desenvolvidos no município entre os anos de 2011 e 2014.

O conceito de metacontingência facilita a compreensão de fenômenos sociais complexos, que envolvem grande número de pessoas, com a descrição de redes de contingências comportamentais entrelaçadas (CCEs), nas quais os comportamentos de diferentes agentes interagem numa relação de dependência de forma recorrente e geram impactos sociais no ambiente denominados de produtos agregados (PAs). Esse conceito contribui também para a compreensão sobre o desenvolvimento e a continuidade de práticas culturais, ao considerar consequências culturais externas (CCs) que tem função de selecionar ou não esses arranjos sociais (CCEs $\rightarrow$ PAs). Ou seja, a programação de consequências culturais específicas tem o potencial de modificar ações de um grande número de pessoas e, desse modo, alterar os produtos agregados resultantes dessa interação.

As análises dos 10 Passos essenciais para a construção cidades resilientes deram origem a 15 metacontingências, cada uma com CCEs e PAs específicos. Essas metacontingências estabelecem relação entre si, resultando na redução de risco de desastres, com a diminuição de perdas humanas e materiais, que é um produto agregado (PA) primário comum a todos esses arranjos. A Figura 17 mostra as interações estabelecidas entre as 15 metacontingências.

A Metacontingência Quadro Institucional e Legislativo é um pré-requisito para a implementação da Campanha, e gera PAs fundamentais para o desenvolvimento das outras metacontingências envolvidas nos passos essenciais, como a elaboração e o aperfeiçoamento de um conjunto de legislações que fortalecem as estratégias do município no enfrentamento de desastres (ver Tabela 3), apresentadas nos resultados, com regulamentações oficiais de Campinas entre os anos 2012 e 2014. 
O Decreto municipal no 17.783 de 28 de novembro de 2012 é uma regulamentação que merece ênfase, pois reorganizou o Sistema Municipal de Proteção e Defesa Civil (SIMPDEC) e o alinhou à Política Nacional de Proteção e Defesa Civil (PNPDEC). Estabeleceu diretrizes para o funcionamento de uma entidade de liderança na administração pública do município, responsável por coordenar as atividades locais de redução de risco de desastre, e seus órgãos e setores participantes. Ademais, vinculou o Departamento de Defesa Civil ao Gabinete do Prefeito, o que garantiu o apoio administrativo do prefeito ao SIMPDEC e conferiu maior autonomia à Defesa Civil.

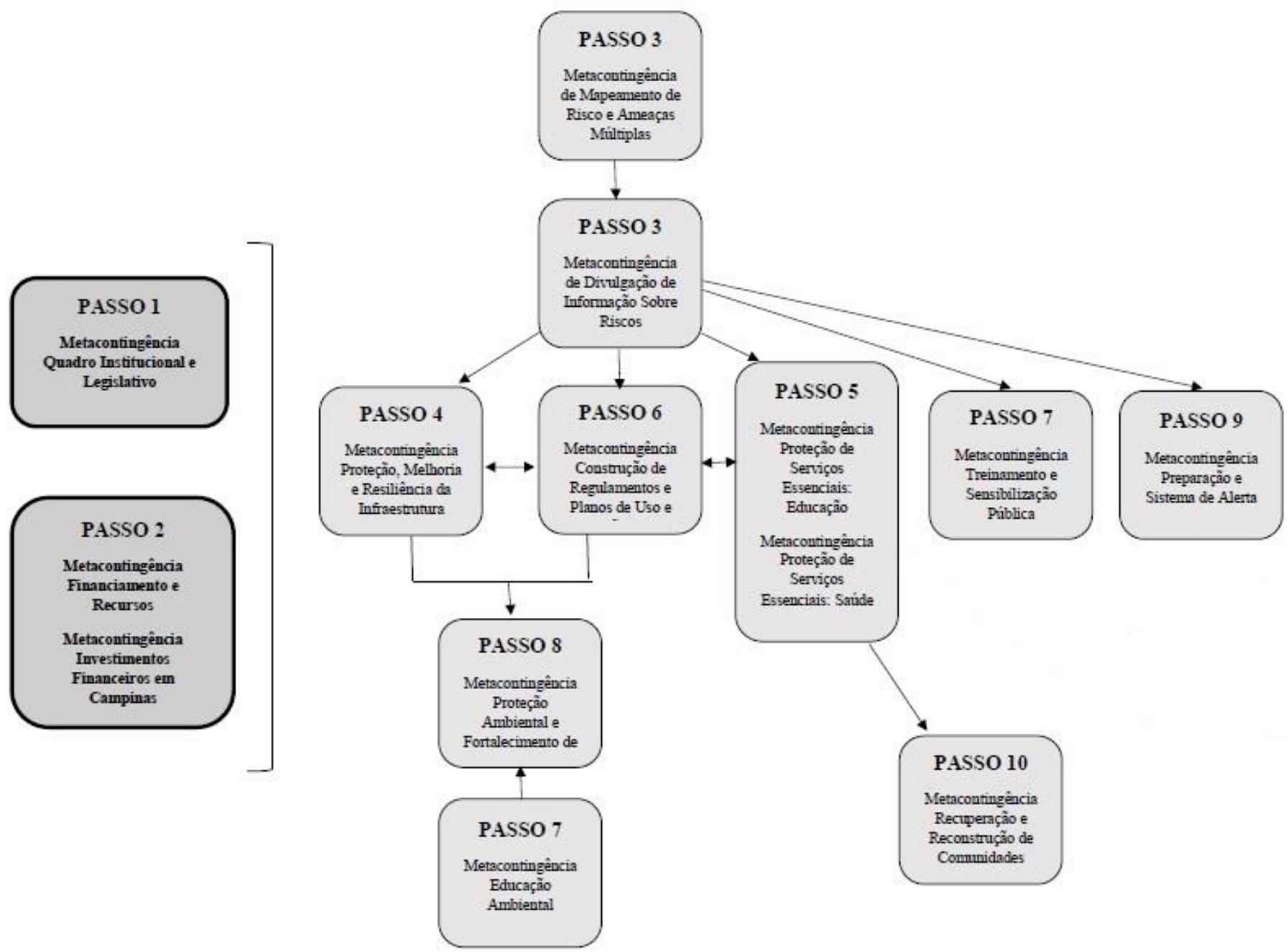

Figura 17. Relações entre as metacontingências dos 10 passos essenciais para construir cidades resilientes. 
Todorov (2012) alerta que a existência de leis não é garantia para a ocorrência dos comportamentos, sendo necessário que o Estado utilize seu poder e controle por meio dos Poderes executivos e Judiciários para gerar obediência. Portanto, a participação efetiva do chefe do poder público executivo local favorece tomadas rápidas e efetivas de decisão. Em Campinas, o prefeito tem papel de destaque na implementação da Campanha e participa das iniciativas de redução de risco de desastre, com o desenvolvimento de decretos municipais, a criação de grupos técnicos para desenvolver atividades, a ativação de fundos e o repasse de verbas para as atividades requeridas.

A elaboração de um quadro legislativo consistente é uma estratégia necessária favorece a recorrência de CCEs de redução de risco de desastres nos órgãos municipais, ainda que ocorram mudanças de membros, devido à falecimento, transferência ou demissão de servidores. No Brasil, frequentemente, mudanças de gestão após processos eleitorais implicam na alteração de equipes gestoras, o que pode levar à interrupção de metacontingências efetivas no serviço público brasileiro e coloca em risco a recorrência futura dessas ações entrelaçadas e seus produtos agregados, os quais se mostraram efetivos e favoráveis à proteção dos cidadãos. Desse modo, a criação de leis, estatutos e protocolos colabora para a transmissão de contingências comportamentais entrelaçadas entre gerações, mesmo num cenário e que haja uma mudança completa das equipes.

As metacontingências do Passo 2 - Metacontingência Financiamento e Recursos e Metacontingência Investimentos Financeiros em Campinas - também são pré-requisito para os todos os outros Passos, pois os produtos agregados (PAs) de seus entrelaçamentos se referem à capacidade orçamentária para que as atividades de redução de risco previstas nas providências sejam desenvolvidas no município (e.g., mapeamento de risco, sistemas de 
alerta, programas assistenciais para comunidades vulneráveis, infraestrutura resiliente e uso responsável do solo).

No Passo 3, a Metacontingência Mapeamento de Risco e Ameaças Múltiplas é contexto antecedente para a Metacontingência Divulgação de Informação Sobre Riscos, a qual, por sua vez, é ocasião para as metacontingências relacionadas à construção de infraestrutura (Passo 4), regulamentação do uso do solo (Passo 6), proteção de escolas e centros de saúde (Passo 5), treinamento e sensibilização pública (Passo 7), além de manter relação com o desenvolvimento de sistemas de alerta e alarme (Passo 9). O aumento de 242\% de orientações a moradores e do monitoramento de áreas de risco e a informatização de dos mecanismos de consulta sobre riscos do município disponíveis aos cidadãos são PAs de destaque.

A Metacontingência Construção de Regulamentos e Planos de Uso e Ocupação do Solo do Passo 6 e a Metacontingência Proteção, Melhoria e Resiliência da Infraestrutura do Passo 4 mantém relação estreita, pois regulamentos para o uso do solo também se aplicam às obras de infraestrutura e os resultados de ambas contribuíram para o PA de redução de 64\% de áreas de risco no município de Campinas. Ademais, produtos agregados dessas duas metacontingências relacionados a vistorias e concessão de licenças ambientais para empreendimentos públicos e privados contribuem para a Metacontingência Proteção Ambiental e Fortalecimento dos Ecossistemas, do Passo 8, uma vez que colaboram para a promoção de desenvolvimento sustentável. O desenvolvimento do aplicativo licenciamento online, que permite a solicitação e acompanhamento virtual de licenças ambientais é um PA relevante que reduz a burocratização para a realização de empreendimentos de acordo com restrições ambientais. A utilização desse aplicativos, assim como os outros já citados acima reduzem o custo das respostas que favorecem a diminuição de risco de desastres, como 
informar-se sobre os riscos locais, obter informações sobre risco para o desenvolvimento de projetos urbanos e conseguir documentação ambiental necessária para o desenvolvimento de empreendimentos. Quanto maior o custo de resposta, menor a probabilidade de sua ocorrência e vice-versa (Chung, 1965; Miller; 1968; Weiner, 1965,).

A Metacontingência Educação Ambiental, do Passo 7, também contribui para a Metacontingência Proteção Ambiental e Fortalecimento dos Ecossistemas, do Passo 8, pois resulta em propostas de educação ambiental, PAs úteis para que seja alcançada gestão sustentável de recursos naturais do município. Os entrelaçamentos da Metacontingência Treinamento e Sensibilização Pública em redução de Risco de Desastre, também do Passo 7, resultam em cursos de formação e simulações de situações de emergência, que promovem o desenvolvimento de repertórios comportamentais competentes de muitos indivíduos para minimizar ou evitar danos em situações de desastres. E, ainda, esses operantes desenvolvidos contribuem para as metacontingências dos Passo 9 e Passo 10, relacionados às estratégias de resposta e reconstrução das comunidades após a ocorrência de desastres.

No Passo 9, a Metacontingência Preparação e Sistemas de Alerta é contexto antecedente para a Metacontingência Recursos para Resposta Efetiva, com destaque ao produto de monitoramento integral da Região Metropolitana de Campinas. As metacontingências do Passo 5 (Metacontingências Proteção de Serviços Essenciais: Educação e Metacontingências Proteção de Serviços Essenciais: Saúde) participam das CCEs dessa metacontingência do Passo 9, já que o funcionamento dessas instituições tem função essencial durante um desastre. Ademais, a continuidade de atividades em hospitais e escolas contribuem para a recuperação dos afetados em desastres e ao retorno às suas atividades, o que indica que as metacontingências do Passo 5 também mantém relação com a Metacontingência Recuperação e Reconstrução das Comunidades, identificada no Passo 10. 
Desde 2008, não há registro em Campinas, de paralisações de atividades escolares devido a impactos de chuvas ou outros fenômenos naturais.

Os 10 Passos essenciais para a construção cidades resilientes, portanto, abrangem o planejamento de intervenções: (1) pré-desastre, de prevenção, mitigação e preparação; (2) durante o desastre, com ações de resposta à emergência; e (3) pós desastre, com medidas voltadas para recuperação dos afetados. A Figura 18 mostra que as cinco fases de gestão do risco e gerenciamento de desastre estão contempladas nos Passos, com a concentração da maioria dos Passos nas etapas que antecedem o desastre.

\section{Passo 1}

\section{Passo 2}

Passo 3

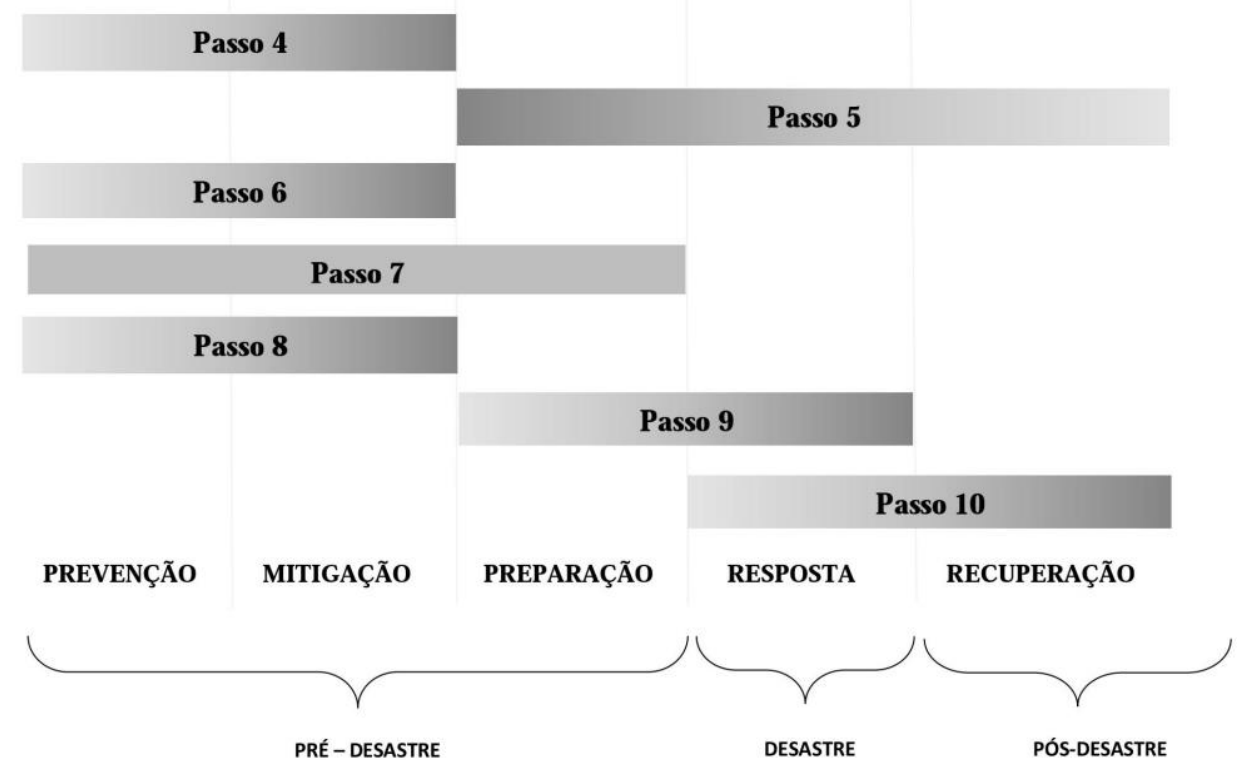

Figura 18. Os 10 passos essenciais para construir cidades resilientes e as fases de gerenciamento de desastre. 
As proposições da Estratégia Internacional de Redução de Desastre (EIRD), com o estabelecimento de escritórios regionais (continentais) e nacionais, assim como o enfoque local da Campanha Cidades Resilientes, implicam na descentralização de políticas e práticas de redução de risco de desastres, o que se diferencia do posicionamento inicial da ONU, cujos esforços, na década de 1970, concentravam-se na centralização de um escritório capaz de articular medidas preventivas para a redução de desastre. Essa capacidade de raciocínio e ação local para a resolução de problemas com impactos globais é, segundo Nevin (2010), efetiva pois promove o engajamento de indivíduos em projetos cooperativos de pequena escala e o contato com consequências de suas ações em menor período de tempo. A conclusão de uma etapa, o reconhecimento dos demais e incentivos financeiros podem ter função reforçadora e fortalecer esses comportamentos de engajamento individual. No entanto, deve ser dada atenção também à programação de consequências selecionadoras da ação articulada de muitos indivíduos, que ocorreu em Campinas, por meio de prêmios nacionais e internacionais, trazendo prestígio, verbas e investimentos financeiros para o município, e da avaliação e reconhecimento internacional, que leva à passagem do Ciclo 1 para o Ciclo 2 da Campanha. No Brasil, os dados apresentados nos resultados sobre o número considerável de cidades que aderiram à Campanha e ainda não avançaram para o Ciclo 2 demandam que novos estudos sejam desenvolvidos, a fim de investigar possíveis razões para esse fenômeno e os tipos de investimentos estratégicos adicionais necessários para aumentar a probabilidade de avanço.

Esta pesquisa documental, baseada em bancos de dados oficiais descreveu as relações entre comportamentos (ações de múltiplos agentes) e a forma como essas ações estão organizadas, produzindo resultados específicos, para os quais se busca a manutenção em futuras gerações de equipes municipais, atuando na minimização de riscos e no enfrentamento de desastres. O modelo disponibilizado pelo município de Campinas em São Paulo torna-se 
estímulo para outras ações implementadas pelo país. E, a divulgação dos resultados, incluindo bases de dados online, otimiza entrelaçamentos, trocas de experiência e adoção de ações que se mostraram efetivas no país. 


\section{Referências}

Aitsi-Selmi, A., \& Murray, V.. (2015). The Sendai framework: disaster risk reduction through a health lens. Bulletin of the World Health Organization, 93(6), 362.

Alavosius, M., Mattaini, M. (2011) Editorial: Behavior Analysis, Sustainnability, Resilience and Adaptation. Behavior and Social Issues, 20, 1-5. Recuperado de: doi 10.5210/bsi.v20i0.3782.

Alavosius, M., Houmanfar, R., Rodriquez, J. (2005) Unity of purpose/unity of effort: privatesector preparedness in times of terror. Disaster Prevention and Management, 14 (5), pp. 666680. Recuperado de: DOI 10.1108/09653560510634098.

Alavosius, M.P., Braksick, L., Daniels, A.C., Harshbarger, D., Houmanfar, R. and Zeilstra, J. (2002). The impact of terrorism on the US economy and business. Journal of Organizational Behavior Management, 22 (4), pp. 3-26.

Albuquerque, B. S., \& Zacarias, G. M. (2016). A psicologia como aliada à gestão de risco em desastres. Revista Ordem Pública, 9(1), 109-120.

Alves, H. R. (2015) Gestão de Desastres Naturais: A Utilização do Princípio da Vedação ao Retrocesso Socioambiental e a Participação da População Rumo à Construção da Resiliência Urbana. Em Campelo, L. G. B; Yoshida, C.Y.M; Cavallazzi, R. L. (Orgs.). Gestão de Desastres Naturais: A Utilização do Princípio da Vedação ao Retrocesso Socioambiental e a Participação da População Rumo à Construção da Resiliência Urbana (pp. 30-59) João Pessoa: CONPEDI.

Alves, A. L., Dos Santos, J. F. A., Cartagena, S. M. C. (2011). Módulo IV: Gestão e Redução de Riscos de Desastre. Em Alves, A. L., Dos Santos, J. F. A., Cartagena, S. M. C. Capacitação Básica em Defesa Civil: livro texto para educação à distância, Florianópolis: Centro Universitário de Estudos e Pesquisa sobre Desastres (CEPED UFSC). Recuperado em 15 de dezembro de 2016 de http://www.ceped.ufsc.br.

Austin, J., Hatfield, D. B., Grindle, A. C., \& Bailey, J. S. (1993). Recycling in office environments: The effects of specific, informative cues. Journal of Applied Behavior Analysis, 26, 247-253. http://dx.doi.org/10.1901/jaba.1993.26-247

Baia, F. H., Azevedo, F. F., Segantini, S. M., Macedo, R. P., \& Vasconcelos, L. A. (2014)._Effects of different magnitudes of individual consequences and cultural consequences on_culturant's selection. Acta Comportamentalia, 23(3), 257-272.

Bacon-Prue, A., Blount, R., Pickering, D., \& Drabman, R. (1980). An evaluation of thre litter control procedures-Trash receptacles, paid workers, and the marked item technique Journal of Applied Behavior Analysis, 13, 165-170.

Bastos, P. A. (2015) Descrição de relações culturais em uma organização bancária (Dissertação de Mestrado). Universidade Federal do Pará, Belém. 
Biglan, A., Ary, D. V., Smolkowski, K., Duncan, T. E., \& Black, C. (2000). A randomized control trial of a community intervention to prevent adolescente tobacco use. Tobacco Control, 9, 2432 .

Biglan, A. (2009). The role of advocacy organizations in reducing negative externalities. Journal of Organizational Behavior Management, 29, 215-230.

Biglan, A. (2015). The nurture effect: How the science of human behavior can improve our lives and our world. Oakland, CA: New Harbinger Publications.

Bodstein, A., De Lima, V. V. A., \& De Barros, A. M. A. (2014). A vulnerabilidade do idoso em situações de desastres: necessidade de uma política de resiliência eficaz. Ambiente \& Sociedade, 17(2), 157-174.

Brandão, A. D. M. (2012). Efeitos da radiação ionizante sobre o comportamento operante: um estudo de alguns parâmetros temporais das sessões de irradiação e das sessões experimentais. Dissertação de mestrado, Universidade de Brasília.

Brasil. (2014). Ministério da Integração Nacional. Secretaria Nacional de Defesa Civil Sitio Governamental. Recuperado em: http://www.integracao.gov.br.

Brasil (2016) Marcos na História da Redução do Risco de Desastres. Recuperado em 03 de outubro de 2016 de https://www.unisdr.org/who-we-are/history.

Brothers, K. J., Krantz, P. J., \& McClannahan, L. E. (1994). Office paper recycling: A function of container proximity. Journal of Applied Behavior Analysis, 27, 153-160. http://dx.doi.org/10.1901/jaba.1994.27-153

Cabral, M. D. C., \& Todorov, J. C. (2016). Contingências e Metacontingências no Processo Legislativo da Lei sobre a Remição da Pena Pelo Estudo. Revista Brasileira de Análise do Comportamento, 11(2), 195-202.

Caldas, R. A. (2009). Experimental analogs of selection and extinction of metacontingencies [Análogos experimentais de seleção e extinção de metacontingências]. Unpublished master's thesis. Pontifícia Universidade Católica de São Paulo, São Paulo, Brazil

Carmo, R. L., \& Anazawa, T. M. (2014). Mortalidade por desastres no Brasil: o que mostram os dados. Ciência \& Saúde Coletiva, 19(9) 3669-3681.

Carrara, K. (2004). Causalidade, relações funcionais e contextualismo: algumas indagações a partir do behaviorismo radical. Interações, 9(17), 29-54.

Carvalho, I.C. V. (2013) Contingências e metacontingências na Lei de Diretrizes e Bases da Educação Nacional - LDB. Dissertação de mestrado, Universidade de Brasília.

Carvalho, P. D. P., Neto, M. B. D. C., \& Gouveia Jr, A. (2015). The effects of uncontrollable shocks on the aggressive behavior of the Siamese fighting fish (Betta splendens). Behavior Analysis: Research and Practice, 15(1), 50. 
Catania, A. C. (1999). Aprendizagem: comportamento, linguagem e cognição (DG Souza, Trad.). Porto Alegre: Artmed.(Trabalho original publicado em 1998).

CEPED (2011). Atlas brasileiro de desastres naturais 1991 a 2010: Volume Brasil. Florianópolis: CEPED UFSC.

Chung, S. (1965) Effects on efforts on response rate. Journal of Experimental Analysis of Behavior, 8, 1-7.

Conselho Federal de Psicologia (2013) Nota técnica sobre a atuação de psicóloga (o) s em situações de emergências e desastres, relacionadas com a política de defesa civil. Recuperado de: http://site.cfp.org.br/emergencias-e-desastres-2/

CRED, UNISDR (2016) The human cost of weather related disasters 1995- 2015. Recuperado de: https://www.unisdr.org/2015/docs/climatechange/COP21_WeatherDisastersReport_20.

Dalmau, B.L, Machado, M. A. Franco, C.V. (2015) A campanha cidades resilientes e o Plano nacional de Gestão de riscos e desastres naturais: avanços e perspectivas na construção de comunidades menos vulneráveis. Cadernos Adenauer XVI, 2, 95 - 113.

DeLeon, I. G., \& Fuqua, R. W. (1995). The effects of public commitment and group feedback on curbside recycling. Environment and Behavior, 27, 233-250. http://dx.doi.org/10.1177/0013916595272007

Dwyer, W. O., Leeming, F.C., Cobern, M.K., Porter, B.E., \& Jackson, J. M. (1993). Critical review of behavioral interventions to preserve the environment: Research since 1980. Environment and Behavior, 25, 485-505. http://dx.doi.org/10.1177/0013916593255001

EIRD (1994) Estrategia y Plan de Acción de Yokohama para un Mundo más Seguro. Genebra: EIRD.

Estes, W. K., \& Skinner, B. F. (1941). Some quantitative properties of anxiety. Journal of Experimental Psychology, 29, 390-400.

Fonseca, F. N. F. (2012) Contingências e metacontingências no Twitter: uma análise da campanha presidencial brasileira de 2010. Dissertação de mestrado, Universidade de Brasília.

Franceschini, A. C. T., Samelo, M. J., Xavier, R. N., \& Hunziker, M. H. L. (2012). Effects of consequences on patterns of interlocked contingencies: A replication of a metacontingency experiment. Revista Latinoamericana de Psicología, 44, 87-95.

Fava, V. M. D. (2014). Comportamento das famílias beneficiárias do Programa Bolsa Família: uma perspectiva analítico-comportamental do cumprimento das condicionalidades de Educação e de Saúde. Tese de Doutorado. Universidade de Brasília.

Gadelha, C. T. (2010). Evolução cultural em análogos experimentais de metacontingências: seleção de diferentes produtos agregados. Dissertação de Mestrado. Pontifícia Universidade Católica de São Paulo, São Paulo. 
Gaillard, J.C. \& Jigyasu, R. (2016) Measurement and evidence: whose resilience for whom? Resilience Development Initiative Working Paper Series, 11, 3-15.

Gallego-Lopez, C.; Essex, J. (2016) Understanding risk and resilient infrastructure investment. Evidence on Demand. Recuperado de: http://dx.doi.org/10.12774/eod_tg.july2016.gallegolopezessex3

Geller, E. S., Farris, J. C., \& Post, D. S. (1973). Prompting a consumer behavior for pollution control. Journal of Applied Behavior Analysis, 6, 367-376.

Geller, E. S., Winett, R. A., \& Everett, P. B. (1982). Environmental preservation: New strategies for behavior change. New York: Pergamon Press.

Gil, A. C. (2012). Delineamento da Pesquisa. In Métodos e técnicas de pesquisa social. (6 $6^{\mathrm{a}}$ ed). São Paulo: Atlas.

Glenn, S. S. (1986/2005). Metacontingências em Walden Dois. (R. C. Martone \& D. S. C. Ferreira, Trads.). Em J. C. Todorov, R. C. Martone, M. B. Moreira (Orgs.), Metacontingências: comportamento, cultura e sociedade. Santo André: ESETec.

Glenn, S. S., Malott, M. E., Andery, M. A. P. A., Benvenuti, M., Houmanfar, R. A., Sandaker, I.. \& Vasconcelos, L. A. (2016). Toward Consistent Terminology in a Behaviorist Approach to Cultural Analysis. Behavior and Social Issues, 25, 11-27.

Gonçalves, C. D. (2016). "Desastres naturais”. Algumas considerações: vulnerabilidade, risco e resiliência. Territorium, 19, 5-14.

Grant, T. M. (2014) Behavior Analysis on a Cultural Level: Changes in Recycling Rates as a Function of Posted Rules (Dissertação de Mestrado). Saint Louis University.

Guha-Sapir, D., P. Hoyois, \&R. Below. (2014). Annual disaster statistical review 2013: The numbers and trends. Centre for Research on the Epidemiology of Disasters. Recuperado de: http://www.cred.be/ sites/default/files/ADSR_2013.pdf.

Gusso, H.L., Sampaio, A.A. S. (2011) Sustentabilidade e aquecimento global: A análise do comportamento pode ajudar? Boletim Contexto, 34, 10-18.

Hayes, S. C., \& Cone, J. D. (1981). Reduction of residential consumption of electricity through simple monthly feedback. Journal of Applied Analysis of Behavior, 14, 81-88. http://dx.doi.org/10.1901/jaba.1981.14-81

Heward, W. L. \& Chance, P. (2010). Climate change: Meeting the challenge. The Behavior Analyst, 33(2), 197-206.

Jacobs, H. E., Bailey, J. S., \& Crews, J. I. (1984). Development and analysis of a communitybased resource recovery. Journal of Applied Behavior Analysis, 17, 127-145.

Keller, J. J. (2010). The recycling solution: How I increased recycling on Dilworth Road. The Behavior Analyst, 33, 171-173. (Trabalho original publicado em 1991). 
Kill, R. F. (2016). Análise de Metacontingências da Lei 12.608/12 que Define a Política Nacional de Proteção e Defesa Civil (Dissertação de Mestrado). Universidade de Brasília.

Lamal, P. A. (1991). Three metacontingencies in the pre-perestroika Soviet Union. Behavior and Social Issues, 1, 75-90

Lamal, P. A., \& Greenspoon, J. (1992). Congressional metacontingencies. Behavior and Social Issues, 2, 71-81.

Lehman, P. K. \& Geller, E. S. (2004). Behavior analysis and environmental protection: Accomplishments and potential for more. Behavior and Social Issues, 13, 13-32.

Lei no 12.608/2012. (2012). Política Nacional de Proteção e Defesa Civil (PNPDEC). Recuperado em: http://www.planalto.gov.br/ccivil_03/_Ato2011-2014/2012/Lei/L12608.htm

Leite, F. L. (2009). Efeitos de instruções e história experimental sobre a transmissão de práticas de escolha em microculturas de laboratório. Dissertação de Mestrado, Universidade Federal do Pará, PA.

Lovell, E., Bahadur, A., Tanner, T., Morsi, H. (2016) Resilience The Big Picture Tops Themes and Trends. The Rockfeller Foundation. Recuperado de https://www.odi.org/publications/10446-resilience-big-picture-top-themes-and-trends.

Maier, S. F., \& Seligman, M. E. P. (1976). Learned helplessness: Theory and evidence. Journal of Experimental Psychology: General, 105(1), 3-46

Martins, A. L. A. (2009). O Sistema Único de Saúde: contingências e metacontingências nas Leis Orgânicas de Saúde. Dissertação de mestrado, Universidade de Brasília.

Martins, M. H., Tavanti, R. M., \& Spink, M. J. P. (2016). Versões de vulnerabilidade em artigos científicos brasileiros sobre desastres ambientais. Athenea Digital. Revista de pensamiento e investigación social, 16(3), 347-366.

Matos, M. A. (2001). Comportamento governado por regras. Revista Brasileira de Terapia Comportamental e Cognitiva, 3(2), 51-66.

Martone, R. C., \& Todorov, J. C. (2012). O desenvolvimento do conceito de metacontingência. Revista Brasileira de Análise do Comportamento,3(2), 181-190.

McMakin, A. H., Malone, E. L., \& Lundgren, R. E., (2002). Motivating residents to conserve energy without financial incentives. Environment and Behavior, 34, 848- 836. http://dx.doi.org/10.1177/001391602237252.

Meyer, S. (2003). Análise funcional do comportamento. Primeiros passos em análise do comportamento e cognição, 75-91.

Miller, L. K. (1968)Escape from na effortful situation. Journal of the Experimental Analysis of Behavior, 11, 619-627.

Nevin, J. A. (2010). The power of cooperation. The Behavior Analyst, 33(2), 189. 
Pereira, D. M., Szlafsztein, C. F., \& Araújo, F. A. (2016). Avaliação de Risco de Desastres na Bacia Hidrográfica do Rio Purus (Brasil) com Base em Índices Compostos. Revista da ANPEGE, 12(17), 167-190.

Peters \& Thomas (2016) Resilience across the post-2015 frameworks: how to create greater coherence. ODI Working Paper. Recuperado em https://www.odi.org/sites/odi.org.uk/files/resource-documents/11006.

Poterie, A. T., \& Baudoin, M. A. (2015). From Yokohama to Sendai: Approaches to participation in international disaster risk reduction frameworks. International Journal of Disaster Risk Science, 6(2), 128-139.

Prudêncio, M. G. A. (2006). Leis e Metacontingências: Análise do controle do Estatuto da Criança e do Adolescente sobre práticas Jurídicas em Processos de Infração de Adolescentes no Distrito Federal. Dissertação de Mestrado. Universidade de Brasília.

Rakos, R. F. (1991). Perestroika, Glasnost, and internacional cooperation: a behavior analysis. Behavior and Social Issues, 1, 91-101

Rodrigues, T. (2010). Notas. Notícias e recensões: A Estratégia Internacional de Redução de Desastres. Revista Territorium, 17, 223 - 227.

Rockefeller Foundation (2016) Resilience. Washington: The Rockefeller Foundation. Recuperado de www.rockefellerfoundation.org/our-work/topics/resilience

Saconatto, A. T., \& Andery, M.A.P.A. (2013). Seleção por metacontingências: um análogo experimental de reforçamento negativo. [Selection by metcontingencies: An experimental analog of negative reinforcement.] Interação em Psicologia, 17, 1-10

Schinko, T., Mechler, R., \& Hochrainer-Stigler, S. (2016). A methodological framework to operationalize climate risk management: managing sovereign climate-related extreme event risk in Austria. Mitigation and Adaptation Strategies for Global Change, 1-24.

Schultz, P. W. (1998). Changing behavior with normative feedback interventions: A field experiment on curbside recycling. Basic and Applied Social Psychology, 21, 2536.http://dx.doi.org/10.1207/s15324834basp2101_3.

Siebert, C. (2012). Resiliência urbana: planejando as cidades para conviver com fenômenos climáticos extremos. Anais do VI ENAPPAS. Belém, Pará.

Sidman, M. (1995). Coerção e suas implicações (Tradução de Maria Amália Andery \& Teresa Maria Sério). Campinas: Editora Livro Pleno.(Obra original publicada em 1989).

Silva, C. H. R. T (2012) Desastres Naturais e Desenvolvimento Sustentável. Núcleo de Estudos e Pesquisas, Consultoria Legislativa, Senado Federal. Recuperado de https://www12.senado.leg.br/publicacoes/estudos-legislativos/tipos estudos/outraspublicacoes/temas-e-agendas-para-o-desenvolvimento-sustentavel/desastresnaturais-e desenvolvimento-sustentavel.

Skinner, B.F. (1957) Verbal Behavior. New York: Appleton-Century-Crofts. 
Skinner, B. F. (1972) Walden II: Uma Sociedade do Futuro. São Paulo: Herder.

Skinner, B. F. (1981). Selection by consequences. Science, 213, 501-504, http://dx.doi.org/10.1017/S0140525X0002673X.

Skinner, B.F. (1990) Can Psychology Be a Science of Mind? American Psychologist, 45 (11), 1206-1210, http://dx.doi.org/10.1037/0003-066X.45.11.1206.

Staats, H., van Leeuwen, E., \& Wit, A. (2000). A longitudinal study of informational interventions to save energy in an office building. Journal of Applied Behavior Analysis, 33, 101-104. http://dx.doi.org/10.1901/jaba.2000.33-101.

Toledo, T. F. N., \& Benvenuti, M. F. L. (2016). Efeitos da Exigência de Desempenhos Entrelaçados Sobre Linha de Base em Esquema Simples de Reforço. Revista Brasileira de Análise do Comportamento, 11(2), 184-194.

Toledo, T. F. N., Benvenuti, M. F. L., Sampaio, A. A., Marques, N. S., dos Anjos Cabral, P. A., de Souza Araújo, L. A. \& Moreira, L. R. (2015). Free culturant: A software for the experimental study of behavioral and cultural selection. Psychology \& Neuroscience, 8(3), 366 - 384.

Tominaga, L. K.; Santoro, J.; Amaral, R. (Orgs). (2009). Desastres naturais: conhecer para prevenir. São Paulo: Instituto Geológico.

Thompson, S. C., \& Stoutemyer, K. (1991). Water as a commons dilemma The effects of education that focuses on long-term consequences and individual action. Environment and Behavior, 23, 314-333. http://dx.doi.org/10.1177/0013916591233004.

Thompson, L. G. (2010). Climate change: The evidence and our options. The Behavior Analyst, $33(2), 153-170$.

Todorov, J. C. (1987/2005) A Constituição como Metacontingência. Em J. C. Todorov, R. C.Martone, M. B. Moreira (Orgs.) Metacontingências: comportamento, cultura e sociedade. Santo André: ESETec.

Todorov, J.C. (2012) Contingências de seleção cultural. Revista Brasileira de Análise do Comportamento, 8 (2), 95-105.

Todorov, J. C.; Moreira, M.; Prudêncio, M. R. A. \& Pereira, G. C. C. (2004). O Estatuto da Criança e do Adolescente como metacontingência. In: M. Z. S. Brandão; F. C. S. Conte; F. S. Brandão; Y. K. Ingberman; V. L. M. Silva; S. M. Oliani (orgs). Sobre Comportamento e Cognição: contingências e metacontingências, contextos sócioverbais e o comportamento do terapeuta, 44-51. Santo André: ESETec.

UNISDR (2005) Marco de Ação de Hyogo 2005-2015: Aumento da resiliência das nações e das comunidades frente aos desastres. Genebra: UNISDR.

UNISDR (2009). Terminology on disaster risk reduction. Genebra, ONU.

UNISDR (2010). Como Construir Cidades Mais Resilientes: Um Guia Para Gestores Públicos Locais. Uma contribuição à Campanha Global 2010-2015. Genebra: UNISDR. 
UNISDR (2012). Como Construir Cidades Mais Resilientes - Um Guia Para Gestores Públicos Locais. Uma contribuição à Campanha Global 2010 - 2015 Construindo Cidades Resilientes - Minha cidade está se preparando 2005-2015. Genebra. Recuperado de: http://www.unisdr.org/files/26462_guiagestorespublicosweb.pdf

UNISDR (2015) Marco de Sendai para a Redução do Risco de Desastres 2015-2030. Genebra: UNISDR.

UNISDR (2015) Proposed Updated Terminology on Disaster Risk Reduction: A Technical Review Facilitated. Recuperado em 20 de janeiro de 2017 de http://www.preventionweb.net/files/45462_backgoundpaperonterminologyaugust20.

Vale, O. C (2016) Metacontingências na novela Salve Jorge: A mídia televisiva no enfrentamento do tráfico de pessoas. Dissertação de mestrado, Universidade de Brasília.

Vasconcelos, I. G., Todorov, J. C. (2015) Experimental Analysis of The Behavior os Persons um Groups: Selection of na Aggregate Product in a Metacontingency. Behavior and Social Issues, $24,111-125$.

Vasconcelos, L. A. (1995). Considerações sobre eventos radioativos e seus efeitos psicossociais. Psicologia: Teoria e Pesquisa, 11(3), 243-248.

Vasconcelos, L.A., Gimenes, L. S. (1999) Efeitos da Radiação Ionizante Sobre Comportamentos Mantidos por Contingências Operantes. Psicologia: Teoria e Pesquisa, 15 (3), 219-225.

Vichi, C. (2005). Igualdade ou Desigualdade: Manipulando um análogo experimental de prática cultural em laboratório. In: J. C. Todorov, R. C. Martone, M. B. Moreira (Orgs.), Metacontingências: comportamento, cultura e sociedade, 81-100. SantoAndré: ESETec.

Vichi, C., \& Tourinho, E. Z. (2012). Consequências culturais x consequências comportamentais na literatura experimental de pequenos grupos. Acta Comportamentalia, 20, 201-215.

Vichi, C., Andery, M. A. P. A., \& Glenn, S. S. (2009). A metacontingency experiment: The effects of contingent consequences on patterns of interlocking contingencies of reinforcement. Behavior and Social Issues, 18, 41-57.

Vieira, M. C., Andery, M. A. P. A., \& Pessôa, C. V. Condições antecedentes em metacontingências. Acta Comportamentalia: Revista Latina de Análisis del Comportamiento, 24(4).

Ximenes, E. F., Freitas, C. M. \& Cerutti, D. (2014) Glossário da Estratégia Internacional para Redução de Desastres. Recuperado em: 27 de junho de 2016, de http://www.fiocruz.br/omsambiental/cgi/cgilua.exe/sys/start.htm?infoid=293\&sid=15

Weiner, H. (1965). Real and imagined cost effects upon human fixed-interval responding. Psychological Reports, 17, 659-662

Werner, C. M., Turner, J., Shipman, K., Twitchel, F. S., Dickson, B. R., Bruschke, G. V., von Bismark, W. B. (1995). Commitment, behavior and attitude change: Na analysis of voluntary 
recycling. Journal of Environmental Psychology, 15, 197-208. http://dx.doi.org/10.1016/0272-4944(95)90003-9.

Winett, R. A., Hatcher, J. W., Fort, T. R., Leckliter, L. N., Love, S. Q., Riley, A. W., et al. (1982). The effects of videotape modeling and daily feedback on residential electricity conservation, home temperature and humidity, perceived comfort, and clothing worn: Winter and summer. Journal of Applied Behavior Analysis, 15, 381- 402. 


\section{Anexos}

\section{Anexo A - Critérios ou questões-chaves da Ferramenta de Autoavaliação do Governo Local (LGSAT) utilizados para avaliar as providências estabelecidas para cada um dos 10 passos da Campanha de cidades resilientes}

\begin{tabular}{|c|c|c|}
\hline \multicolumn{2}{|c|}{ PASSO } & Questões-chave ou critérios \\
\hline 1 & 1. & $\begin{array}{l}\text { Até que ponto as organizações locais (incluindo o governo local) estão capacitadas } \\
\text { (conhecimento, experiência, mandato oficial) para a redução de risco de desastres e adaptação } \\
\text { à mudança climática? }\end{array}$ \\
\hline & 2. & $\begin{array}{l}\text { Até que ponto existem parcerias entre as comunidades, setor privado e autoridades Locais para } \\
\text { reduzir o risco? }\end{array}$ \\
\hline & 3. & $\begin{array}{l}\text { Quanto o governo local apoia comunidades vulneráveis locais (especialmente mulheres, } \\
\text { idosos, enfermos, crianças) a participarem ativamente na tomada de decisão sobre a redução de } \\
\text { risco, formulação de políticas, planejamento e processos de implantação? }\end{array}$ \\
\hline & 4. & $\begin{array}{l}\text { Até que ponto o governo local participa do planejamento nacional da Redução de Risco de } \\
\text { Desastres? }\end{array}$ \\
\hline \multirow[t]{6}{*}{2} & 5. & $\begin{array}{l}\text { Até que ponto o governo local tem acesso a recursos financeiros adequados para realizar as } \\
\text { atividades de redução de risco? }\end{array}$ \\
\hline & 6. & $\begin{array}{l}\text { Até que ponto o governo local aloca recursos financeiros suficientes para realizar atividades de } \\
\text { Redução de Risco de Desastres incluindo resposta efetiva a desastres e recuperação? }\end{array}$ \\
\hline & 7. & $\begin{array}{l}\text { Qual é a extensão dos serviços financeiros (por exemplo, esquemas de poupança e crédito, } \\
\text { macro e microsseguro) disponíveis para as famílias vulneráveis e marginalizadas instaladas em } \\
\text { áreas de risco? }\end{array}$ \\
\hline & 8. & $\begin{array}{l}\text { Até que ponto o micro financiamento, auxílio em dinheiro, empréstimos facilitados, garantias } \\
\text { de empréstimos, etc. estão disponíveis para que as famílias afetadas possam reiniciar os meios } \\
\text { de subsistência após desastres? }\end{array}$ \\
\hline & 9. & $\begin{array}{l}\text { Como os incentivos econômicos para investir na redução de risco de desastres para as famílias } \\
\text { e empresas (prêmios de seguro reduzidos para as famílias, isenções fiscais para as empresas) } \\
\text { são estabelecidos? }\end{array}$ \\
\hline & 10. & $\begin{array}{l}\text { Até que ponto as associações empresariais locais, como câmaras de comércio e similares, } \\
\text { apoiam empenhos às pequenas empresas para a continuidade dos negócios durante e após os } \\
\text { desastres? }\end{array}$ \\
\hline \multirow[t]{5}{*}{3} & 11. & $\begin{array}{l}\text { Até que ponto o governo local realizou avaliações de risco de desastres completos para os } \\
\text { principais setores de desenvolvimento vulneráveis em sua autoridade local? }\end{array}$ \\
\hline & 12. & $\begin{array}{l}\text { Até que ponto essas avaliações de risco são regularmente atualizadas, por exemplo, } \\
\text { anualmente, ou em uma base bi-anual? }\end{array}$ \\
\hline & 13. & $\begin{array}{l}\text { Com que regularidade o governo local transmite para a comunidade informações sobre as } \\
\text { tendências locais de ameaças e medidas de redução de risco (utilizando um Plano de } \\
\text { Comunicação de Risco, por exemplo), incluindo avisos prévios de provável impacto de risco? }\end{array}$ \\
\hline & 14. & $\begin{array}{l}\text { Até que ponto as avaliações de risco locais, estão associadas e apoiadas nos conhecimentos e } \\
\text { avaliações comunitárias e nos planos de gestão nacionais e estaduais? }\end{array}$ \\
\hline & 15. & $\begin{array}{l}\text { De que maneira as avaliações de risco de desastres estão incorporadas em todos os planos de } \\
\text { desenvolvimento local relevante de uma forma consistente? }\end{array}$ \\
\hline \multirow[t]{2}{*}{4} & 16. & $\begin{array}{l}\text { Até que ponto as políticas de uso do solo e os regulamentos de planejamento para habitação e } \\
\text { infra-estrutura de desenvolvimento levam o risco de desastre atual e o projetado (incluindo os } \\
\text { riscos relacionados com o clima) em conta? }\end{array}$ \\
\hline & 17. & Quão adequadamente equipamentos públicos críticos e infraestruturas localizados em áreas de \\
\hline
\end{tabular}




\begin{tabular}{|c|c|c|}
\hline & 18. & $\begin{array}{l}\text { alto risco recebem avaliações de risco para todos os tipos de ameaça e de segurança? } \\
\text { Quão adequadas são as medidas que estão sendo tomadas para proteger instalações públicas e } \\
\text { de infra-estrutura críticas aos danos provocados por desastres? }\end{array}$ \\
\hline \multirow[t]{6}{*}{5} & 19. & $\begin{array}{l}\text { Até que ponto as escolas, hospitais e unidades de saúde recebem atenção especial para } \\
\text { avaliações de risco para "todas as ameaças" em sua autoridade local? }\end{array}$ \\
\hline & 20. & Quão seguras são todas as principais escolas, hospitais e unidades de saúde em relação a \\
\hline & Ta & a 1A (Continuação) \\
\hline & 21. & desastres de forma que tenham capacidade de se manter operacionais durante emergências? \\
\hline & 22. & $\begin{array}{l}\text { Até que ponto o governo local ou outros níveis de governo têm programas especiais para } \\
\text { avaliar regularmente escolas, hospitais e unidades de saúde acerca da manutenção, } \\
\text { cumprimento dos códigos de construcão, seguranca geral, riscos relacionados ao clima, etc? }\end{array}$ \\
\hline & & $\begin{array}{l}\text { Até que ponto os simulados e exercícios regulares de preparação para desastres são realizados } \\
\text { em escolas, hospitais e centros de saúde? }\end{array}$ \\
\hline \multirow[t]{2}{*}{1.} & 23. & $\begin{array}{l}\text { Até que ponto os regulamentos de uso e ocupação do solo para áreas de risco, e os códigos de } \\
\text { construção, de segurança e de saúde são aplicados em todas as zonas de desenvolvimento e } \\
\text { tipos de construção? }\end{array}$ \\
\hline & 24. & $\begin{array}{l}\text { Quão fortes são os regulamentos existentes (planos de uso e ocupação do solo, códigos de } \\
\text { construção, etc) para apoiar a redução de risco de desastres locais? }\end{array}$ \\
\hline \multirow[t]{4}{*}{2.} & 25. & $\begin{array}{l}\text { Com que regularidade o governo local conduz programas de conscientização e educação sobre } \\
\text { Redução de Risco de Desastres e prevenção de catástrofes para as comunidades locais? }\end{array}$ \\
\hline & 26. & $\begin{array}{l}\text { Até que ponto o governo local oferece treinamento em redução de risco para as autoridades } \\
\text { locais e líderes comunitários? }\end{array}$ \\
\hline & 27. & $\begin{array}{l}\text { Até que ponto as escolas e faculdades locais incluem cursos, educação ou treinamento na } \\
\text { redução do risco de desastres (incluindo os riscos relacionados com o clima), como parte do } \\
\text { currículo de educação? }\end{array}$ \\
\hline & 28. & $\begin{array}{l}\text { Quão conscientes estão os cidadãos dos planos de abandono ou exercícios para evacuações, } \\
\text { quando necessários? }\end{array}$ \\
\hline \multirow[t]{4}{*}{3.} & 29. & $\begin{array}{l}\text { Até que ponto as políticas de Redução de Risco de Desastre de governo locais, estratégias e } \\
\text { planos de implantação são integrados com o desenvolvimento ambiental e planos de gestão dos } \\
\text { recursos naturais existentes? }\end{array}$ \\
\hline & 30. & $\begin{array}{l}\text { Até que ponto o governo local apoia a restauração, proteção e gestão sustentável dos serviços } \\
\text { ambientais? }\end{array}$ \\
\hline & 31. & $\begin{array}{l}\text { Quanto que as organizações da sociedade civil e os cidadãos participam na proteção, } \\
\text { restauração e gestão sustentável dos serviços dos ecossistemas? }\end{array}$ \\
\hline & 32. & $\begin{array}{l}\text { Quanto o setor privado participa na implantação de planos de gestão ambientais e de } \\
\text { ecossistemas em seu município? }\end{array}$ \\
\hline \multirow[t]{6}{*}{4.} & 33. & $\begin{array}{l}\text { Até que ponto as instituições locais têm acesso às reservas financeiras para providenciar } \\
\text { resposta efetiva a desastres e recuperação rápida? }\end{array}$ \\
\hline & 34. & $\begin{array}{l}\text { Até que ponto os centros de alerta estão estabelecidos, com pessoal adequado (ou pessoal de } \\
\text { plantão) e com recursos suficientes (back ups de energia, redundância de equipamentos etc ) o } \\
\text { tempo todo? }\end{array}$ \\
\hline & 35. & Quanto que os sistemas de alerta e alarme permitem a participação adequada da comunidade? \\
\hline & 36. & $\begin{array}{l}\text { Até que ponto o governo local tem um centro de operações de emergência (COE) e / ou um } \\
\text { sistema de comunicação de emergência? }\end{array}$ \\
\hline & 37. & $\begin{array}{l}\text { Com que regularidade os exercícios simulados são realizados com a participação de } \\
\text { organizações governamentais, não governamentais, líderes locais e voluntários relevantes? }\end{array}$ \\
\hline & 38. & $\begin{array}{l}\text { Quão disponíveis são os recursos-chave para uma resposta eficaz, tais como suprimentos de } \\
\text { emergência, abrigos de emergência, rotas de abandono dentificadas e planos de contingência } \\
\text { permanentes? }\end{array}$ \\
\hline \multirow[t]{3}{*}{5.} & 39. & $\begin{array}{l}\text { Qual o investimento que o governo local faz em recursos e conhecimentos para ajudar as } \\
\text { vítimas de impactos psico-sociais (psicológico, emocional) dos desastres? }\end{array}$ \\
\hline & 40. & $\begin{array}{l}\text { Até que ponto as medidas para redução de risco de desastres estão integradas a ações de } \\
\text { recuperação pós-desastre e atividades de reabilitação (ou seja, reconstruir melhor, subsistência } \\
\text { de reabilitação?) }\end{array}$ \\
\hline & 41. & $\begin{array}{l}\text { Até que ponto o Plano de Contingência (ou plano similar) inclui um esquema para a } \\
\text { recuperação pós-catástrofe e reconstrução, incluindo avaliação das necessidades de } \\
\text { reabilitação e meios de subsistência? }\end{array}$ \\
\hline
\end{tabular}




\section{Anexo B - Dados obtidos da cidade de Campinas-SP, nos dois ciclos da Campanha, seguidos das notas de autoavaliação dos critérios da ferramenta LGSAT}

\section{Tabela B1}

Passo 1 dos 10 Passos da Campanha "Construindo cidades Resilientes: Minha cidade está se preparando", e os dados obtidos em Campinas-SP, de acordo com os critérios de autoavaliação e seus respectivos níveis de avanço, nos ciclos 1 e 2 da Campanha.

\footnotetext{
Campanha Construindo Cidades Resilientes: Minha cidade está se preparando - ONU 2010-2015

Passo 1: Quadro institucional e Administrativo

Coloca em prática ações de organização e coordenação para compreender e aplicar ferramentas de redução de risco de desastres com base na participação de grupos de cidadãos e da sociedade civil. Construa alianças locais. Assegure que todos os departamentos compreendam o seu papel na redução de riscos de desastres e preparação.
}

\section{Dados de Campinas - São Paulo}

Critério 1: Até que ponto as organizações locais (incluindo o governo local) estão capacitadas (conhecimento, experiência, mandato oficial) para a redução de risco de desastres e adaptação à mudança climática?

Relatório 2011-2013, $1^{\circ}$ ciclo, nível de progresso alcançado: 5

$\rightarrow$ Reorganizações do Sistema Municipal de Proteção e Defesa Civil (SIMPDEC).

- Em 2005: parceria com instituições de ensino e pesquisa para realizar capacitação e aperfeiçoamento de recursos humanos nas ações de prevenção e respostas aos desastres - SIMDEC.

- Decreto 17.783 de 28 de novembro de 2012: O Sistema deve se responsabilizar pelo planejamento, articulação, coordenação e execução de programas de defesa contra desastres. O SIMPDEC, agora ligado ao gabinete do prefeito, passou a coordenar as ações relacionadas com a redução de desastres e investiu em mapeamento de áreas de risco e capacitação e aperfeiçoamento de recursos humanos, voltado para o cumprimento de metas do estudo de Prospecção de Cenários.

$\rightarrow$ Em 2005, Prefeitura - estudo de Prospecção de Cenários para um período de 10 anos. Missão: analisar o estudo "Defesa Civil na Redução de Desastres".

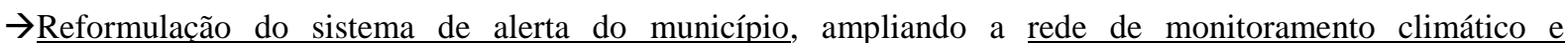
meteorológico (42 sensores, 2 radares meteorológicos) e o quadro de servidores (de 35 para 72). Ferramentas de sistema de alerta de Defesa Civil que realiza adaptação e transmissão de dados para o TerraMA2 desenvolvido pelo Instituto Nacional de Pesquisas Espaciais (INPE).

$\rightarrow$ Desde 2005 - Programa de capacitação continuada de servidores e da comunidade em geral, com cursos gratuitos e vagas disponibilizadas para 32 municípios do Estado de São Paulo

Relatório 2013-2014, $2^{\circ}$ ciclo, nível de progresso alcançado: 5

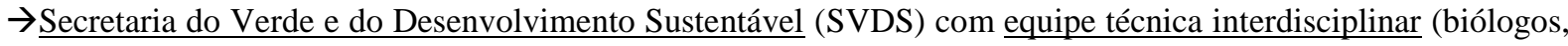
geógrafos, ecólogos e geólogos) qualificados para estudar, propor e implementar medidas efetivas para a redução de risco de desastres e adaptação às mudanças climáticas.

- Participa da Operação Verão e da Operação Estiagem;

- Emite autorização para intervenções em Áreas de Preservação Permanente (APP);

- Vistorias de processos erosivos ou córregos urbanos assoreados; e

- Consolida Bancos de Áreas Verdes (BAV - espaços especialmente protegidos do município).

$\rightarrow$ Decreto $N^{\circ} 18.045$ de 24 de julho de 2013 - criação do Comitê da Cidade Resiliente (CCR), vinculado à Secretaria Municipal de Chefia de Gabinete do Prefeito (SMCGB), coordenado por esta Secretaria, por intermédio do Departamento de Defesa Civil. 


\section{TABELA B1 (Continuação)}

- Competências: promover a articulação conjunta das diversas estratégias de redução de desastres no município; analisar as informações coletadas e armazenadas pelos órgãos da Administração Pública e a comunidade em geral relacionadas com a redução de desastres; criar o Observatório da Cidade Resiliente; discutir conjuntamente os problemas, o intercâmbio de informações, a definição de prioridades de ação e a articulação dos programas de redução de desastres no âmbito municipal; promover a integração e cooperação das relações e ações dos múltiplos órgãos das diferentes entes da federação (município, estado e União), e apoiar outros municípios que aderiram à Campanha Cidades Resilientes.

- Atribuições: disponibilizar informações referentes às ações de redução de desastres para divulgação no Observatório da Cidade Resiliente; elaborar relatório do progresso local sobre a implementação do Quadro de Ação de Hyogo.

$\rightarrow$ Decreto $N^{\circ} 17.921$ de 27 de março de 2013 - Criação do Projeto de Proteção Comunitária, vinculado ao Sistema Municipal de Proteção e Defesa Civil (SIMPDEC).

- Conta com a participação de voluntários dos órgãos de apoio do SIMPDEC ou cidadãos voluntários, brasileiros ou estrangeiros, maiores de 18 anos de idade, preferencialmente vinculados e indicados formalmente pelas associações de moradores, clubes de serviços ou outras entidades filantrópicas.

- Anualmente o Departamento de Defesa Civil promove o Curso de Capacitação de Voluntário de Defesa Civil (CVDC) e o Curso de Aperfeiçoamento de Voluntários em Defesa Civil (CADC) com validade para 02 (dois) anos

$\rightarrow$ 27/12/2013 - Instalação de sensor de enchente comunitário, acoplado ao sistema de alarme central, importante para situações que exigem rápida saída de moradores da área de inundação.

$\rightarrow$ Departamento de Limpeza Urbana (DLU), com apoio técnico e logístico do Consórcio Tecnologia Ambiental - implantação dos ecopontos, minimizando os impactos negativos de lançamento de resíduos em locais públicos e conscientizar a população sobre a continuidade da responsabilidade sobre o resíduo gerado.

Critério 2: Até que ponto existem parcerias entre as comunidades, setor privado e autoridades locais para reduzir o risco?

Relatório 2011-2013, $1^{\circ}$ ciclo, nível de progresso alcançado: 5

$\rightarrow$ A reorganização do SIMPDEC em 2012 instituiu a sua composição pelos órgãos da administração pública municipal, empresas de economia mista, autarquias, entidades privadas e comunidade, sob a coordenação do Departamento de Defesa Civil.

\section{Relatório 2013-2014, $2^{\circ}$ ciclo, nível de progresso alcançado: 5}

$\rightarrow$ Secretaria Municipal de Habitação (SEHAB) - parcerias com a comunidade com reuniões informativas e de orientação. Monitoramento das áreas passíveis de ocupação, visando prevenir adensamento nas áreas de risco. Parceria junto a entidades representativas de famílias como Associação de Moradores, Sociedade Amigos de Bairro, buscando evitar novas ocupações de áreas de risco.

$\rightarrow$ Secretaria Municipal de Cidadania, Assistência e Inclusão Social (SMCAIS) - equipe técnica participa de treinamento e ações promovidas pela Defesa Civil, comunidades, setor privado e autoridades locais, orientando e prevenindo riscos de desastres.

Critério 3: Quanto governo local apoia comunidades vulneráveis locais (especialmente mulheres, idosos, enfermos, crianças) a participarem ativamente na tomada de decisão sobre a redução de risco, formulação de políticas, planejamento e processos de implantação?

Relatório 2011-2013, $1^{\circ}$ ciclo, nível de progresso alcançado: 5

$\rightarrow$ Formação de Núcleos Comunitários de Defesa Civil (NUDEC), conforme estabelecido no SIMPDEC, com o objetivo de propiciar o envolvimento das comunidades que estão em situação de risco no processo de conscientização e mudança cultural nas áreas de segurança social e preservação ambiental. 


\section{TABELA B1 (Continuação)}

\section{Relatório 2013-2014, $2^{\circ}$ ciclo, nível de progresso alcançado: 5}

$\rightarrow \underline{\text { SEHAB }}$ - Prioridade da titularidade das mulheres no recebimento de unidades habitacionais; o Artigo $2^{\circ}$ do Programa Auxílio Moradia (Lei Municipal 13.197/2007) dispõe sobre a prioridade de titularidade para vítimas de violência de gênero.

$\rightarrow \underline{\text { SMCAIS }}$ - Serviços preventivos de apoio em comunidades que se encontram em situação de risco (em especial aos que se encontram mais vulneráveis como mulheres, crianças e idosos), por meio das Proteções Básica e Especial (DAS, CRAS, CREAS), e serviço de acolhimento institucional para atendimento da população em situações emergenciais e de calamidades.

Critério 4: Até que ponto o governo local participa do planejamento nacional da Redução de Risco de Desastres?

Relatório 2011-2013, $1^{\circ}$ ciclo, nível de progresso alcançado: 5

$\rightarrow$ A Política Nacional de Proteção e Defesa Civil (PNPDC), instituída pela Lei 12608 de 10 de abril de 2012, dispõe sobre o Sistema Nacional de Proteção e Defesa Civil (SINPDEC) e o Conselho Nacional de Proteção e Defesa Civil (CONPDEC).

$\rightarrow \mathrm{O}$ município de Campinas alinha-se à estratégia de Gestão de Risco e Desastres da Secretaria Nacional de Proteção e Defesa Civil (SEDEC), sendo considerado uma das cidades prioritárias para o governo federal.

\section{Relatório 2013-2014, $2^{\circ}$ ciclo, nível de progresso alcançado: 5}

$\rightarrow$ O Sistema Nacional de Proteção e Defesa Civil (SINPDEC):

- É constituído pelos órgãos e entidades da administração pública federal, dos estados, do Distrito Federal e dos municípios e pelas entidades públicas e privada de atuação significativa na área de proteção e defesa civil

- Centralizado pela Secretaria Nacional de Defesa Civil (SEDEC), órgão do Ministério da Integração Nacional, responsável por coordenar o planejamento, articulação e execução dos programas, projetos e ações de proteção e defesa civil

- Órgão consultivo: Conselho Nacional de Proteção e Defesa Civil (CONPDEC)

- Órgãos regionais de proteção e defesa civil responsáveis pela articulação, coordenação e execução do SINPDEC em nível regional.

- Órgãos estaduais e do Distrito Federal de proteção e defesa civil responsáveis pela articulação, coordenação e execução do SINPDEC em nível estadual.

- Órgãos municipais de proteção e defesa civil responsáveis pela articulação, coordenação e execução do SINPDEC em nível municipal. Órgãos setoriais dos três âmbitos de governo abrangem os órgãos, envolvidos na ação da Defesa Civil.

SINPDEC poderá mobilizar a sociedade civil para atuar em situação de emergência ou estado de calamidade pública, coordenando o apoio logístico para o desenvolvimento das ações de proteção e defesa civil. 


\section{Tabela B2}

Passo 2 dos 10 passos da "Campanha Construindo Cidades Resilientes: Minha cidade está se preparando", e os dados obtidos em Campinas-SP, de acordo com os critérios de autoavaliação e seus respectivos níveis de avanço, nos ciclos 1 e 2 da Campanha.

\section{Campanha Construindo Cidades Resilientes - ONU 2010-2015}

\section{Passo 2: Recursos e Financiamento}

Atribua um orçamento para a redução de risco de desastres e forneça incentivos para proprietários em áreas de risco, famílias de baixa renda, comunidades, empresas e setor público para investir na redução dos riscos que enfrentam.

\section{Dados de Campinas - São Paulo}

Critério 1: Até que ponto o governo local tem acesso a recursos financeiros adequados para realizar as atividades de redução de risco.

Relatório 2011-2013, $1^{\circ}$ ciclo, nível de progresso alcançado: 4

$\rightarrow$ A Secretaria Municipal de Infraestrutura (SEINFRA) desenvolveu um plano de ação, com duração de 10 anos,

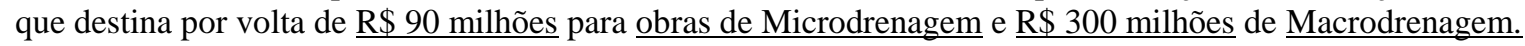

$\rightarrow$ A Secretaria Municipal de Habitação (SEHAB) recebe da Prefeitura Municipal de Campinas a parcela orçamentária de $\mathrm{R} \$ 8.400 .000 .00$, dos quais $\underline{\mathrm{R} \$ 2.000 .000,00}$ são indicados para orçamento de auxílio moradia. Vinculado a esta Secretaria, o Fundo de Apoio à População de Sub-habitação Urbana (FUNDAP) tem dotação orçamentária de $\mathrm{R} \$ 3.000 .000,00$ a ser destinado à reconstrução ou reforma das moradias de famílias afetadas por desastres.

$\rightarrow$ A Secretaria de Planejamento de Desenvolvimento Urbano (SEPLAN) reservou o orçamento de R\$ $270.000,00$ para 2012 destinados à elaboração de estudos para implementação das Macrozonas, à contratação de consultorias e impressão de cadernos que subsidiam os Planos Locais.

Relatório 2013-2014, $2^{\circ}$ ciclo, nível de progresso alcançado: 4

$\rightarrow$ A Sociedade de Abastecimento de Água e Saneamento (SANASA) tem ampliado serviços prestados para o tratamento e abastecimento de água e tratamento e afastamento de esgoto. Além disso, possui um Programa que oferece apoio técnico e operacional a inúmeros órgãos da Prefeitura Municipal de Campinas, tanto para ações preventivas como emergenciais.

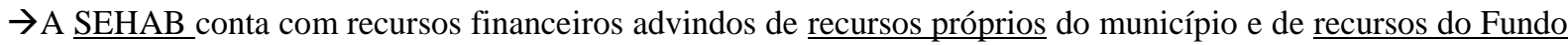
de Apoio à População de Sub-habitação Urbana (FUNDAP) e do Fundo Municipal de Habitação.

$\rightarrow$ São alocados recursos financeiros da Secretaria Municipal de Cidadania, Assistência e Inclusão Social (SMCAIS), por meio de mobilizações realizadas pelas equipes técnicas nos territórios em ações de redução de riscos.

$\rightarrow$ A Secretaria Municipal de Cooperação nos Assuntos de Segurança Pública (SMCASP) tem poucos recursos próprios e, para possibilitar melhor infraestrutura para realização de atividades de segurança pública, tem buscado a realização de convênio junto à Secretaria Nacional de Segurança Pública do Ministério da Justiça (SENASP/MJ).

Critério 2: Até que ponto o governo local aloca recursos financeiros suficientes para realizar atividades de Redução de Risco de Desastres, incluindo resposta efetiva a desastres e recuperação?

Relatório 2011-2013, $1^{\circ}$ ciclo, nível de progresso alcançado: 4

$\rightarrow$ C Cartão de Pagamento de Defesa Civil (CPDC) auxilia a Administração Pública no controle dos gastos, financiando ações da Defesa Civil com agilidade por meio de convênios com o governo federal para ações de recuperação de desastres. 


\section{TABELA B2 (Continuação)}

\section{Relatório 2013-2014, $2^{\circ}$ ciclo, nível de progresso alcançado: 4}

$\rightarrow \underline{\text { A SEHAB }}$ é responsável por realizar vistorias preventivas e emergenciais, monitoramento sistemático de prevenção, e incluir famílias no Programa Auxílio Moradia, encaminhando-as aos empreendimentos habitacionais, quando ocorre remoção imediata de uma área de risco que será objeto de recuperação ambiental.

$\rightarrow$ A SMCAIS está elaborando um Plano de Ação que será encaminhado ao Ministério de Desenvolvimento Social e Combate à Fome (MDS) para solicitar co-financiamento federal para o Serviço de Proteção em Situações de Calamidades Públicas e Emergenciais, conforme a Resolução do Conselho Nacional de Assistência Social (CNAS) de 12 de junho de 2013.

$\rightarrow$ A Secretria Municipal de Serviços Públicos (SMSP) coordena serviços considerados ações de prevenção de riscos de desastres, tais como limpeza urbana, conservação e manutenção de áreas verdes, urbanização, reformas de praças, arborização urbana (poda, extração e replantio); limpeza e manutenção de escolas e creches municipais; manutenção permanente de ruas de terra; recape e fresagem das principais vias; e manutenção permanente de buracos em vias públicas.

Critério 3: Qual é a extensão dos serviços financeiros (por exemplo, esquemas de poupança e crédito, macro e microsseguro) disponíveis para as famílias vulneráveis e marginalizadas instaladas em áreas de risco? Relatório 2011-2013, $1^{\circ}$ ciclo, nível de progresso alcançado: 3

$\rightarrow$ Criação do Fundo de Apoio à População de Subhabitação Urbana (FUNDAP), o qual capta e distribui recursos a serem concedidos como empréstimos para famílias moradoras de favelas em processo de urbanização. Além disso, o município conta com o Auxílio Moradia, uma ajuda de custo para famílias atingidas por desastres ou removidas de áreas de risco, para o pagamento de aluguel.

\section{Relatório 2013-2014, $2^{\circ}$ ciclo, nível de progresso alcançado: 3}

\section{$\rightarrow \underline{\text { SMCAIS: }}$}

- Em caso de emergência e calamidades, oferta programas de transferência de renda e inclusão em benefícios socioassistenciais, como Bolsa Família, Programa de Erradicação do Trabalho Infantil (PETI), Beneficio da Prestação Continuada (BPC);

- "Renda Cidadã", um programa de concessão temporária de renda para famílias com renda per capita mensal de até meio salário mínimo, visando a sua autossustentação;

- O Programa Ação Jovem oferta bolsa aos jovens agregada à formação social e em cultura digital, visando a preparação do bolsista para o atendimento a comunidade;

- O município também disponibiliza serviços financeiros para as famílias, como crédito, macro e microsseguro;

- Articula-se com as demais secretarias para garantir o encaminhamento das linhas de crédito disponíveis pelo Banco Popular da Mulher, vinculado à Secretaria Municipal de Trabalho e Renda e ao Fundo de Apoio à População de Sub-habitação Urbana (FUNDAP).

$\rightarrow \underline{\text { Secretaria Municipal de Trabalho e Renda (SMTR): }}$

- Início da reestruturação do Programa Municipal de Economia Solidária, com o objetivo de aumentar a capacidade de reciclagem das cooperativas e melhorar as condições de trabalho dos cooperados;

- Inauguração do CPAT Campo Grande - atender a demanda de uma região com mais de 145 mil habitantes. A ação faz parte do plano de governo, de descentralizar os serviços públicos e aproximar a prestação de serviços da população. Até o momento, mais de 3 mil pessoas já foram atendidas na nova unidade;

- O CPAT já ofereceu, no ano de 2013, 12.058 vagas de trabalho, um aumento de $16 \%$ em relação a 2012 ; 


\section{TABELA B2 (Continuação)}

- O Banco Popular da Mulher, uma entidade solidária municipal sem fins lucrativos, oferece linhas de crédito com reduzidas taxas de juros para empreendedores que não têm acesso ao sistema financeiro tradicional e desejam ampliar seu próprio negócio.

Critério 4: Até que ponto o micro-financiamento, auxílio em dinheiro, empréstimos facilitados, garantias de empréstimos, etc. estão disponíveis para que as famílias afetadas possam reiniciar os meios de subsistência após desastres?

Relatório 2011-2013, $1^{\circ}$ ciclo, nível de progresso alcançado: 3

$\rightarrow$ A SMTR realoca recursos para viabilizar convênios para instalação do Centro de Economia solidária. Esta Secretaria, em parceria com a Secretaria Municipal de Desenvolvimento Econômico, desenvolve proposta de acordo com o tipo de desastre, e a partir da decretação de Situação de Emergência ou Estado de Calamidade Pública.

Relatório 2013-2014, $2^{\circ}$ ciclo, nível de progresso alcançado: 3

$\rightarrow$ A linha de crédito existente no FUNDAP atende de forma satisfatória as demandas que são encaminhadas à SEHAB.

Critério 5: Como os incentivos econômicos para investir na redução de risco de desastres para as famílias $e$ empresas (prêmios de seguro reduzidos para as famílias, isenções fiscais para as empresas) são estabelecidos? Relatório 2011-2013, $1^{\circ}$ ciclo, nível de progresso alcançado: 3

$\rightarrow$ A Política Habitacional no município de Campinas reserva prioridades às famílias residentes em áreas de risco.

Relatório 2013-2014, $2^{\circ}$ ciclo, nível de progresso alcançado: 3

$\rightarrow$ A SANASA tem executado obras de saneamento, com prática constante de redução e risco de desastres, por meio de procedimentos que minimizam os impactos de suas realizações.

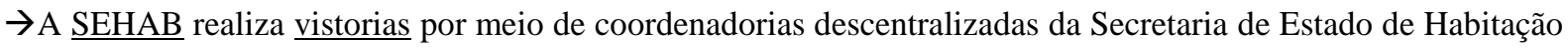
de Interesse Social e de consultoria técnica pela Coordenadoria de Planejamento Físico Habitacional.

$\rightarrow$ A Secretaria de Desenvolvimento Econômico, Social e Turismo (SDEST) conta com um Núcleo de Prospecção de Investimentos Nacionais e Internacionais, a fim de buscar investimentos produtivos para a geração de emprego e renda para Campinas.

$\rightarrow \mathrm{O}$ município terá em breve unidades de duas empresas chinesas e duas brasileiras que totalizam investimentos

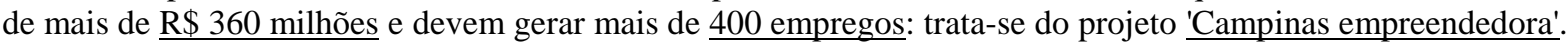

$\rightarrow$ Loja de departamentos anunciou em junho que planeja investir $\mathrm{R} \$ 10$ milhões para instalar quatro lojas da rede. Há a expectativa da geração de 1.000 empregos relacionados às áreas de marketing, gerência e prestação de serviços.

$\rightarrow$ Companhia brasileira na área de biotecnologia anunciou a intenção de investir $\mathrm{R} \$ 3$ milhões para instalar em Campinas um banco de congelamento de células-tronco.

Critério 6: Até que ponto as associações empresariais locais, como câmaras de comércio e similares, apoiam empenhos às pequenas empresas para a continuidade dos negócios durante e após os desastres?

Relatório 2011-2013, $1^{\circ}$ ciclo, nível de progresso alcançado: 3

$\rightarrow$ Apoio da Associação Comercial e Industrial de Campinas (ACIC) e do Centro das Industrias do Estado de São Paulo. 


\section{TABELA B2 (Continuação)}

\section{Relatório 2013-2014, $2^{\circ}$ ciclo, nível de progresso alcançado: 4}

$\rightarrow$ As associações empresariais locais não possuem plano de ação específico para o apoio durante e após os desastres, pois possuem ação reativa, de acordo com as peculiaridades de cada pequena empresa diante de um desastre.

$\rightarrow$ A Secretaria Municipal de Cidadania e Assuntos de Segurança Pública (SMCASP) firmou convênio com o Itaú o Projeto Câmera Cidadã, ampliando em mais 74 o número de câmeras de monitoramento da cidade sem custos para a Administração Municipal (de 120 para 362). Esse número foi alcançado por meio da recuperação dos equipamentos e de uma parceria com algumas agências bancárias. 


\section{Tabela B3}

Passo 3 dos 10 Passos da Campanha "Construindo cidades Resilientes: Minha cidade está se preparando", e os dados obtidos em Campinas-SP, de acordo com os critérios de autoavaliação e seus respectivos níveis de avanço, nos ciclos 1 e 2 da Campanha.

\section{Campanha Construindo Cidades Resilientes - ONU 2010-2015}

\section{Passo 3: Avaliações de Risco e Ameaças Múltiplas}

Mantenha os dados sobre os riscos e vulnerabilidades atualizados, prepare as avaliações de risco e utilizeas como base para planos de desenvolvimento urbano e tomadas de decisão. Certifique-se de que esta informação e os planos para a resiliência da sua cidade estão prontamente disponíveis ao público e totalmente discutido com eles.

\section{Dados de Campinas - São Paulo (Relatório 2013-2014)}

Critério 1: Até que ponto o governo local realizou avaliações de risco de desastres completos para os principais setores de desenvolvimento vulneráveis em sua autoridade local?

Relatório 2011-2013, $1^{\circ}$ ciclo, nível de progresso alcançado: 5

$\rightarrow$ O Departamento de Defesa Civil do município de Campinas mantém um banco de dados de áreas de riscos de inundação, enchentes, alagamentos, escorregamento e erosão catalogadas pelo Instituto de Pesquisas Tecnológicas (IPT), que é atualizado anualmente.

$\rightarrow$ A Secretaria Municipal do Verde, Meio Ambiente e Desenvolvimento Sustentável (SVDS) também possui um banco de dados, resultante do mapeamento da rede hidrográfica do município, contemplando rios, córregos, tanques, açudes, nascentes e barragens, com indicação das bacias hidrográficas e a sobreposição com a malha urbana, de modo que facilite a identificação das situações mais críticas.

$\rightarrow$ A Secretaria Municipal de Planejamento e Desenvolvimento Urbano (SEPLAN) realiza estudos para implementação das Macrozonas. Vistorias preventivas para verificação de qualquer atividade avaliada de natureza perigosa. No período de 2008 a 2013 foram realizadas 2.211 vistorias, da quais 458 tivera, com registro de anormalidade. Além disso, houve a catalogação de 34 áreas vulneráveis à incêndios florestais e de áreas com materiais radioativos.

\section{Relatório 2013-2014, $2^{\circ}$ ciclo, nível de progresso alcançado: 5}

$\rightarrow$ Foi realizada, em 2013, a Delimitação de Áreas em Muito e Alto Risco a Enchentes e Movimentos de Massa no município de Campinas, pelo Serviço Geológico do Brasil (CPRM). Segundo a classificação resultante, não foram destacados setores em muito alto risco e foram destacados 18 setores em situação de risco alto, que correspondem a 29 áreas de risco. Em 2003, dez anos antes, foram mapeadas 75 áreas de. O CPRM é uma empresa federal, ligada ao Ministério de Minas e Energia

$\rightarrow$ A Secretaria Municipal de Habitação (SEHAB), em parceria com Universidades, realizou estudos sistemáticos e aprofundados das áreas. Além disso, foram efetivados estudos de mancha de inundação dos córregos e dos rios do município, para subsidiar futuras remoções de família residentes de áreas de risco.

Critério 2: Até que ponto essas avaliações de risco são regularmente atualizadas, por exemplo, anualmente, ou em uma base bi-anual?

Relatório 2011-2013, $1^{\circ}$ ciclo, nível de progresso alcançado: 5

$\rightarrow$ Diariamente, todas as anormalidades são lançadas no sistema de Gerenciamento de Ocorrências de Defesa Civil (GODC) e, anualmente, o mapeamento de área de risco é atualizado.

\section{Relatório 2013-2014, $2^{\circ}$ ciclo, nível de progresso alcançado: 5}

$\rightarrow$ O Departamento Municipal de Defesa Civil realiza, anualmente, a atualização de áreas de riscos, contando com o apoio do IPT e do CPRM. 


\section{TABELA B3 (Continuação)}

$\rightarrow$ A Companhia de Habitação Popular de Campinas (Cohab-Campinas) entrega em dezembro o documento de registro oficial para 1.430 donos de imóveis no DIC 6, a partir do qual eles poderão obter a escritura definitiva e oficial de suas propriedades.

Critério 3: Com que regularidade o governo local transmite para a comunidade informações sobre as tendências locais de ameaças e medidas de redução de risco (utilizando um Plano de Comunicação de Risco, por exemplo), incluindo avisos prévios de provável impacto de risco?

Relatório 2011-2013, $1^{\circ}$ ciclo, nível de progresso alcançado: 5

$\rightarrow$ A Secretaria Municipal de Saúde (SMS) realiza campanhas informativas relacionadas com a dengue e a Defesa Civil realiza campanhas de conscientização da comunidade anualmente durante o período da Operação Verão e Operação Estiagem.

$\rightarrow$ A Secretaria Municipal de Cidadania, Assistência e Inclusão Social (SMCAIS), a Secretaria Municipal de Saúde (SMS), a Secretaria Municipal de Serviços Públicos (SMSP), Secretaria Municipal de Planejamento e Desenvolvimento Urbano (SEPLAN), a Secretaria Municipal de Habitação (SEHAB) e a Sociedade de Abastecimento de Água e Saneamento (SANASA) compõem o Grupo Executivo da Operação Verão, que conta com ações preventivas realizadas na ação da Defesa Civil. Algumas medidas, como orientação às famílias e vistoria de residências, são feitas o ano todo e não somente no período da Operação Verão (novembro - abril). $\mathrm{Na}$ última Operação, houve 24 mil ações de orientação com os moradores de áreas de risco, 7 mil a mais do que a anterior (aumento de 242\%), refletindo na diminuição de ocorrências. Em 2010/2011, 359 casas foram demolidas preventivamente, contra 54 no último período. O número de pessoas em abrigos também caiu de 232 para 17.

Relatório 2013-2014, $2^{\circ}$ ciclo, nível de progresso alcançado: 5

$\rightarrow O$ Departamento de Defesa Civil realizou as seguintes atividades de prevenção;

Operação Verão 2011/2012 = 18.338 famílias visitadas

Operação Estiagem 2013 = 7.800 famílias visitadas no entorno de Matas

Critério 4: Até que ponto as avaliações de risco locais, estão associadas e apoiadas nos conhecimentos $e$ avaliações comunitárias e nos planos de gestão nacionais e estaduais?

Relatório 2011-2013, $1^{\circ}$ ciclo, nível de progresso alcançado: 4

$\rightarrow$ Campinas conta com pluviômetros comunitários instalados em áreas de risco, que podem ser monitorados pela própria comunidade. Boletins meteorológicos são enviados via e-mail diariamente, com a possibilidade de serem enviados alertas a qualquer momento.

\section{Relatório 2013-2014, $1^{\circ}$ ciclo, nível de progresso alcançado: 4}

$\rightarrow$ A Secretaria Municipal de Cooperação nos Assuntos de Segurança Pública (SMCASP) ocupa ativamente representações em conselhos municipais e estaduais, como os Conselhos Comunitários de Segurança (CONSEG'S), que abrem a oportunidade de colher as demandas locais de segurança pública.

$\rightarrow$ Programa Nacional de Segurança Pública Com Cidadania (PRONASCI) tem como uma das diretrizes o estreitamento do relacionamento com as comunidades locais, favorecendo a integração entre as políticas referentes à segurança pública que são orientadas a partir das diretrizes nacionais e as demandas regionalizadas. $\rightarrow$ Foi criado o Gabinete Metropolitano de Gestão Estratégica de Segurança Pública (GAMESP) através de resolução assinada em Campinas no dia 27 de fevereiro de 2013, após tratativas da Administração Municipal com o Governo do Estado para integração de ações de segurança pública. Dessa maneira as gestões entre municípios até mesmo do Estado são integradas.

Critério 5: De que maneira as avaliações de risco de desastres estão incorporadas em todos os planos de desenvolvimento local relevante de uma forma consistente?

Relatório 2011-2013, $1^{\circ}$ ciclo, nível de progresso alcançado: 4 


\section{TABELA B3 (Continuação)}

$\rightarrow$ O Plano de Macrozoneamento do município de Campinas tem o objetivo de planejar e gerir o seu crescimento urbano, compreendendo tanto a zona urbana, como a zona rural, com base em condutas voltadas para as soluções dos problemas urbanos estruturais da cidade. Campinas foi subdividida em 9 macrozonas, que se distinguem pela dinâmica de desenvolvimento e para as quais foram definidas diretrizes estratégicas de orientação para um desenvolvimento adequado.

\section{Relatório 2013-2014, $2^{\circ}$ ciclo, nível de progresso alcançado: 5}

$\rightarrow$ A prefeitura instalou um totem interativo instalado no $18^{\circ}$ andar do Paço Municipal, que modernizou a rotina do atendimento ao público do Departamento de Informação, Documentação e Cadastro (DIDC) da Secretaria de Planejamento e Desenvolvimento Urbano (SEPLAN). Esse equipamento contém os aplicativos online utilizados pelos técnicos da área que permite acesso ao cidadão, possibilitando consultas visuais no mapa da cidade e a localização de informações de seu interesse. Substituiu os mapas que ficavam colados nas paredes da recepção técnica, utilizados pelo contribuinte para encontrar informações necessária para desenvolver o seu projeto.

$\rightarrow$ Dentre os aplicativos disponíveis estão zoneamento online, restrições aeroportuárias, número de quarteirão e da Planta de Referência Cadastral (PRC), mapa geoidal, marcos geodésicos, consultas visuais de mapas e demais informações técnicas pertinentes ao planejamento urbano. O Zoneamento Online pode ser acessado por meio do endereço eletrônico: http://zoneamento.campinas.sp.gov.br/ ou clicando no banner que está disponível no Portal da Prefeitura. 


\section{Tabela B4}

Passo 4 dos 10 Passos da Campanha "Construindo cidades Resilientes: Minha cidade está se preparando", e os dados obtidos em Campinas-SP, de acordo com os critérios de autoavaliação e seus respectivos níveis de avanço, nos ciclos 1 e 2 da Campanha.

\section{Campanha Construindo Cidades Resilientes - ONU 2010-2015}

\section{Passo 4: Proteção, Melhoria e Resiliência de Infraestrutura}

Investir e manter uma infraestrutura que reduza riscos, como obras de drenagem para evitar inundações; e, conforme necessário, investir em ações de adaptação às mudanças climáticas

Dados de Campinas - São Paulo (Relatório 2013-2014)

Critério 1: Até que ponto as políticas de uso do solo e os regulamentos de planejamento para habitação e infra-estrutura de desenvolvimento levam o risco de desastre atual e o projetado (incluindo os riscos relacionados com o clima) em conta?

Relatório 2011-2013, $1^{\circ}$ ciclo, nível de progresso alcançado: 4

Habitação: Sim Comunicação: Não $\quad$ Transporte: Sim Não

$\rightarrow$ A Lei de Uso e Ocupação do Solo (LUOS), enviada à Câmara Municipal de Campinas, estabelece o uso e ocupação solo.

Relatório 2013-2014, $2^{\circ}$ ciclo, nível de progresso alcançado: 4

$\rightarrow$ A Serviços Técnicos Gerais (SETEC), autarquia do município de Campinas com autonomia financeira e administrativa, tem como uma das responsabilidades a fiscalização do uso do solo público. Além disso, atua na administração e fiscalização do comércio e da publicidade em solo público, onde os equipamentos são autorizados após a sua análise e as análises da Empresa Municipal de Desenvolvimento de Campinas (EMDEC), gestora do transporte e trânsito na cidade, e do Departamento de Parques e Jardins (DPJ), quando em área de praças.

$\rightarrow$ A Secretaria Municipal de Planejamento e Desenvolvimento Urbano (SEPLAN), por meio do Departamento de Controle Urbano (DECON), fiscaliza obras e atividades comerciais em solo privado, emite alvará para uso e eventos e emite certidão de uso do solo.

$\rightarrow$ A mesma Secretaria, por meio do Departamento de Uso e Ocupação do Solo (DUOS), responsabiliza-se pela aprovação de loteamentos, anexação e subdivisão de lotes, pelo levantamento panialtimétrico e pela aprovação de edificações em solo privado.

Critério 2: Quão adequadamente equipamentos públicos críticos e infraestruturas localizados em áreas de alto risco recebem avaliações de risco para todos os tipos de ameaça e de segurança?

Relatório 2011-2013, $1^{\circ}$ ciclo, nível de progresso alcançado: 4

$\rightarrow$ Cada órgão público municipal executa ações de prevenção e correção de acordo com suas atribuições. A Secretaria Municipal de Serviços Públicos (SMSP) ofertará apoio suplemenrtar, em caso de desastres.

Relatório 2013-2014, $2^{\circ}$ ciclo, nível de progresso alcançado: 4

$\rightarrow$ A Secretaria Municipal de Habitação (SEHAB) realiza a avaliação de risco e a segurança dos equipamentos públicos.

$\rightarrow$ A Secretaria Municipal de Verde e Desenvolvimento Sustentável (SVDS), por meio do Setor de Fiscalização Ambiental (SFA), participa das ações da Operação Verão e da Operação Estiagem, da Defesa Civil. Estas ações envolvem a avaliação da situação dos barramentos públicos e a definição da sua necessidade de manutenção e os dados obtidos são compilados e georreferenciados em banco de dados da fiscalização ambiental, contribuindo para a construção de mapas futuros de vulnerabilidade ambiental do município. Além disso, são feitas vistorias 


\section{TABELA B4 (Continuação)}

preventivas de avaliação do grau de assoreamento dos córregos, cujos dados permitem realizar um cronograma de liberação de autorizações para intervenção em área de preservação permanente (APP) para execução dos trabalhos de desassoreamento. A necessidade de solicitação de licenças ambientais para execução de obras públicas, emitidas pelo Grupo de Trabalho de Apoio ao Licenciamento de Projetos de Serviços Municipais (GTALPS), consiste em outro importante instrumento de avaliação de risco dos equipamentos públicos.

\section{$\rightarrow$ A SMSP}

Algumas ações que promovem qualidade de vida à população e redução significativa de risco de desastres: - Construção de Parque Linear e reassentamento de famílias ao longo das margens do Córrego Taubaté - Jardim do Lago;

- Construção e regularização fundiária dos seguintes núcleos residenciais: Santa Mônica, São Marcos e Jardim Campineiro;

-Reurbanização e restauração ambiental de Área Verde invadida no Loteamento Campo Belo;

- Implantação do Parque Ecológico da Vila União, com retirada de entulho, readequação topográfica e plantio de 25.000 mudas de espécie nativa;

- Restauração da Área Verde do Loteamento Via Norte, atualmente invadido por usuários de drogas e depósito de entulhos, e sua futura reurbanização com plantio de 10.000 mudas de espécies nativas;

- Restauração Ciliar da Área Verde do Loteamento Itajaí, com retirada de 1,5 toneladas de entulho complementada com restauração e readequação topográfica com o plantio de 16.000 mudas de espécies nativas;

- Restauração e Urbanização da Praça localizada no Jardim Conceição no Distrito de Sousas, área em APP invadida com sub residências, e retirada das mesmas por medidas judiciais.

Critério 3: Quão adequadas são as medidas que estão sendo tomadas para proteger instalações públicas e infra-estrutura críticas aos danos provocados por desastres?

Relatório 2011-2013, $1^{\circ}$ ciclo, nível de progresso alcançado: 4

$\rightarrow$ Existe um trabalho de monitoramento por parte de Informática dos Municípios Associados (IMA) que desenvolve backups periódicos e adequados de todo o sistema de infraestrutura crítica do município de campinas. Trata-se de uma empresa de economia mista, que tem como principal acionista a Prefeitura Municial de Campinas.

\section{Relatório 2013-2014, $2^{\circ}$ ciclo, nível de progresso alcançado: 4}

$\rightarrow$ A diretoria da Central Integrada de Monitoramento de Campinas (CIMCamp) elabora projetos de ordem estratégica que contemplam o monitoramento das instalações municipais por meio de fibras óticas, links de rádio, telefone ou celulares. Uma série de protocolos será implementada, por meio do novo sistema de monitoramento de câmeras do CIMcamp, sendo colocados em prática mediante acionamento de alarmes. $\mathrm{O}$ software permite integrar sensores pluviométricos, de incêndio predial, de incêndio florestal, de invasão, de falta de energia elétrica, de rompimento de adutoras, de anormalidades no trânsito e outros.

$\rightarrow$ O CIMCamp, possui representantes da Guarda Municipal, Defesa Civil, SAMU, SETEC, EMDEC e Polícias Militar e Civil. A integração e cooperação desses órgãos permite que haja o diagnóstico de necessidade da ocorrência, o acionamento de agentes das áreas envolvidas e a tomada rápida de decisões e atitudes de resolução. Inclui trabalho voltado à segurança no trânsito, à qualidade no transporte, ao uso e ocupação ordenada do solo, à prevenção de desastres naturais e ao combate à criminalidade. São utilizadas três fontes de informação: sistema de câmeras e radares, sistema de radiocomunicação utilizado pelos agentes e a central telefônica. Os equipamentos são instalados em pontos estratégicos, considerando principalmente a grande incidência de ocorrências. Além disso, o cidadão pode acionar a CIMCamp 24 horas por dia 


\section{Tabela B5}

Passo 5 dos 10 Passos da Campanha "Construindo cidades Resilientes: Minha cidade está se preparando", e os dados obtidos em Campinas-SP, de acordo com os critérios de autoavaliação e seus respectivos níveis de avanço, nos ciclos 1 e 2 da Campanha.

\section{Campanha Construindo Cidades Resilientes: Minha cidade está se preparando - ONU 2010-2015}

Passo 5: Proteção de Serviços Essenciais: Educação e Saúde

Avalie a segurança de todas as escolas e centros de saúde e atualize tais avaliações conforme necessário.

Dados de Campinas - São Paulo - ONU 2010-2015

Critério 1: Até que ponto as escolas, hospitais e unidades de saúde recebem atenção especial para avaliações de risco para "todas as ameaças" em sua autoridade local?

Relatório 2011-2013, $1^{\circ}$ ciclo, nível de progresso alcançado: 4

$\rightarrow$ Cabe ao Departamento de Apoio à Escola (DAE), da Secretaria Municipal de Educação (SME) supervisionar a necessidade de serviços, aquisição, armazenamento e distribuição de produtos, além de transporte, manutenção, reforma e construção de Unidades Educacionais;

$\rightarrow$ Órgão do DAE, a Coordenadoria de Arquitetura Escolar (CAE) responsabiliza-se por:

Elaborar projeto e memorial descritivo de novas unidades educacionais e reforma das escolas existentes;

Pela avaliação, encaminhamento e acompanhamento de ações de manutenção em geral;

Identificar áreas para implantação de novas unidades educacionais;

Gerenciar e fiscalizar contratos e serviços de reparo;

Visitar locais para locação.

Relatório 2013-2014, $2^{\circ}$ ciclo, nível de progresso alcançado: 4

$\rightarrow$ Idem. Ver atribuições do DAE e CAE descritas no critério 1.

Critério 2: Quão seguras são todas as principais escolas, hospitais e unidades de saúde em relação a desastres de forma que tenham capacidade de se manter operacionais durante emergências?

Relatório 2011-2013, $1^{\circ}$ ciclo, nível de progresso alcançado: 4

$\rightarrow$ Em 2003, em virtude de forte temporal, 25 escolas foram afetadas. Desde 2008, nenhuma escola teve a atividade paralisada em virtude de ocorrências relacionadas com desastres.

$\rightarrow$ Estudos para aplicação do Manual "Requisitos Mínimos para a Educação: Preparação, Resposta e Reconstrução", do INEE (Rede Inter-Institucional de Educação em Situação de Emergência) estão sendo iniciados em Campinas. Esse manual é resultado de esforços de um grupo de trabalho formado por 19 organizações especializadas na área da educação em situações de conflito lentos e rápidos, catástrofes naturais e situações de emergência em ambientes rurais e urbanos. Devem ser adotadas medidas para garantir resposta humanitária coordenada às emergências, assegurando o direito à educação durante essas situações e a reconstrução pós-crise (INEE, 2010).

$\rightarrow \underline{\text { Programa Conta Escola - Transferência trimestral de recursos fornecido pela prefeitura às escolas da rede }}$ municipal, conferindo orçamento destinado à na compra de materiais pedagógicos ou equipamentos, pequenos reparos ou obras de manutenção.

Relatório 2013-2014, $2^{\circ}$ ciclo, nível de progresso alcançado: 4

$\rightarrow$ Idem. Ver atribuições do CAE descritas no critério 1. 


\section{TABELA B5 (Continuação)}

Critério 3: Até que ponto o governo local ou outros níveis de governo têm programas especiais para avaliar regularmente escolas, hospitais e unidades de saúde acerca da manutenção, cumprimento dos códigos de construção, segurança geral, riscos relacionados ao clima, etc?

Relatório 2011-2013, $1^{\circ}$ ciclo, nível de progresso alcançado: 4

$\rightarrow$ Os órgãos da administração pública garantem o cumprimento do Código de Obras, cabendo à Secretaria Municipal de Planejamento e Desenvolvimento Urbano (SEPLAN) a fiscalização de prédios públicos e particulares. Anualmente, no período de chuvas intensas, que coincide com férias escolares, a CAE desenvolve obras de manutenção estrutural (e.g., telhados, drenagem, revisão e recarga de aparelhos de ar condicionado e substituição de padrão de energia).

\section{Relatório 2013-2014, $2^{\circ}$ ciclo, nível de progresso alcançado: 4}

$\rightarrow \underline{\text { Lei } \mathrm{n}^{\circ} 9.858 \text { de 28/09/1998 - Dispõe sobre a obrigatoriedade de hospitais, prontos-socorros e clínicas do }}$ município de Campinas instalarem geradores de energia elétrica. Obedecendo à legislação, o Hospital Municipal Dr. Mário Gatti conta com dois grupos de geradores que garantem que os equipamentos hospitalares (Prontos Socorros Adulto e Infantil; Unidade de Terapia Intensiva Adulta e Pediátrica; enfermarias; Lactário; Centro Cirúrgico; Central de Materiais; Cozinha; iluminação do prédio administrativo; servidor de processamento de dados (CPD); e Laboratório do Hospital) continuem funcionando, caso a rede elétrica seja danificada. A garantia da continuidade dos serviços é fundamental para salvar a vida de pacientes ainda internados, em procedimento cirúrgico ou que irão passar por atendimentos. O funcionamento dos geradores é verificado diariamente por um técnico eletricista e mensalmente é feira manutenção preventiva mensal e corretiva pela empresa fabricante.

$\rightarrow$ Segundo a Companhia Paulista de Força e Luz (CPFL), diante de falta de energia, a prioridade de reestabelecimento acontece em hospitais, postos de saúde, delegacias, escolas e locais previamente cadastrados.

Critério 4: Até que ponto os simulados e exercícios regulares de preparação para desastres são realizados em escolas, hospitais e centros de saúde?

Relatório 2011-2013, $1^{\circ}$ ciclo, nível de progresso alcançado: 4

$\rightarrow$ Pelo menos uma vez ao ano, é realizado simulado nos hospitais quando há o Exercício Aeronáutico Completo do Aeroporto Internacional de Campinas.

$\rightarrow$ Nas escolas, programam-se palestras educativas, utilizando recursos audiovisuais, com apresentação de equipamentos utilizados pela Defesa Civil e órgãos de emergenciais, distribuição de material impresso, e dinâmica de grupo. O Projeto Defesa Civil Mirim tem como objetivo conscientizar crianças e adolescentes sobre ações preventivas que evitam ou minimizam os riscos de desastres, tornando-os multiplicadores das ações de Defesa Civil.

\section{Relatório 2013-2014, $2^{\circ}$ ciclo, nível de progresso alcançado: 4}

$\rightarrow$ Em 2012, a Defesa Civil participou de exercício simulado de acidente aéreo que envolveu parte da Rede Médica Hospitalar e do Serviço de Atendimento Móvel de Urgência (SAMU) de Campinas, as Polícias Civil, Militar e Rodoviária, o CIMCamp, Corpo de Bombeiros, Empresa Brasileira de Infraestrutura Aeroportuária (Infraero), Empresa Municipal de Desenvolvimento de Campinas (EMDEC) e concessionárias Colinas e Autoban).

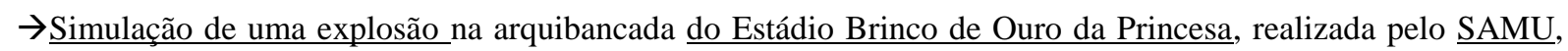
envolvendo equipes municipais das áreas de saúde, de trânsito e de segurança, CIMCamp, Defesa Civil, Corpo de Bombeiros e profissionais do Samu de outras cidades da região. Cerca de 200 estudantes do Ensino Fundamental das redes pública e privada, e universitários dos cursos de medicina e enfermagem participaram. $\mathrm{O}$ Simulado tem como objetivo preparar as equipes para uma situação real de tragédia, avaliando medidas de segurança. 


\section{TABELA B5 (Continuação)}

$\rightarrow$ A Defesa Civil, em conjunto com Guarda Municipal de Campinas, realizou simulação em Escola Municipal da Cidade. Além disso, foram ofertados cursos de Prevenção de Acidentes - Primeiros Socorros em parceria com o Corpo de Bombeiros. 


\section{Tabela B6}

Passo 6 dos 10 Passos da Campanha "Construindo cidades Resilientes: Minha cidade está se preparando", e os dados obtidos em Campinas-SP, de acordo com os critérios de autoavaliação e seus respectivos níveis de avanço, nos ciclos 1 e 2 da Campanha.

\section{Campanha Construindo Cidades Resilientes: Minha cidade está se preparando - ONU 2010-2015}

\section{Passo 6: Aplicação de Regulamentos e Planos de Uso e Ocupação do Solo}

Aplique e imponha regulamentos realistas, compatíveis com o risco de construção e princípios de planejamento do uso do solo. Identifique áreas seguras para cidadãos de baixa renda e desenvolva a urbanização dos assentamentos informais, sempre que possível.

\section{Dados de Campinas - São Paulo}

Critério 1: Até que ponto os regulamentos de uso e ocupação do solo para áreas de risco, e os códigos de construção, de segurança e de saúde são aplicados em todas as zonas de desenvolvimento e tipos de construção?

Relatório 2011-2013, $1^{\circ}$ ciclo, nível de progresso alcançado: 4

$\rightarrow$ Por meio da fiscalização das secretarias municipais: de Planejamento e Desenvolvimento Urbano (SEPLAN), do Verde e Desenvolvimento Sustentável (SVDS), de Habitação (SEHAB) além da Serviços Técnicos Gerais (SETEC).

Relatório 2013-2014, $2^{\circ}$ ciclo, nível de progresso alcançado: 5

$\rightarrow$ A Lei N 6.031 de 29 de dezembro de 1988 - Lei de Uso e Ocupação do Solo (LUOS) - submetida às premissas do Plano Diretor da cidade, é a principal legislação municipal que regulamenta o ordenamento e ocupação territorial de Campinas, estabelecendo regras para a organização da ocupação do espaço urbano. Essa legislação dispõe sobre a categorização de uso de solo (uso habitacional, comercial, de serviços, institucional e industrial), a classificação das edificações e dos estabelecimentos nas áreas construídas (pequeno, médio ou grande porte), a adequação dos usos do solo às diretrizes de zoneamento (permitido, tolerado e proibido) e os parâmetros para sua ocupação (critérios e disposições a serem obedecidas).

$\rightarrow$ A Lei Complementar $N^{\circ} .09$ de 23 de dezembro de 2003 dispõe sobre o código de obras e edificações do município de Campinas, estabelecendo procedimentos necessários para o licenciamento, fiscalização, projeto, execução e preservação de obras e edificações de órgãos ou serviços públicos. Tem como finalidades (1) regular a atividade edilícia (que diz respeito à edificação); (2) atribuir direitos e responsabilidades do Município, do proprietário ou possuidor de imóvel, e do profissional, atuantes na atividade edilícia; (3) estabelecer documentos e instituir mecanismos destinados ao controle da atividade edilícia; (4) estabelecer diretrizes básicas de conforto, higiene, salubridade e segurança a serem atendidas nas obras e edificações; (5) definir critérios a serem atendidos na preservação, manutenção e intervenção em edificações existentes (Art. $2^{\circ}$ ).

De acordo com essa lei, cabe à prefeitura (Art. $5^{\circ}$ ):

- Licenciar os projetos aprovados;

- Fiscalizar a execução e manutenção das condições de estabilidade, segurança e salubridade das obras e edificações;

- Embargar a execução de obras que não atendam ao disposto na legislação edilícia.

$\rightarrow$ A Serviços Técnicos Gerais (SETEC), autarquia do município de Campinas com autonomia financeira e administrativa, tem como uma das responsabilidades a fiscalização do uso do solo público. Além disso, atua na administração e fiscalização do comércio e da publicidade em solo público, onde os equipamentos são autorizados após a sua análise, impedindo a instalação caso considere área de risco.

$\rightarrow$ A prefeitura tem feito a informatização dos registros do patrimônio público relativos do município. Além disso, criou processo licitatório para contratação de empresa para fazer fotografia e compor a base cartográfica da cidade, atualizando o cadastro físico-territorial de Campinas. Propiciará o levantamento aerofotogramétrico da cidade em 2014. 


\section{TABELA B6 (Continuação)}

$\rightarrow$ A equipe técnica da Secretaria de Planejamento e Desenvolvimento Urbano (SEPLAN) desenvolveu o aplicativo zoneamento online, por meio do qual é possível a consulta virtual do zoneamento de toda a cidade e da legislação urbanística específica para as áreas pesquisadas. Ou seja, esse sistema fornece a localização dos imóveis, o respectivo zoneamento, com os usos permitidos e restrições existentes. Pode ser acessado. Essa nova ferramenta diminuiu em $30 \%$ a solicitação presencial de informações sobre zoneamento.

$\rightarrow$ A SVDS emite licenças ambientais nos casos de obras localizadas em áreas de proteção ambiental. Para a sua obtenção, são consideradas a certidão de uso e ocupação do solo, emitidas pela SEPLAN e vistorias nestas áreas onde investiga-se sobre a viabilidade do projeto considerando, entre outros fatores, os riscos ao meio ambiente, à saúde pública e à segurança.

$\rightarrow$ A SEPLAN emitiu, no ano de 2013, 4.532 alvarás de uso de solo e tem número semelhante de pedidos aguardando a finalização da análise. A Secretaria Municipal de Assuntos Jurídicos (SEMAJ) desenvolveu projeto de lei para simplificar e desburocratizar a emissão desses alvarás para estabelecimentos de até 1,5 mil metros quadrados.

$\rightarrow$ Após constatar que uma média de 500 processos de regularização de edificações clandestinas não obtiveram solução por lei de anistia que perdeu eficácia este ano, a prefeitura enviou novo projeto de lei de regularização de clandestinos, atendendo, desse modo, demanda da população mais carente da cidade, donos de construções populares.

$\rightarrow$ Equipes da SEPLAN fizeram forças-tarefa para destravar obras de 5.000 unidades residenciais do "Programa Minha Casa Minha Vida", embargadas pelo Ministério Público. Esse esforço resultou na emissão de 1.011 alvarás de aprovação de projeto, totalizando $710.945,27$ metros quadrados de construção e a expedição de 4.877 certificados de conclusão de obras, totalizando 1 milhão de metros quadrados de área construída.

Critério 2: Quão fortes são os regulamentos existentes (planos de uso e ocupação do solo, códigos de construção, etc) para apoiar a redução de risco de desastres locais?

Relatório 2011-2013, $1^{\circ}$ ciclo, nível de progresso alcançado: 4

$\rightarrow \mathrm{O}$ Código de Projetos e Execução de Obras e Edificações do Município de Campinas (Lei Complementar № 09 de 23 de dezembro de 2003) estabelece diretrizes e procedimentos administrativos a serem obedecidos no licenciamento, fiscalização, projeto, execução e preservação de obras e edificações.

Relatório 2013-2014, $2^{\circ}$ ciclo, nível de progresso alcançado: 5

$\rightarrow$ Secretaria Municipal de Planejamento e Desenvolvimento Urbano (SEPLAN)

Definir e implementar programas e projetos de desenvolvimento do município, abrangendo as áreas de meio ambiente, desenvolvimento físico-territorial e urbanístico;

Promover a integração metropolitana e o fomento ao desenvolvimento econômico;

Estudar e propor áreas de proteção ambiental e de recomposição de vegetação ciliar no âmbito do Município;

Avaliar as políticas públicas com influência no Município, em especial quanto ao impacto ambiental; Formular e propor um Código Ambiental Municipal;

Sugerir, no planejamento do uso do solo municipal, instrumentos de melhoria da qualidade ambiental; Promover a articulação e a integração dos diversos órgãos da administração nos três níveis de governo, no que concerne às ações de defesa do meio ambiente;

Promover estudos, normas e padrões de planejamento ambiental e urbano;

Desenvolver os planos locais de Gestão Urbana, conforme as diretrizes estabelecidas no Plano Diretor do Município;

Sistematizar as informações da Prefeitura Municipal na área de sua atuação; Formular e propor alterações e normas quanto a Estudos de Impacto Ambiental (EIA), Relatórios de Impactos Ambientais - RIMA e Estudos de Impacto de Vizinhança (RIVE);

Estabelecer os termos de referência dos aspectos ambientais para os planos, programas e projetos de outras áreas da administração municipal. 


\section{Tabela B7}

Passo 7 dos 10 Passos da Campanha "Construindo cidades Resilientes: Minha cidade está se preparando", e os dados obtidos em Campinas-SP, de acordo com os critérios de autoavaliação e seus respectivos níveis de avanço, nos ciclos 1 e 2 da Campanha.

\section{Campanha Construindo Cidades Resilientes: Minha cidade está se preparando - ONU 2010-2015}

\section{Passo 7: Treinamento, Educação e Sensibilização Pública}

Certifique-se de que programas de educação e treinamento sobre a redução de risco de desastres estejam em vigor nas escolas e comunidades.

\section{Dados de Campinas - São Paulo}

Critério 1: Com que regularidade o governo local conduz programas de conscientização e educação sobre Redução de Risco de Desastres e prevenção de catástrofes para as comunidades locais?

Relatório 2011-2013, $1^{\circ}$ ciclo, nível de progresso alcançado: 5

Programas incluem questões de diversidade cultural? Sim.

Programas são sensíveis às perspectivas de gênero? Sim.

$\rightarrow$ São realizadas campanhas durante o ano todo, principalmente durante a Operação Verão, desenvolvida no período chuvoso, e a Operação Estiagem, na época em que ocorrem seca e incêndios.

\section{Relatório 2013-2014, $2^{\circ}$ ciclo, nível de progresso alcançado: 4}

$\rightarrow$ Em 2013, a Secretaria Municipal dos Direitos da Pessoa com Deficiência e Mobilidade Reduzida (SMPED) e o Departamento de Defesa Civil promoveram o seminário "Viver com Deficiência e Desastres", que teve como objetivo discutir sobre as necessidades de pessoas com deficiência em cenários de desastres. Contou com a participação do Serviço de Atendimento Móvel de Urgência (SAMU), da Sociedade de Abastecimento de Água e Saneamento (SANASA), Corpo de Bombeiros e de membros das defesas civis de 12 cidades (Atibaia, Americana, Catanduva, Cajamar, Limeira, Louveira, Monte Mor, Mogi Guaçu, Nova Odessa, Paulínia, Santa Bárbara d'Oeste e São Paulo).

$\rightarrow$ A SANASA conduz o Plano de Segurança da Água (PSA), que envolve ações preventivas e programas voltados para a conscientização das comunidades sobre saneamento básico. Essas medidas colaboram com a conscientização sobre a redução de riscos de desastres.

$\rightarrow$ Ordem de Serviço $N^{\circ} 03^{21}$ : Institui o Centro de Capacitação de Proteção e Defesa Civil (CCPDC) no Departamento da Defesa Civil de Campinas, com as seguintes competências: (1) capacitar, aperfeiçoar e treinar os funcionários do Departamento de Defesa Civil de Campinas, estabelecendo cooperação técnica com órgãos integrantes do Sistema Municipal de Proteção e Defesa Civil (SIMPDEC); (2) assegurar a profissionalização e a qualificação, em caráter permanente, de recursos humanos para as ações de Proteção e Defesa Civil através dos cursos de Formação de Agente de Proteção e Defesa Civil (CFA) e de Formação de Gestores de Proteção e Defesa Civil (CFG), conforme estabelece o artigo Art. $6^{\circ}$, do decreto 17.783 de 28 de novembro de 2012, inciso VII, que reorganiza o Sistema Municipal de Proteção e Defesa Civil; (3) realizar o Curso de Capacitação de Voluntário de Defesa Civil (CVDC) e o Curso de Aperfeiçoamento de Voluntários em Defesa Civil (CADC), conforme estabelece o Art. $6^{\circ}$ do decreto $\mathrm{N}^{\circ} 17.921$ de 27 de março de 2013, que cria Projeto de Proteção Comunitária no âmbito do Município de Campinas; (4) preparar, aperfeiçoar e treinar membros dos Núcleos Comunitários de Defesa Civil (NUDECs) e fomentar a participação da sociedade civil; promover o Curso de Formação e Reciclagem de Brigadistas de Combate às Enchentes, instituído pelo decreto $\mathrm{N}^{\circ} 17.576 \mathrm{de} 02 \mathrm{de}$ maio de 2012, que dispõe sobre o Programa "Brigadas de Prevenção e Combate a Enchentes" no município de Campinas; (6) Capacitar integrantes do Sistema Municipal de Proteção e Defesa Civil na participação da Campanha Construindo Cidades Resilientes, conforme estabelece o Art. $6^{\circ}$ do decreto 17.783 de 28 de novembro de 2012, inciso IV, que reorganiza o Sistema Municipal de Proteção e Defesa Civil; (7) fomentar a pesquisa e

21 Diário Oficial do Município de Campinas, 28 de junho de 2013. Disponível em: http://www.preventionweb.net/applications/hfa/lgsat/en/image/href/2339. 


\section{TABELA B7 (Continuação)}

trabalhos técnicos nas atividades relacionadas à Redução de Desastres; (8) promover simpósios, congressos e palestras.

Critério 2: Até que ponto o governo local oferece treinamento em redução de risco para as autoridades locais e líderes comunitários?

Relatório 2011-2013, $1^{\circ}$ ciclo, nível de progresso alcançado: 4

$\rightarrow$ São realizados simulados que envolvem órgãos integrantes do SIMPDEC e a comunidade. Além disso, são desenvolvidas campanhas educativas para a comunidade, com distribuição de material impresso e o Curso de Formação de Agente de Defesa Civil (CFA), realizado anualmente.

Relatório 2013-2014, $2^{\circ}$ ciclo, nível de progresso alcançado: 4

$\rightarrow$ Em 2013, realizou-se um exercício simulado de abandono de área de risco na Vila Brandina, Campinas, que envolveu a Defesa Civil, a EMDEC, o Corpo de Bombeiros e o SAMU e aproximadamente 300 moradores. Simulou-se ocorrência de incêndio, com a remoção preventiva dos residentes da área, tendo como objetivo orientá-los a identificar e a reagir efetivamente em situações de risco, de modo a complementar o trabalho dos órgãos competentes. Ao final, os moradores puderam assistir a uma apresentação do Canil da Guarda Municipal de Campinas ${ }^{22}$.

\section{Critério 3: Até que ponto as escolas e faculdades locais incluem cursos, educação ou treinamento na redução do risco de desastres (incluindo os riscos relacionados com o clima), como parte do currículo de educação? Relatório 2011-2013, $1^{\circ}$ ciclo, nível de progresso alcançado: 4}

$\rightarrow$ A Lei No 14.474, de 31 de outubro de 2012 institui o Programa de Sustentabilidade Ambiental na Rede Municipal de Ensino no município de Campinas, por meio do qual as escolas públicas municipais devem desenvolver atividades diversas (palestras, oficinas e ações) de conscientização de problemas ambientais da cidade. Cabe à Secretaria Municipal de Educação (SME) e à Secretaria Municipal do Verde, Meio Ambiente e Desenvolvimento Sustentável (SVDS) fornecer incentivo às escolas à organização do Programa e a garantia de condições básicas para a execução dos projetos ${ }^{23}$.

\section{Relatório 2013-2014, $2^{\circ}$ ciclo, nível de progresso alcançado: 4}

$\rightarrow$ O Programa Minha Escola na SANASA é desenvolvido com estudantes do ensino fundamental e médio das escolas da rede Municipal de Campinas e da rede Estadual de São Paulo. A metodologia inclui visitas em Estações de Tratamento de Água (ETAs) e palestras educativas, que ressaltam a importância do saneamento para evitar poluição de água e o risco de enchentes.

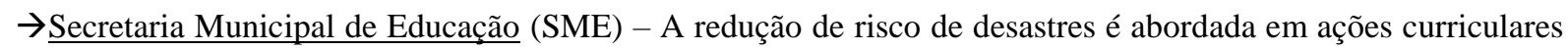
específicas das escolas municipais, mas não existe sistematização desse conteúdo.

$\rightarrow$ Decreto $N^{\circ} 17.885$, de 27 de fevereiro de $2013^{24}$ - cria o Grupo Técnico Municipal da Política e do Plano Municipal de Educação Ambiental (GTEA), constituído por representantes da Secretaria Municipal do Verde e do Desenvolvimento Sustentável (SVDS), Secretaria Municipal de Educação (SME), Secretaria Municipal de Cultura Esportes e Lazer (SMCEL), Secretaria Municipal de Habitação (SEHAB), Secretaria Municipal dos Direitos da Pessoa com Deficiência e Mobilidade Reduzida (SMPED), Secretaria Municipal do Planejamento e Desenvolvimento Urbano (SEPLAN), e de conselhos municipais, tais como o Conselho Municipal de Meio

\footnotetext{
${ }^{22}$ Prefeitura de Campinas. Disponível em: http://www.campinas.sp.gov.br/noticias-integra.php?id=18639.

${ }^{23}$ Lei $^{\circ} 14.474$ de 31 de outubro de 2012. .Disponível em: https://leismunicipais.com.br/a/sp/c/campinas/leiordinaria/2012/1447/14474/lei-ordinaria-n-14474-2012-institui-o-programa-de-sustentabilidade-ambiental-narede-municipal-de-ensino-e-da-outras-providencias

${ }_{24}$ Decreto $\mathrm{n}^{\circ} 17.885$ de 27 de fevereiro de 2013. Disponível em: https://leismunicipais.com.br/a/sp/c/campinas/decreto/2013/1788/17885/decreto-n-17885-2013-cria-o-grupotecnico-municipal-da-politica-e-do-plano-municipal-de-educacao-ambiental-e-da-outras-providencias
} 


\section{TABELA B7 (Continuação)}

Ambiente (COMDEMA), Conselho Gestor da Área de Proteção Ambiental de Campinas (CONGEAPA), Conselho Municipal de Defesa Animal (CMDA), Conselho Municipal de Educação (CME), Conselho Municipal de Cultura (CMC) e Conselho Municipal da Pessoa com Deficiência (CMPD). O grupo foi criado para desenvolver proposta de plano e política pública sobre educação ambiental em Campinas.

Critério 4: Quão conscientes estão os cidadãos dos planos de abandono ou exercícios para evacuaçães, quando necessários?

Relatório 2011-2013, $1^{\circ}$ ciclo, nível de progresso alcançado: 4

$\rightarrow \mathrm{Na}$ Operação Verão 2012/2013, 34.000 famílias receberam orientações sobre procedimentos para enfrentamento de situações de desastres.

\section{Relatório 2013-2014, $2^{\circ}$ ciclo, nível de progresso alcançado: 3}

$\rightarrow$ A Defesa Civil Municipal desenvolve ações de prevenção e de orientação nas escolas do município de Campinas, adotando a metodologia da Escola Segura, contida em guia proposto pelo Fundo das Nações Unidas para a Infância (UNICEF). ${ }^{25}$

25 Índice de Seguridad Escolar. UNICEF. Disponível em: http://s3.amazonaws.com/ineeassets/resources/Indice_de_Seguridad_Escolar_ISE_Final.pdf 


\section{Tabela B8}

Passo 8 dos 10 Passos da Campanha "Construindo cidades Resilientes: Minha cidade está se preparando", e os dados obtidos em Campinas-SP, de acordo com os critérios de autoavaliação e seus respectivos níveis de avanço, nos ciclos 1 e 2 da Campanha.

\section{Campanha Construindo Cidades Resilientes: Minha cidade está se preparando - ONU 2010-2015}

\section{Passo 8: Proteção Ambiental e Fortalecimento dos Ecossistemas}

Proteja os ecossistemas e barreiras naturais para mitigar inundações, tempestades e outros perigos a que sua cidade seja vulnerável. Adapte-se à mudança climática por meio da construção de boas práticas de redução de risco.

\section{Dados de Campinas - São Paulo}

Critério 1: Até que ponto as políticas de Redução de Risco de Desastre de governo locais, estratégias e planos de implantação são integrados com o desenvolvimento ambiental e planos de gestão dos recursos naturais existentes?

Relatório 2011-2013, $1^{\circ}$ ciclo, nível de progresso alcançado: 4

$\rightarrow$ Decreto $\mathrm{n}^{\circ} 16.920$ de 8 de janeiro de 2010 - criação do Grupo de Controle e Contenção de Ocupações, Parcelamentos Clandestinos e Danos Ambientais no Município de Campinas. Possui representantes de cinco secretarias municipais: Habitação (SEHAB), Urbanismo (SEPLAN), Segurança Pública (SMCASP), Serviços Públicos (SMSP), Meio Ambiente e Desenvolvimento Sustentável (SVDS) e do Gabinete do Prefeito (SMCGP). Tem como objetivo garantir o uso regular do solo, preservar as áreas de interesse ambiental e uniformizar procedimentos para reduzir as ocupações irregulares, evitando adensamento em áreas de risco. ${ }^{26}$

Relatório 2013-2014, $2^{\circ}$ ciclo, nível de progresso alcançado: 4

$\rightarrow$ Secretaria de Estado do Meio Ambiente (SEMA): Programa Município Verde Azul (PMVA) estimula as prefeituras paulistas na elaboração e execução de políticas voltadas para o desenvolvimento sustentável. Sugere dez diretivas norteadoras da agenda ambiental local e oferece capacitação técnica aos representantes de cada município.

$\rightarrow$ Em 2014, Campinas recebeu pela primeira vez o selo Verde Azul, do Programa Município VerdeAzul, alcançando a $14^{\mathrm{a}}$ posição nesse programa. No ano anterior, havia alcançado a posição $220^{\mathrm{a}}$, o que indica um avanço nas políticas ambientais do município. $\mathrm{O}$ selo garante à gestão municipal a prioridade na captação de recursos junto ao Governo do Estado, por meio do Fundo Estadual de Prevenção e Controle da Poluição (FECOP).

$\rightarrow$ A Sociedade de Abastecimento de Água e Saneamento (SANASA) tem participado da gestão dos recursos hídricos.

$\rightarrow$ Ações da Secretaria Municipal de Serviços Públicos (SMSP): diagnóstico qualitativo e quantitativo das espécies arbóreas urbanos, prevenindo o risco de queda durante o período chuvoso; processamento correto de resíduos da construção civil, incluindo o reaproveitamento de materiais; aumento do número de ecopontos; aumento da coleta e do aproveitamento de materiais recicláveis.

$\rightarrow$ A Secretaria do Verde, Meio Ambiente e Desenvolvimento Sustentável (SVDS) elabora planos de gestão de recursos naturais que, em parceria com ações da Defesa Civil, colaboram para um modelo de desenvolvimento sustentável, com medidas de educação ambiental, monitoramento das áreas de risco e recuperação dessas áreas. Planos de gestão de recursos naturais elaborados pela: Plano Municipal de Recursos Hídricos, Plano Municipal de Áreas Verdes, Plano Municipal de Educação Ambiental, Plano Municipal de Proteção Animal, Plano Municipal de Recuperação e Conservação da Mata Atlântica e Plano Municipal de Saneamento Básico.

\footnotetext{
${ }^{26}$ Prefeitura de Campinas. Disponível em: http://campinas.sp.gov.br/noticias-integra.php?id=385.
} 


\section{TABELA B8 (Continuação)}

$\rightarrow$ O Fundo de Recuperação, Manutenção e Preservação do Meio Ambiente (PROAMB) foi reativado pela
prefeitura, que destinara a quantia de $\underline{7,8 \text { milhões de reais para ações na área de meio ambiente e sustentabilidade }}$

Critério 2: Até que ponto o governo local apoia a restauração, proteção e gestão sustentável dos serviços ambientais?

Relatório 2011-2013, $1^{\circ}$ ciclo, nível de progresso alcançado: 4

$\begin{array}{lll}\text { Florestas: Sim } & \text { Zonas costeiras: Não } & \text { Zonas húmidas: Não } \\ \text { Recursos hídricos: Sim } & \text { Bacias fluviais: Sim } & \text { Pesca: Não }\end{array}$

$\rightarrow$ O município participa do Programa Cidades Sustentáveis, que faz parte da Rede Nossa São Paulo, do Instituto Ethos, e da Rede Social Brasileira por Cidades Justas e Sustentáveis. Um total de 197 cidades brasileiras participam, com o intuito de obter desenvolvimento econômico e ambiental sustentável. Envolve um plano de metas embasados em 12 eixos (governança; bens naturais comuns; equidade, justiça social e cultura de paz; planejamento e desenho urbano, cultura para a sustentabilidade; gestão local para sustentabilidade; economia local dinâmica criativa e sustentável; consumo responsável e opções de estilo de vida; melhor mobilidade, menos tráfego, ação local para a saúde; do local para o global, educação para sustentabilidade e qualidade de vida).

$\rightarrow$ Decreto ${ }^{\circ} 17.849$ de 23 de janeiro de 2013: Cria o Grupo Gestor da Plataforma Cidades Sustentáveis, que se encarregará da organização das informações necessárias para o cálculo dos 100 indicadores de sustentabilidade da Plataforma Cidades Sustentáveis e da elaboração de Plano de Metas, tendo como referência seus 12 eixos. A coordenação do grupo será composta pelo vice-prefeito, por representantes da Secretaria Municipal do Verde e do Desenvolvimento Sustentável (SVDS), Secretaria Municipal do Planejamento e Desenvolvimento Urbano (SEPLAN) e Secretaria Municipal de Cidadania, Assistência e Inclusão Social (SMCAIS) e Sociedade de

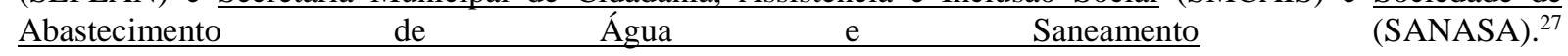

$\rightarrow$ Em 2014, Campinas recebeu prêmio pelo Programa Cidades Sustentáveis, na categoria "Metrópole", cujos critérios de avaliação eram: qualidade e confiabilidade dos dados, quantidade dados preenchidos, quantidade de novos indicadores cadastrados, adequação do programa de metas aos novos indicadores, adoção de indicadores regionalizados, quantidade de anos da série histórica dos indicadores, divulgação e comunicação dos dados para a sociedade, formato de apresentação dos dados e modelos de transparência. O prêmio visa estimular os gestores públicos para a criação, manutenção e atualização de indicadores, programas de metas e informações relevantes sobre políticas públicas voltadas à qualidade de vida e ao desenvolvimento sustentável ${ }^{28}$.

$\rightarrow$ Lei $n^{\circ} 13.658$ de 17 de agosto de 2009: Município de Campinas é autorizado a participar da constituição da Fundação Agência das Bacias Hidrográficas dos Rios Piracicaba, Capivari e Jundiaí (PCJ), com cobranças pelo uso dos recursos hídricos de domínio do Estado de São Paulo. No ente municipal, o controle de resultados da Agência deverá ocorrer por meio da $\underline{\text { SVDS }}^{29}$

\section{Relatório 2013-2014, $2^{\circ}$ ciclo, nível de progresso alcançado: 4}

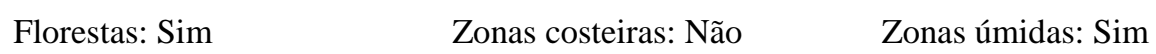

27 Decreto $\mathrm{n}^{\mathrm{o}} 17.849$ de 23 de janeiro de 2013.Disponível em: https://leismunicipais.com.br/a/sp/c/campinas/decreto/2013/1784/17849/decreto-n-17849-2013-dispoe-sobre-acriacao-do-grupo-gestor-da-plataforma-cidades-sustentaveis-2013-01-23.html

${ }^{28}$ Prefeitura de Campinas. Disponível em: http://www.campinas.sp.gov.br/noticias-integra.php?id=25602

${ }^{29}$ Lei $^{\circ} 13.658$ de 17 de agosto de 2009. Disponível em: https://leismunicipais.com.br/a/sp/c/campinas/leiordinaria/2009/1366/13658/lei-ordinaria-n-13658-2009-autoriza-o-municipio-de-campinas-a-participar-daconstituicao-da-fundacao-agencia-das-bacias-hidrograficas-dos-rios-piracicaba-capivari-e-jundiai-dirigida-aoscorpos-de-agua-superficiais-e-subterraneos 


\section{TABELA B8 (Continuação)}

Recursos hídricos: Sim $\quad$ Bacias fluviais: Sim $\quad$ Pesca: Não

$\rightarrow$ A SVDS é responsável por ações de proteção florestal, tais como a criação de unidades de conservação e elabora seus planos de gestão e manejo, licenciamento ambiental de atividades impactantes, exigência de autorização para intervenção em Áreas de Preservação Permanente, inscrição de áreas no Banco de Áreas Verdes e elaboração de Termos de Compromisso Ambiental. As zonas úmidas recebem, ainda, proteção especial por parte da SVDS, por decisão da Lei Orgânica do Município (Art. 190) e do Plano Diretor Municipal (Art. 36) sobre a necessidade de proteção das áreas de várzea.

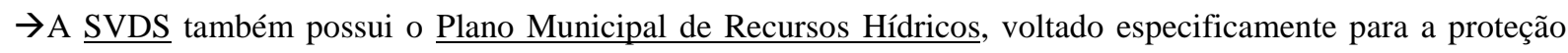
deste bem.

Critério 3: Quanto que as organizaçães da sociedade civil e os cidadãos participam na proteção, restauração e gestão sustentável dos serviços dos ecossistemas?

Relatório 2011-2013, $1^{\circ}$ ciclo, nível de progresso alcançado: 4

$\rightarrow O$ Conselho Municipal de Meio Ambiente (COMDEMA) promove a participação organizada da sociedade civil nas discussões e elaboração da Política Ambiental, no que se refere à preservação, conservação, defesa, recuperação, reabilitação e melhoria do meio ambiente natural e construído no Município de Campinas.

$\rightarrow$ Após a criação da SVDS, tornou-se necessário realizar a revisão da Política de Meio Ambiente de Campinas, contemplando a nova estrutura e adequando os objetivos e instrumentos ${ }^{30}$.

\section{Relatório 2013-2014, $2^{\circ}$ ciclo, nível de progresso alcançado: 4}

$\rightarrow$ Além do COMDEMA, Campinas conta com o Conselho Gestor da Área de Proteção Ambiental de Campinas (CONGEAPA), que permite a participação da comunidade nas definições e no acompanhamento de políticas para o desenvolvimento sustentável na Área de Proteção Ambiental.

$\rightarrow$ A população pode cadastrar denúncias pelo "156", as quais são encaminhadas aos setores competentes para as tomadas de decisão. Essa ferramenta permite que a comunidade participe ativamente na proteção do meio ambiente. $^{31}$

$\rightarrow$ Campinas aderiu ao licenciamento ambiental on-line, sistema que permite que as solicitações de licença ambiental para atividades e empreendimentos de baixo impacto local sejam feitas virtualmente por cidadãos, empreendedores, entidades e empresas de consultorias. O pagamento e acompanhamento das solicitações também são virtuais.

Critério 4: Quanto o setor privado participa na implantação de planos de gestão ambientais e de ecossistemas em seu município?

Relatório 2011-2013, $1^{\circ}$ ciclo, nível de progresso alcançado: 4

$\rightarrow \mathrm{O}$ Censo da Economia Verde é um cadastramento, desenvolvido pela Informática dos Municípios Associados (IMA), que possibilita que empresas, cidadãos e ONGs que se enquadrem em áreas afins de sustentabilidade (entidades ambientalistas, ecoeducação, ecocidadãos, ecoprodução, ecoserviços, ecoturismo, pontos de descarte e reciclagem de resíduos) consultem e preencham dados das ações na área de sustentabilidade. Tem o objetivo de dar maior visibilidade às iniciativas do município que contribuem para o desenvolvimento de uma economia verde. O Conselho Gestor da Área de Proteção Ambiental de Campinas (CONGEAPA), anteriormente ligado à

\footnotetext{
${ }^{30}$ Política Municipal de Meio Ambiente. Disponível em: http://campinas.sp.gov.br/governo/meioambiente/politica_meio_ambiente.php.

${ }^{31}$ Relatório de atividades desenvolvidas pela Da Secretaria do Verde Meio Ambiente e Desenvolvimento

Sustentável. Disponível em: http://www.campinas.sp.gov.br/arquivos/meio-ambiente/relatorio_ea_2013.pdf.
} 


\section{TABELA B8 (Continuação)}

SEPLAN, passou a ser da SVDS, responsabilizando-se pela regulamentação do Censo Verde e criação do grupo gestor técnico. ${ }^{32}$

\section{Relatório 2013-2014, $2^{\circ}$ ciclo, nível de progresso alcançado: 4}

$\rightarrow \mathrm{O}$ setor privado possui representatividade nos conselhos COMDEMA e CONGEAPA. Além disso, ao solicitarem licenciamento ambiental, as empresas comprometem-se a cumprir os Termos de Compromisso Ambiental e outras exigências técnicas das licenças prévia, de instalação e de operação, o que garante o seu desenvolvimento sustentável e a diminuição dos impactos ambientais causados por seus empreendimentos.

$\rightarrow$ A SVDS coordena o plano de gestão ambiental do Banco das Áreas Verdes (BAV), que visa a recuperação e ampliação das áreas verdes do município, oferecendo à população a possibilidade de desfrutar do uso do espaço público, com um meio ambiente ecologicamente equilibrado. A Secretaria Municipal de Desenvolvimento Econômico e Turismo (SDEST) fornece orientações às empresas sobre a importância de seguir os parâmetros estabelecidos pelo plano sobre os BAVs, a fim de manter o ecossistema de Campinas e região equilibrado, evitando o desmatamento. As empresas recebem incentivo econômico para inscrever a sua área no BAV e participar do plano, como a isenção do Imposto sobre a Propriedade Predial e Territorial Urbana (IPTU).

\footnotetext{
${ }^{32}$ Prefeitura de Campinas. Disponível em: http://www.campinas.sp.gov.br/noticias-integra.php?id=17267.
} 


\section{Tabela B9}

Passo 9 dos 10 passos da "Campanha Construindo Cidades Resilientes: Minha cidade está se preparando", e os dados obtidos em Campinas-SP, de acordo com os critérios de autoavaliação e seus respectivos níveis de avanço, nos ciclos 1 e 2 da Campanha.

\section{Campanha Construindo Cidades Resilientes - ONU 2010-2015}

\section{Passo 9: Preparação, Sistemas de Alerta e Alarme, e Resposta Efetivos}

Instale sistemas de alerta e alarme, e capacidades de gestão de emergências em seu município, e realize regularmente exercícios públicos de preparação

\section{Dados de Campinas - São Paulo}

$\overline{\text { Critério 1: Até que ponto as instituições locais têm acesso às reservas financeiras para providenciar resposta }}$ efetiva a desastres e recuperação rápida?

Relatório 2011-2013, $1^{\circ}$ ciclo, nível de progresso alcançado: 4

$\rightarrow$ As secretarias municipais integrantes do Sistema Municipal de Proteção e Defesa Civil (SIMPDEC) possuem dotação orçamentária própria, podendo receber suplementação da autoridade municipal, caso necessário.

\section{Relatório 2013-2014, $2^{\circ}$ ciclo, nível de progresso alcançado: 4}

$\rightarrow$ Programa Auxílio Moradia atende pessoas ou famílias em situação de risco pessoal e/ou social, incluindo recursos emergenciais destinado a pessoas de baixa renda, em situação de vulnerabilidade ou risco social, residentes em áreas de risco de enchentes e desabamentos, quando declarada situação de calamidade pública seguintes modalidades. ${ }^{33}$

Critério 2: Até que ponto os centros de alerta estão estabelecidos, com pessoal adequado (ou pessoal de plantão) e com recursos suficientes (backups de energia, redundância de equipamentos etc) o tempo todo?

Relatório 2011-2013, $1^{\circ}$ ciclo, nível de progresso alcançado: 5

$\rightarrow$ O Sistema de Atendimento Telefônico 199, instalado na Informática dos Municípios Associados (IMA) e a Central Integrada de Monitoramento de Campinas (CIMCAMP) possuem gerador de energia.

\section{Relatório 2013-2014, $2^{\circ}$ ciclo, nível de progresso alcançado: 5}

$\rightarrow$ No atendimento a ocorrências e na prevenção de emergências a Defesa Civil utiliza alguns sistemas informatizados (e.g., TerraMA2 - Monitoramento, Análise e Alerta; SIADEC (Sistema Integrado de Alerta da Defesa Civil; GODC (Gerenciamento de Ocorrências da Defesa Civil); e CIMcamp).

$\rightarrow O$ Centro Integrado de Monitoramento de Campinas (CIMCamp), órgão vinculado à Secretaria Municipal de Cooperação no Assuntos de Segurança Pública (SMCASP), monitora 143 pontos estratégicos da cidade, utilizando 372 câmeras que retransmitem imagens à Central. Integra órgãos como EMDEC, Guarda Municipal, Polícia Militar, Corpo de Bombeiros, SAMU e Defesa Civil. O CIMCamp compartilha com a EMDEC um gerador de grande porte, suficiente para manter os serviços essenciais do prédio em funcionamento e autonomia das atividades.

$\rightarrow$ Um novo sistema de atendimento de ocorrências em arquitetura web, Gerenciamento de Ocorrências da Defesa Civil (GODC), foi criado e permite o acesso dos dados de forma descentralizada, cuja base está localizada no datacenter da Informática de Municípios Associados (IMA), sofrendo backups periódicos e adequados.

${ }^{33}$ Lei $\mathrm{n}^{\circ} 13.197$ de 14 de dezembro de 2007. Disponível em: https://leismunicipais.com.br/a/sp/c/campinas/leiordinaria/2007/1319/13197/lei-ordinaria-n-13197-2007-dispoe-sobre-a-instituicao-do-programa-auxiliomoradia-e-suas-modalidades-na-forma-que-especifica 


\section{TABELA B9 (Continuação)}

$\rightarrow$ Até março de 2014, a Região Metropolitana de Campinas (RMC) deve estar integralmente monitorada pela Defesa Civil, com estações meteorológicas em suas 19 cidades, sendo a primeira metrópole da América Latina a ter $100 \%$ de controle para a prevenção de catástrofes naturais. Recursos estaduais devem auxiliar a construção das estações, as quais receberão manutenção do Instituto Agronômico de Campinas (IAC). Com isso, a Defesa Civil da região conseguirá fazer um plano mais abrangente durante as operações Verão e Estiagem.

$\rightarrow$ Campinas utiliza uma ferramenta desenvolvida pelo Instituto Nacional de Pesquisas Espaciais (Inpe), que faz o geoprocessamento para controle, recuperação, armazenamento e processamento de dados ambientais, (TerraMA2). Esse sistema integra dados hidrometeorológicos e informações adicionais necessárias para análises e definição de alertas, considerando o risco de ocorrência de desastres de origem natural provocados por eventos climáticos. Ademais, permite acesso a dados atuais de observação e previsão climática e gera modelos matemáticos para a criação de mapas de risco.

$\rightarrow$ A Serviços Técnicos Gerais (SETEC) possui o Grupo de Atendimento de Emergência (GAE), com funcionários e voluntários treinados para situações de emergências e desastres de grandes proporções que o serviço funerário municipal possa vir a atender.

$\rightarrow$ A EMDEC conta com agentes, técnicos, analistas e pessoal de manutenção, que colocarão em prática operações emergenciais durante a ocorrência de temporais ou desastres (e.g., bloqueios em vias, monitoramento do trânsito e indicação de rotas de desvio).

\section{Critério 3: Quanto que os sistemas de alerta e alarme permitem a participação adequada da comunidade? Relatório 2011-2013, $1^{\circ}$ ciclo, nível de progresso alcançado: 4}

$\rightarrow \mathrm{O}$ portal da prefeitura disponibiliza todos os dados relacionados a alertas e alarmes. O sistema telefônico 156 , integrado ao sistema telefônico 199 da Defesa civil pode ser acionado pelo cidadão e possui funcionamento $24 \mathrm{~h}$.

$\rightarrow O$ Sistema de Alerta da Defesa Civil de Campinas (SIADEC) conta com informações geradas pelos: Centro de Pesquisas Meteorológicas e Climáticas Aplicadas à Agricultura (CEPAGRI), Sistema de Alerta a Inundações do Estado de São Paulo (SAISP), Centro de Gerenciamento de Emergências de São Paulo (CGE), instituto de pesquisas meteorológicas (IPMET), Centro integrado de informações agrometeorológicas (CIIAGRO), Centro de Previsão de Tempo e Estudos Climáticos (CPTEC) e Fundação de Apoio à Pesquisa Agrícola (FUNDAG) ${ }^{34}$.

\section{Relatório 2013-2014, $2^{\circ}$ ciclo, nível de progresso alcançado: 5}

$\rightarrow$ A comunidade tem participação ativa no sistema de alarmes por meio dos callcenter local da Guarda Municipal, do SAMU e da EMDEC e da central de atendimento da Defesa Civil.

$\rightarrow$ Existe um projeto da CIMCamp disponibilizar um sistema de alertas que integram os cidadãos como multiplicadores de ações preventivas e contingenciais nas situações de risco, permitindo também que as populações sejam alertadas por sirenes e painéis eletrônicos em semáforos, prédios públicos e rodovias e via SMS e redes sociais.

$\rightarrow$ A Prefeitura de Campinas disponibilizou um localizador de serviços e equipamentos online, uma ferramenta de busca em seu portal direcionada à população.

Critério 4: Até que ponto o governo local tem um centro de operações de emergência (COE) e / ou um sistema de comunicação de emergência?

Relatório 2011-2013, $1^{\circ}$ ciclo, nível de progresso alcançado: 5

$\rightarrow$ Possui o Centro Integrado de Monitoramento de Campinas (CIMcamp), com funcionamento 24 horas e integra diversos órgãos públicos relacionados (segurança pública, trânsito, saúde, fiscalização e Defesa Civil).

34 Sistema de Aleta da Defesa Civil de Campinas 2012. Disponível em: http://www.preventionweb.net/applications/hfa/lgsat/en/image/href/1859 


\title{
TABELA B9 (Continuação)
}

\begin{abstract}
Relatório 2013-2014, $2^{\circ}$ ciclo, nível de progresso alcançado: 5
$\rightarrow$ De acordo com o Decreto $\mathrm{N}^{\circ} 17.536$, de 12 de março de 2012, o serviço tecnológico desenvolvido no CIMCamp auxiliará na prestação de serviços públicos municipais, pelos órgãos e entes competentes, da seguinte forma $^{35}$ :

I - detecção de ocorrências, permitindo atuação de forma integrada e ágil frente aos eventos relacionados à segurança do cidadão, sejam eles patrimonial ou contato direto entre a Administração Municipal e o munícipio, prestando informações e esclarecimentos sobre os serviços prestados pelo CIMCamp;

II - disponibilidade para contato direto entre a Administração Municipal e o munícipe, prestando informações e esclarecimentos sobre os serviços prestados pelo CIMCamp;

III - oferta de atendimentos de urgência e emergência, por via telefônica;

IV - promoção de encaminhamentos de solicitações e/ou reclamações, relativas aos serviços prestados pelo CIMCamp, aos órgãos e/ou entes competentes, por meio de sistemas informatizados, respeitadas as competências de cada um.
\end{abstract}

Critério 5: Com que regularidade os exercícios simulados são realizados com a participação de organizações governamentais, não governamentais, líderes locais e voluntários relevantes?

Relatório 2011-2013, $1^{\circ}$ ciclo, nível de progresso alcançado: 5

$\rightarrow$ São realizados, no mínimo, 2 simulados anuais.

Relatório 2013-2014, $2^{\circ}$ ciclo, nível de progresso alcançado: 5

$\rightarrow$ Em 2013, foram realizados simulados, tais como simulação de explosão em estádio; de incêndio em comunidade e de soterramento.

Critério 6: Quão disponíveis são os recursos-chave para uma resposta eficaz, tais como suprimentos de emergência, abrigos de emergência, rotas de abandono identificadas e planos de contingência permanentes? Relatório 2011-2013, $1^{\circ}$ ciclo, nível de progresso alcançado: 4

Estoques de suprimentos de emergência: Sim

Rotas seguras de evacuação identificadas: Sim

Abrigos de emergência: Sim

Plano de contingência ou plano de preparação da comunidade para desastres para todos os grandes riscos: Sim

$\rightarrow$ Os 10 principais pontos de alagamento no município de Campinas contam com rotas de desvio.

\section{Relatório 2013-2014, $2^{\circ}$ ciclo, nível de progresso alcançado: 4}

Estoques de suprimentos de emergência: Sim

Abrigos de emergência: Sim

Rotas seguras de evacuação identificadas: Sim

Plano de contingência ou plano de preparação da comunidade para desastres para todos os grandes riscos: Sim

$\rightarrow$ A Prefeitura Municipal de Campinas dispõe de uma Unidade de Acolhimento Institucional (UAI) para vítimas de desastres em situação de desabrigo, que tiveram perdas parciais ou totais de moradia, objetos ou utensílios pessoais. Ademais, uma equipe técnica de referência no Departamento de Operações da Assistência Social $\underline{(D O A S)}$, atende e planeja ações relacionadas a este serviço, realizando o trabalho de forma intersetorial, visando suprir as necessidades emergenciais e a garantia de direitos pós evento de calamidade pública. Esse departamento também oferece um plantão social, com equipe técnica ativa integralmente, podendo se deslocar a

35 Decreto $\mathrm{n}^{\mathrm{o}} 17.536$ de 12 de março de 2012. Disponível em: https://leismunicipais.com.br/a/sp/c/campinas/decreto/2012/1754/17536/decreto-n-17536-2012-dispoe-sobre-ocentro-integrado-de-monitoramento-de-campinas-cimcamp-ja-constituido-no-municipio-e-da-outrasprovidencias 


\section{TABELA B9 (Continuação)}

locais de atendimento necessários. Por fim, Campinas conta com um almoxarifado onde são mantidos materiais necessários no caso de ocorrência de desastres (e.g., cestas básicas, roupas, colchões e cobertores).

$\rightarrow$ A Secretaria Municipal de Cidadania, Assistência e Inclusão Social (SMCAIS) responsabiliza-se por garantir a segurança alimentar e nutricional de indivíduos ou coletividades em situação de emergência, por meio da Diretoria de Segurança Alimentar e Nutricional (DSAN), que também desenvolve ações compartilhadas com a Centrais de Abastecimento Campinas (CEASA), como a campanha de doação de alimentos. Para o pronto atendimento ao desastre, a SMCAIS disponibiliza o "kit lanche" para vítimas e socorristas. 


\section{Tabela B10}

Passo 10 dos 10 Passos da Campanha "Construindo cidades Resilientes: Minha cidade está se preparando", e os dados obtidos em Campinas-SP, de acordo com os critérios de autoavaliação e seus respectivos níveis de avanço, nos ciclos 1 e 2 da Campanha.

\section{Campanha Construindo Cidades Resilientes: Minha cidade está se preparando - ONU 2010-2015}

\section{Passo 10: Recuperação e Reconstrução de Comunidades}

Após qualquer desastre, assegure que as necessidades dos sobreviventes estejam no centro da reconstrução, por meio do apoio direto e por suas organizações comunitárias de modo a projetar e ajudar a implementar ações de resposta e recuperação, incluindo a reconstrução de casas e de meios de subsistência.

\section{Dados de Campinas - São Paulo}

Critério 1: Qual o investimento que o governo local faz em recursos e conhecimentos para ajudar as vítimas de impactos psico-sociais (psicológico, emocional) dos desastres?

Relatório 2011-2013, $1^{\circ}$ ciclo, nível de progresso alcançado: 4

$\rightarrow \mathrm{O}$ atendimento de vítimas de desastres por assistentes sociais da Secretaria Municipal de Saúde (SMS) e da

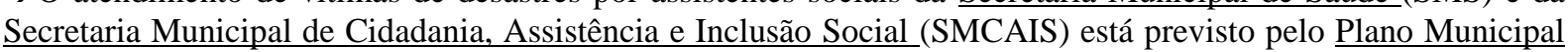
Integrado de Gerenciamento de Assistência Humanitária para Situações de Desastres (GETAH).

Relatório 2013-2014, $2^{\circ}$ ciclo, nível de progresso alcançado: 5

$\rightarrow$ Departamento de Vigilância Socioassistencial da SMCAIS é responsável pela: (1) construção do Plano Municipal de Assistência Social; (2) produção, sistematização e análise das informações territorializadas sobre as situações de vulnerabilidade e risco de famílias; e (3) estabelecimento dos padrões de qualidade dos serviços prestados pela rede pública e/ou conveniada, produzindo análises relativas à demanda por serviços e benefícios socioassistenciais.

$\rightarrow \mathrm{O}$ cofinanciamento de serviços da rede socioassistencial privada permitiu que, nos serviços da proteção social básica e especial (por meio dos Centros de Referência CRAS e CREAS), fossem atendidos 21.786 usuários ao longo de 2013.

$\rightarrow$ A Coordenadoria de Transferência de Renda e Cadastro Social realiza a gestão dos benefícios dos programas de transferência de renda municipais, estaduais e federais. Organiza: ações referentes ao cadastramento de beneficiários (atualização dos bancos de dados e sistematização das informações sobre o pagamento de benefícios) e planejamento e execução do processo de cadastramento das famílias de baixa renda, utilizando o Cadastro Único de Programas Sociais.

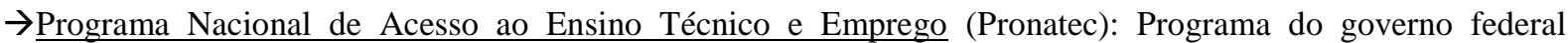
desenvolvido em Campinas, sob a responsabilidade da Secretaria de Cidadania, Assistência e Inclusão Social (SMCAIS), da Secretaria de Trabalho e Renda (SMTR) e Secretaria Municipal de Educação (SME). Oferece qualificação profissional para beneficiários do Bolsa Família, desempregados, matriculados na rede de ensino público, trabalhadores domésticos, cadastrados no CADúnico para Programas Sociais trabalhadores informais e autônomos. Os cursos oferecidos são gratuitos, realizados em parceria com o Serviço Nacional de Aprendizagem Comercial (SENAC), Serviço Nacional de Aprendizagem Industrial (SENAI) e Serviço Social de Aprendizagem do Transporte (SENAT) - ofereceram 5.944 vagas em 2013 ).

Critério 2: Até que ponto as medidas para redução de risco de desastres estão integradas a ações de recuperação pós-desastre e atividades de reabilitação (ou seja, reconstruir melhor, subsistência de reabilitação)?

Relatório 2011-2013, $1^{\circ}$ ciclo, nível de progresso alcançado: 4 


\section{TABELA B10 (Continuação)}

$\rightarrow$ Em situação de desastre, moradias em área de risco serão interditadas e as família serão removidas para abrigos públicos ou para Auxílio Moradia, caso estejam inscritas no Programa Habitacional Minha Casa Minha Vida.

\section{Relatório 2013-2014, $2^{\circ}$ ciclo, nível de progresso alcançado: 5}

$\rightarrow$ Secretaria Municipal de Habitação (SEHAB): remoção das famílias de forma preventiva, a demolição das residências em risco, a remoção dos entulhos e promoção da recuperação ambiental da área em consonância com os projetos habitacionais.

$\rightarrow$ O Programa Minha Casa Minha Vida acontece em parceria com estados, municípios, empresas e entidades sem fins lucrativos.

Critério 3: Até que ponto o Plano de Contingência (ou plano similar) inclui um esquema para a recuperação pós-catástrofe e reconstrução, incluindo avaliação das necessidades de reabilitação e meios de subsistência? Relatório 2011-2013, $1^{\circ}$ ciclo, nível de progresso alcançado: 4

$\rightarrow$ Quando os recursos municipais se esgotam, o prefeito poderá decretar situação de emergência ou Estado de Calamidade Pública e solicitar apoio suplementar ao governo estadual ou federal. A última Situação de Emergência foi decretada em 2003.

$\rightarrow$ Sistema de Gerenciamento de Ações Humanitárias (Donare): gerenciamento dos donativos recebidos pela Defesa Civil de Campinas, provenientes de pessoa física ou jurídica, durante situações de desastre ou não. Por meio dele, é possível fazer a distribuição dos donativos de acordo com a prioridade de cada local afetado. Além disso, centraliza uma base de dados com informações de voluntários e quantidade de vagas livres e ocupadas nos abrigos cadastrados. Um sistema de gerenciamento online permite que as informações sejam atualizadas em tempo real e o acesso fácil, o que agiliza tomadas de decisão.

\section{Relatório 2013-2014, $2^{\circ}$ ciclo, nível de progresso alcançado: 5}

$\rightarrow$ Decreto municipal $n^{\circ} 17.851$ de 23 de janeiro de 2013: instituiu o Plano Municipal Integrado de Gerenciamento de Assistência Humanitária para Situações de Desastres.

$\rightarrow$ Consiste em um conjunto de medidas planejadas pela prefeitura de Campinas para socorrer com rapidez e eficácia vítimas atingidas por Situação de Emergência ou Estado de Calamidade Pública.

$\rightarrow$ Quando necessário, o conjunto de procedimentos é desencadeado pelos órgãos que integram o Sistema Municipal de Proteção e Defesa Civil (SIMPDEC), dentre os quais estão: Serviço de Atendimento Móvel de Urgência (SAMU), Serviços Técnicos Gerais (SETEC), Assistência e Inclusão Social (SMCAIS), Secretaria Municipal de Saúde (SMS) - Departamento de Vigilância em Saúde, Secretaria Municipal de Comunicação (SMC), Secretaria Municipal de Chefia de Gabinete (SMCG), Centrais de Abastecimento de Campinas (CEASA), Sociedade de Abastecimento de Água e Saneamento (SANASA), Corpo de Bombeiros e Empresa Municipal de Desenvolvimento de Campinas (EMDEC). 